\title{
VARIAÇÕES DA TEMPERATURA FOLIAR DO DOSSEL E O SEU EFEITO NA TAXA ASSIMILATÓRIA DE $\mathrm{CO}_{2}$ NA AMAZÔNIA CENTRAL
}

\author{
EdgARD SIZA TRIBUZY
}

Tese apresentada à Escola Superior de Agricultura "Luiz de Queiroz", Universidade de São Paulo, para obtenção do título de Doutor em Ecologia de Agroecossistemas.

PIRACICABA

Estado de São Paulo - Brasil

Abril - 2005 


\title{
VARIAÇÕES DA TEMPERATURA FOLIAR DO DOSSEL E O SEU EFEITO NA TAXA ASSIMILATÓRIA DE $\mathrm{CO}_{2}$ NA AMAZÔNIA CENTRAL
}

\author{
EdgARD SIZA TRIBUZY \\ Engenheiro Agrônomo
}

Orientador: Prof. Dr. Plínio Barbosa de CAmargo

Tese apresentada à Escola Superior de Agricultura "Luiz de Queiroz", Universidade de São Paulo, para obtenção do título de Doutor em Ecologia de Agroecossistemas.

PIR A C I C A B A

Estado de São Paulo - Brasil

Abril - 2005 
Dados Internacionais de Catalogação na Publicação (CIP) DIVISÃO DE BIBLIOTECA E DOCUMENTAÇÃO - ESALQ/USP

Tribuzy, Edgard Siza

Variações da temperatura foliar do dossel e o seu efeito na taxa assimilatória de $\mathrm{CO}_{2}$ na Amazônia Central / Edagrd Siza Tribuzy. - - Piracicaba, 2005.

$84 \mathrm{p}$.

Tese (doutorado) - - Escola Superior de Agricultura Luiz de Queiroz, 2005. Bibliografia.

1. Amazônia Central 2. Dossel (Botânica) 3. Folhas 4. Floresta tropical 5. Fotossíntese 6. Gás carbono 7. Temperatura - Variação I. Título

CDD 634.90913 
"O imenso mundo:

um grão de areia perdido no espaço.

Os povos, animais e as flores dos sete climas:

sombras.

Toda ciência dos homens:

Palavras.

O resultado desta meditação:

Nada..."

Omar Kayam

Dedico:

à mamãe e ao papai. 


\section{AGRADECIMENTOS}

A Deus, por tudo que tem feito por mim.

A minha Família por tudo.

Ao Laboratório de Ecologia Isotópica no Centro de Energia Nuclear na Agricultura, pela oportunidade.

Ao projeto LBA pela oportunidade e apoio logístico.

A FEALQ pelo apoio financeiro.

Ao departamento Earth System Science da Universidade da Califórnia, Irvine pela parceria e apoio.

Ao INPA pelo apoio logístico, permitir a utilização do campus, área de estudo e liberar apoio de trabalhadores para a realização deste estudo.

Ao PPGI - Ecologia de Agroecossistemas pela oportunidade e auxílio.

Ao amigo e orientador Plínio Barbosa de Camargo, pela orientação sob todos os aspectos e por estar sempre presente nas horas em que eu precisei.

Ao Niro Higuchi pelo apoio dado durante o desenvolvimento da minha formação profissional e pessoal.

Ao Jeffrey $Q$. Chambers pelas contribuições durante o trabalho.

A Cristina A. Felsemburgh pela companhia, discussão, ajuda, correção e apoio em todo o desenvolvimento do trabalho.

Aos pesquisadores Luiz A. Martinelli, Jean P.H.B. Ometto, Susan E. Trumbore e Jim Elheringer pelos ensinamentos, empréstimos de aparelhos, discussões e as contribuições durante o desenvolvimento do trabalho. 
Aos Drs. Luis R. Angelocci e Marcos S. Buckeridge pela inestimáveis contribuições com o trabalho.

Aos amigos Denis U. de Lima, Rafael V. Ribeiro e Tomas Domingues pelo apoio na leitura e discussão do trabalho.

Ao Joaquim dos Santos pela contribuição com organização, correção do meu plano de trabalho e apoio logístico.

Aos colegas do Instituto Nacional de Pesquisa da Amazônia Alberto, Tatiane, Érika, Vilany e Rosana.

Aos colegas do Laboratório de Ecologia Isotópica, Jadson, Ney, Vânia, Santiago, Michele, Michela, José Mauro, Marquinho, Sérgio, Fátima, Adriana pelo bom convívio no trabalho.

A equipe de técnicos e estagiários do Laboratório de Ecologia Isotópica.

A equipe de campo da Estação Experimental de Silvicultura Tropical (Núcleo ZF-2) nas pessoas do Alessandro, Alquimar, Armando, Bertran, Chico, Geraldo, José (lindão), Menezes, Pedro, Quintiliano, Sebastião e Vanderlei.

A Jucleide pelo apoio e dedicação aos nossos filhos Sarah Talita e Edgard Filho e a estes dois por serem a alegria em minha vida.

Em especial gostaria de agradecer a minha mãe Edith Siza Tribuzy e ao meu pai Ivan de Azevedo Tribuzy, por não medirem esforços para que eu concluísse mais este curso. 


\section{SUMÁRIO}

Página

LISTA DE FIGURAS .............................................................................. vii

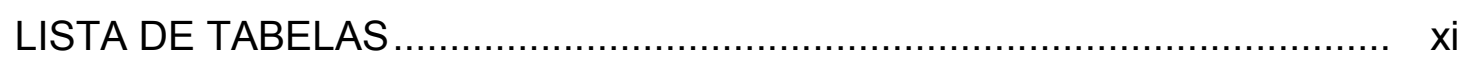

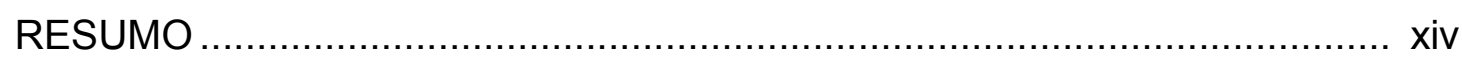

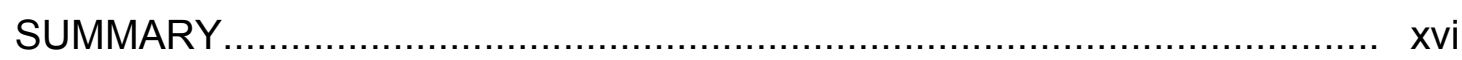

1 INTRODUÇÃO

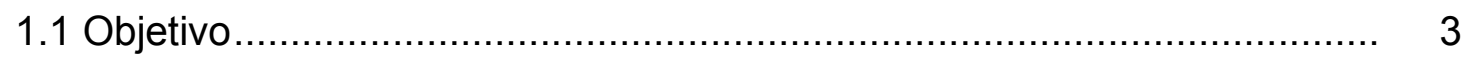

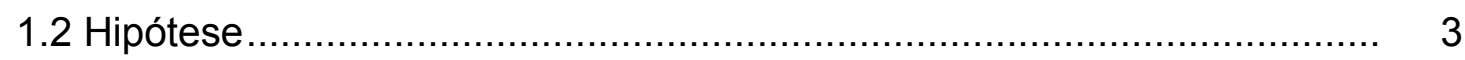

2 REVISÃO DE LITERATURA ............................................................. 5

2.1 Mudanças globais e as florestas tropicais ............................................ 5

2.2 Temperatura do dossel florestal..................................................... 6

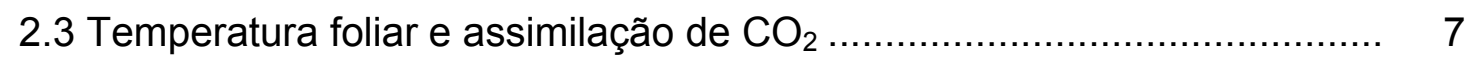

2.4 Teoria do modelo .................................................................... 11

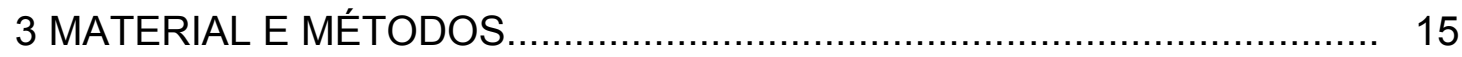

3.1 Caracterização da área.................................................................. 16

3.1.1 Clima

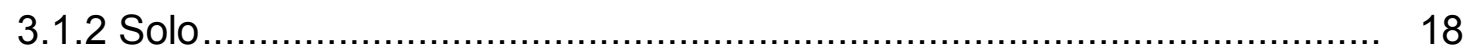

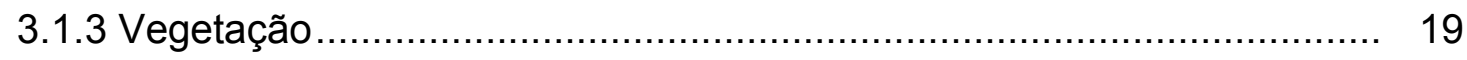

3.2 Local de coleta dos dados ......................................................... 20

3.3 Variáveis climatológicas................................................................. 21

3.4 Material vegetal estudado ............................................................ 21

3.5 Avaliações biofísicas.................................................................... 23

3.6 Medida da temperatura foliar ........................................................ 23 
3.7 Avaliações fisiológicas ........................................................... 24

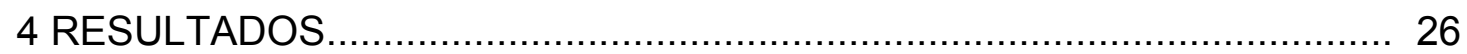

4.1 Caracterização micro-meteorológica .............................................. 26

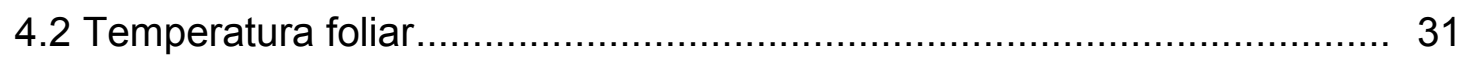

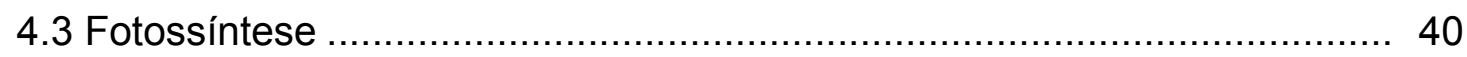

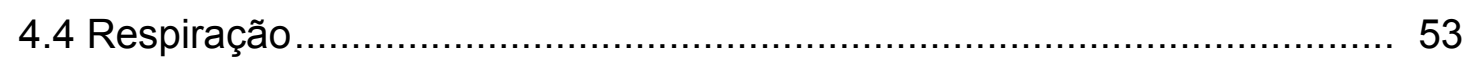

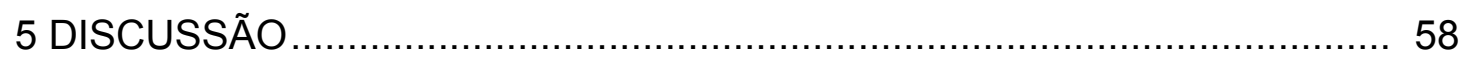

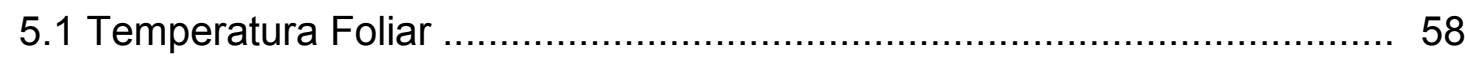

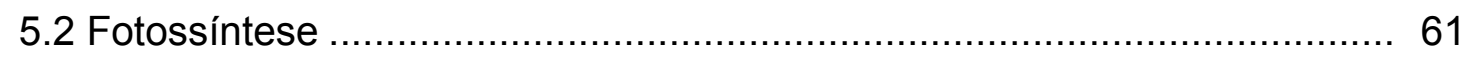

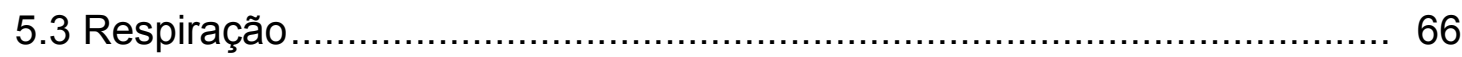

5.4 Variação da temperatura foliar e assimilação de $\mathrm{CO}_{2} \ldots \ldots \ldots \ldots \ldots \ldots \ldots \ldots \ldots . \ldots \ldots$

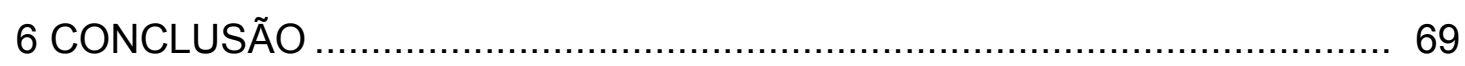

REFERÊNCIAS BIBLIOGRÁFICAS ................................................ 71 


\section{LISTA DE FIGURAS}

Página

1 Precipitação na região de Manaus no período histórico de 1971 a 2000. Dados obtidos da estação meteorológica da Empresa Brasileira de Pesquisa Agropecuária (EMBRAPA/CPAA)

2 Balanço hídrico da região na Manaus no período histórico de 1961 a 1990. Dados obtidos do Instituto Nacional de Meteorologia (INMET) segundo Sentelhas et al. (2005)

3 Distribuição diurna média da radiação fotossinteticamente ativa (RFA), nos períodos seco (a) e chuvoso (b)

4 Distribuição diurna média da temperatura do ar nos períodos seco (a) e chuvoso (b)

5 Distribuição diurna média da umidade relativa do ar (UR, - •- ) e do déficit de saturação de vapor (DSV, - o - ) nos períodos seco (a) e chuvoso (b).

6 Distribuição da precipitação para os períodos de avaliação da temperatura foliar, (a) no período de 26-07 a 27-08-03 na TN-S, (b) de 28-10 a 17-12-03 na T14, (c) de 20-12-03 a 04-02-04 na T34 e (d) de 13-02 a 23-03-04 na BBL4; as figuras (a) e (b) representam a precipitação do período de seco e (c) e (d) do período chuvoso

7 Variação da temperatura foliar máxima em função da altura em que a folha se encontrava no dossel florestal. 
8 Variação diurna da temperatura foliar $\left(\mathrm{T}_{\text {fol }} \longrightarrow\right)$ e da temperatura do ar ( $\mathrm{T}_{\mathrm{ar}}$-----), (a) para o dossel de Pouteria williamii na TN-S no dia 24-0803; (b) para o dossel de Brosimum parinarioides ssp. Parinarioides no dia 06-11-03, ambos (a e b) no período seco; (c) para o dossel de Pouteria cf. erythorchrosa na T34 no dia 25-01-04; e (d) para o dossel de Capirona cf. decorticans na BBL4 no dia 10-03-04, estas duas últimas (c e d) no período chuvoso.

9 Variação da temperatura foliar no ciclo diurno durante as horas sem precipitação (a e c) e nas horas com precipitação (b e d). Dados coletados entre 26-07-03 e 27-08-03 na TN-S (a e b) e entre 28-10-03 e 17-12-03 na T14 (c e d)

10 Variação da temperatura foliar no ciclo diurno durante as horas sem precipitação (a e c) e nas horas com precipitação (b e d). Dados coletados entre 20-12-03 e 04-02-04 na T34 (a e b) e entre 13-02-04 e 23-03-04 na BBL4 (c e d).

11 Distribuição da fotossíntese máxima $\left(A_{\max }\right)$ por temperatura ótima $\left(T_{o t}\right)$ para 29 indivíduos 40

12 Relações da fotossíntese máxima $\left(A_{\max }\right)$ de folhas de sol $(\bullet,-)$ e de sombra (०. - - -) com as características biofísicas das folhas, área específica foliar (a), composição isotópica do carbono 13 (b) e razão entre carbono e nitrogênio (c).

13 Resposta da fotossíntese máxima $\left(A_{\max }\right)$ de cada espécie em função da variação da temperatura foliar $\left(T_{\text {fol }}\right)$ para folhas expostas ao sol (a) e para as folhas de sombra (b).

14 Curvas de respostas da fotossíntese máxima $\left(A_{\max }\right)$ ao aumento da temperatura foliar $\left(T_{\text {fol }}\right)$ de folhas de sol $\left(\bullet,-\_\right)$e folhas de sombra (घ,-----) Valores obtidos a partir das médias: da capacidade máxima de transporte de elétrons $\left(\mathrm{J}_{\max }\right)$, velocidade máxima de carboxilação $\left(V_{c m a x}\right)$ e respiração mitocondrial $(R d)$ de cada planta nas diferentes temperaturas foliares 
15 Curvas de resposta média da capacidade máxima de transporte de elétrons $\left(\mathrm{J}_{\max }, \mu \mathrm{mol}\right.$ é. $\left.\mathrm{m}^{-2} \mathrm{~s}^{-1}\right)$ e velocidade máxima de carboxilação $\left(\mathrm{V}_{\mathrm{cmax}}, \mu \mathrm{mol} \mathrm{CO}_{2} \cdot \mathrm{m}^{-2} \cdot \mathrm{s}^{-1}\right)$ em função da variação da temperatura foliar na comunidade estudada

16 Curva de resposta da condutância estomática (gs) de cada espécie em função da variação da temperatura foliar $\left(T_{\text {fol }}\right)$, para folhas de sol (a) e sombra (b) 50

17 Resposta da condutância estomática (gs) em média para folhas de sol (घ) e sombra (•) da comunidade, em resposta à variação da temperatura foliar.

18 Taxa respiratória $(\mathrm{Rd})$ média para folhas de sol e sombra na temperatura ótima $\left(T_{o t}\right)$ para fotossíntese máxima

19 Curva de resposta da respiração foliar $(R d)$ de cada espécie em função da variação da temperatura foliar $\left(T_{\text {fol }}\right)$ para folhas de sol (a) e sombra (b)

20 Resposta da respiração foliar (Rd) em média para folhas de sol ( $\mathbf{a})$, sombra (•), e o modelo médio dos grupos de folha $(\diamond,--)$ da comunidade, em resposta a variação da temperatura foliar 56 


\section{LISTA DE TABELAS}

Página

1 Torres, identificações de campo (ID) e identificações botânicas das plantas utilizadas no estudo

2 Valores referentes à identificação de campo (Planta), o intercepto com o eixo dos $\mathrm{Y}$ da correlação entre o inverso da temperatura foliar (y-int) e RFA, UR e UR ${ }^{2}$ são os valores das constantes que multiplicam os respectivos parâmetros micro-meteorológicos. Máxima, corresponde aos valores de $\mathrm{T}_{\text {fol }}$ nas condições de baixa UR e alta RFA (45\% e 2000 $\left.\mu \mathrm{mol} . \mathrm{m}^{-2} \mathrm{~s}^{-1}\right)$, Mínima, são os valores de $T_{\text {fol }}$ nas condições de alta UR e baixa RFA (100\% e $50 \mu \mathrm{mol} . \mathrm{m}^{-2} \mathrm{~s}^{-1}$ ) e Amp é a diferença entre a maior e menor temperatura foliar. Dados relativos às observações de temperatura foliar na TN-S no período de 26-07-03 a 27-08-03

3 Valores referentes à identificação de campo (Planta), o intercepto com o eixo dos $\mathrm{Y}$ da correlação entre o inverso da temperatura foliar (y-int) e RFA, UR e UR ${ }^{2}$ são os valores das constantes que multiplicam os respectivos parâmetros micro-meteorológicos. Máxima, corresponde aos valores de $T_{\text {fol }}$ nas condições de baixa UR e alta RFA (45 \% e 2000 $\left.\mu \mathrm{mol} . \mathrm{m}^{-2} \mathrm{~s}^{-1}\right)$, Mínima, são os valores de $\mathrm{T}_{\text {fol }}$ nas condições de alta UR e baixa RFA (100\% e $\left.50 \mu \mathrm{mol} . \mathrm{m}^{-2} \mathrm{~s}^{-1}\right)$ e Amp é a diferença entre a maior 
e menor temperatura foliar. Dados relativos às observações de temperatura foliar na T14 no período de 28-10-03 a 17-12-03

4 Valores referentes à identificação de campo (Planta), o intercepto com o eixo dos $\mathrm{Y}$ da correlação entre o inverso da temperatura foliar (y-int) e RFA, UR e $U R^{2}$ são os valores das constantes que multiplicam os respectivos parâmetros micro-meteorológicos. Máxima, corresponde aos valores de $T_{\text {fol }}$ nas condições de baixa UR e alta RFA (45 \% e 2000 $\left.\mu \mathrm{mol} . \mathrm{m}^{-2} \mathrm{~s}^{-1}\right)$, Mínima, são os valores de $\mathrm{T}_{\text {fol }}$ nas condições de alta UR e baixa RFA (100\% e $50 \mu \mathrm{mol} . \mathrm{m}^{-2} \mathrm{~s}^{-1}$ ) e Amp é a diferença entre a maior e menor temperatura foliar. Dados relativos às observações de temperatura foliar na T34 no período de 20-12-03 a 04-02-04

5 Valores referentes à identificação de campo (Planta), o intercepto com 0 eixo dos $Y$ da correlação entre o inverso da temperatura foliar (y-int) e RFA, UR e UR ${ }^{2}$ são os valores das constantes que multiplicam os respectivos parâmetros micro-meteorológicos. Máxima, corresponde aos valores de $T_{\text {fol }}$ nas condições de baixa UR e alta RFA (45\% e 2000 $\mu \mathrm{mol} . \mathrm{m}^{-2} \mathrm{~s}^{-1}$ ), Mínima, são os valores de $\mathrm{T}_{\text {fol }}$ nas condições de alta UR e baixa RFA (100 \% e $\left.50 \mu \mathrm{mol} . \mathrm{m}^{-2} \mathrm{~s}^{-1}\right)$ e Amp é a diferença entre a maior e menor temperatura foliar. Dados relativos às observações de temperatura foliar na BBL4 no período de 13-02-04 a 23-03-04

6 Dados de trocas gasosas em cada local de coleta (Torre) para cada indivíduo (Planta), condição de exposição da folha a luz (Folha), de temperatura ótima $\left(\mathrm{T}_{\mathrm{ot}}\right)$, curvatura $(\theta)$, capacidade máxima de transporte de elétrons $\left(J_{\max }\right)$, velocidade máxima de carboxilação $\left(V_{c m a x}\right)$, fotossíntese máxima $\left(A_{\max }\right)$, respiração mitocondrial $(R d)$ e condutância estomática na temperatura de $31^{\circ} \mathrm{C}$ (gs)

7 Razão $\left(\mathrm{J}_{\max }: \mathrm{V}_{\text {cmax }}\right)$, correlação da taxa de $\mathrm{J}_{\max }: \mathrm{V}_{\mathrm{cmax}}$, coeficiente de determinação $\left(r^{2}\right)$ e probabilidade da equação de correlação nas diferentes temperaturas estudadas nas folhas de sol 
8 Razão $\left(\mathrm{J}_{\max }: \mathrm{V}_{\mathrm{cmax}}\right)$, correlação da taxa de $\mathrm{J}_{\max }: \mathrm{V}_{\mathrm{cmax}}$, coeficiente de determinação $\left(r^{2}\right)$ e probabilidade da equação de correlação nas diferentes temperaturas estudadas nas folhas de sombra 


\section{VARIAÇÕES DA TEMPERATURA FOLIAR DO DOSSEL E O SEU EFEITO NA TAXA ASSIMILATÓRIA DE $\mathrm{CO}_{2}$ NA AMAZÔNIA CENTRAL}

Autor: EDGARD SIZA TRIBUZY

Orientador: Prof. Dr. PlínIo BARbosa de CAMARgo

\section{RESUMO}

O papel da Floresta Amazônica na ciclagem do carbono tem sido freqüentemente relatado, no entanto, pouco se sabe sobre os aspectos que regula nos processos de assimilação e liberação de carbono da biosfera para a atmosfera. O objetivo deste trabalho foi descrever as respostas dos processos de respiração e fotossíntese com a variação da temperatura foliar, utilizando características biofísicas e dados micro-meteorológicos, para predizer a taxa assimilatória de $\mathrm{CO}_{2}$ de um indivíduo ou da comunidade em estudo. A pesquisa foi conduzida na Estação Experimental de Silvicultura Tropical (núcleo ZF-2), área de pesquisa da Coordenação de Pesquisa de Silvicultura Tropical (CPST) do Instituto Nacional de Pesquisas da Amazônia (INPA), utilizando-se de 4 torres para o acesso as copas. Os elementos climáticos foram monitorados por estações micro-meteorológicas Li-1401. As medidas de temperatura foliar foram realizadas com o auxilio de termopares de cobre-contantan, sendo a fotossíntese e a respiração avaliadas com um analisador de gases por 
infravermelho, com o qual foram obtidas curvas de respostas da fotossíntese a variação de radiação fotossinteticamente ativa (A-RFA), e a variação da concentração interna de $\mathrm{CO}_{2}$ em 4 diferentes temperaturas $\left(\mathrm{A}-\mathrm{C}_{\mathrm{i}}{ }^{-} \mathrm{T}\right)$. Os resultados mostraram que: a temperatura foliar está relacionada com a radiação fotossinteticamente ativa (RFA) e a umidade relativa do ar (UR); a temperatura ótima da fotossíntese foi de $31,1{ }^{\circ} \mathrm{C}$, onde a comunidade apresentou 7,6 $\mu \mathrm{mol} . \mathrm{m}^{-2} \cdot \mathrm{s}^{-1}$ de assimilação líquida de $\mathrm{CO}_{2}$, e a partir desta temperatura houve uma diminuição da fotossíntese máxima; valores de temperaturas foliares maiores que $34,5{ }^{\circ} \mathrm{C}$ diminuíram a velocidade máxima de carboxilação e as acima de $35,7^{\circ} \mathrm{C}$ diminuíram a capacidade máxima de transporte de elétrons; a condutância estomática decresceu com o aumento da temperatura foliar, dentro do intervalo de temperatura estudado, indicando que a limitação estomática pode ser o fator que mais afeta a fotossíntese; e a respiração contribuiu para que o balanço de carbono fosse menor com o aumento da temperatura foliar devido a respiração estar positivamente relacionada com a temperatura foliar. $A$ taxa assimilatória de $\mathrm{CO}_{2}$ foi diminuída devido a aumentos da temperatura foliar, sendo principalmente afetada pela diminuição da condutância estomática e do mesofilo e depois por aumentos da respiração foliar. 


\title{
VARIATIONS CANOPY LEAF TEMPERATURE AND EFFECTS ON $\mathrm{CO}_{2}$ ASSIMALATION RATE AT CENTRAL AMAZON
}

\author{
Author: EDGARD SIZA TRIBUZY \\ Adviser: Prof. Dr. Plínio Barbosa de Camargo
}

\section{SUMMARY}

The role of the Amazon Rain Forest in the carbon budget has been often reported, however little is known about the aspects regulating the processes of carbon assimilation and its release from the biosphere to the atmosphere. The objective of this work was to describe the responses of respiration and photosynthesis processes related to leaf temperature variations by using biophysics characteristics and micro-meteorological data in order to predict $\mathrm{CO}_{2}$ assimilation rates on individual or community level. The research was conducted at the Experimental Station for Tropical Forest research (ZF-2) of the National Institute of Research of the Amazon (INPA). For this study four towers were used to access the canopy. Climatic parameters were monitored by micrometeorological stations Li-1401. The leaf temperature was measured using copper-contantan thermocouples. Photosynthesis and respiration were evaluated with an infra-red gas analyzer, generating light and $\mathrm{CO}_{2}$ curves responses. The results showed that: the leaf temperature was related to the 
photosynthetic active radiation (PAR) and to the relative air humidity (UR). The optimal photosynthesis temperature was $31,1{ }^{\circ} \mathrm{C}$ where the tree community presented $7,6 \mu \mathrm{mol} \cdot \mathrm{m}^{-2} \cdot \mathrm{s}^{-1}$ of net $\mathrm{CO}_{2}$ assimilation. Above this temperature a reduction of the maximal photosynthesis was determined. Leaf temperatures higher than $34,0^{\circ} \mathrm{C}$ decreased the maximal velocity of RuBP carboxilation and temperatures higher than $35,7^{\circ} \mathrm{C}$ decreased the maximal capacity of electrons transportation. The stomatal conductance decreased with increasing leaf temperatures within the temperature interval studied. The results indicated that the stomatal limitation probably represent the main factor that effects photosynthesis. The respiration contributes to reduce the carbon assimilation due to the increase of the leaf temperature because respiration is positively related to leaf temperature. Thus, the $\mathrm{CO}_{2}$ assimilation rates decreased with an increase of leaf temperature and is mainly affected by a decrease of stomatal and mesophyll conductance and by an increase of leaf respiration. 


\section{INTRODUÇÃO}

As mudanças globais têm provocado aumento na concentração dos gases do efeito estufa, e muitas vezes isso tem sido correlacionado ao aquecimento global. Particularmente, o gás carbônico $\left(\mathrm{CO}_{2}\right)$ apresentou aumento de $28 \%$ na sua concentração atmosférica após a revolução industrial, correspondendo ao maior valor de sua concentração nos últimos 420.000 anos (Clark, 2004; Petit et al., 1999). E este cenário ressalta a importância da compreensão dos processos envolvidos na ciclagem do $\mathrm{CO}_{2}$ e os efeitos do aumento de temperatura da atmosfera.

Considerando os reservatórios de carbono (C) em todo mundo, a preservação da floresta amazônica representa a manutenção de um importante estoque deste elemento na forma de biomassa. Do ponto de vista das mudanças globais, a conversão desta floresta primária em campos para instalação de atividades agropecuárias apresenta uma baixa relação custo benefício (Higuchi, 2000).

O processo de mudança da cobertura vegetal da Amazônia influência no aumento da concentração de $\mathrm{CO}_{2}$ de duas formas: diminui a fixação de carbono em biomassa pela mudança da cobertura vegetal, e pela queima libera $C$ estocado como biomassa, contribuindo significativamente para o aumento da concentração deste elemento na atmosfera. O Brasil, por exemplo, emite duas vezes mais $C$ pela queima de florestas do que pela queima de combustíveis fósseis (Higuchi, 2000). 
Assim a compreensão da dinâmica do ciclo de carbono, baseado em dados obtidos em medidas de campo, é importante para o entendimento dos reservatórios e fluxos deste elemento (Pacala et al., 1996). Neste sentido, estudos que visam melhorar o entendimento dos processos fisiológicos das plantas, principalmente os que estão envolvidos com a ciclagem do C, são importantes para gerar informações sobre os efeitos dessas mudanças globais nos padrões de respostas da assimilação de $\mathrm{CO}_{2}$ nos indivíduos ou ecossistemas.

A temperatura $(T)$ tem grande influência nas trocas gasosas das plantas, afetando diretamente a fotossíntese e respiração. A resposta da assimilação líquida de $\mathrm{CO}_{2}$ nas folhas devido a variação da $\mathrm{T}$, pode ser expressa através de uma função de segundo grau, onde após a temperatura ótima, acréscimos de $T$ representará uma diminuição desta taxa de assimilação líquida (Clark, 2004; Baldocchi e Amthor, 2001; Hikosaka, 1997).

A fotossíntese é o processo mais sensível as altas temperaturas, apresentando temperaturas ótimas que variam de 20 a $35^{\circ} \mathrm{C}$ (Berry e Björkman 1980; Hikosaka, 1997; Schrader et al., 2004). Em temperaturas elevadas há fechamento dos estômatos, contribuindo para a diminuição da concentração de $\mathrm{CO}_{2}$ na câmara subestomática $\left(\mathrm{C}_{\mathrm{i}}\right)$, e com isso há redução na capacidade fotossintética devido ao aumento da fotorespiração. Outros fatores como danos nas estruturas dos fotossistemas I e II, e na enzima de carboxilação podem contribuir com a efetiva diminuição da assimilação líquida (Ogren e Oquist, 1984; Brooks e Farquhar, 1985).

Dentro deste contexto, outro importante evento que contribui para o balanço de carbono de uma folha, é a resposta da respiração ao aumento de temperatura, que responde aumentando de forma exponencial, colaborando para a redução da assimilação líquida de $\mathrm{CO}_{2}$ (Clark, 2004; Meir et al., 2001; Loveys et al., 2003). 
Compreender como as mudanças globais modificam os aspectos que regulam os processos fisiológicos das plantas, é um dos grandes desafios da ciência, e este trabalho se propõem a colaborar com este entendimento.

\subsection{Objetivo}

Descrever a variação da temperatura foliar em função das características biofísicas: área específica foliar (AEF), teor de nitrogênio $(N)$ e carbono $(C)$ da folha, e dados micro-meteorológicos: temperatura do $\operatorname{ar}\left(\mathrm{T}_{\mathrm{ar}}\right)$, umidade do ar (UR) e radiação fotossinteticamente ativa (RFA), e as respostas dos processos de respiração e fotossíntese em função da temperatura foliar de um indivíduo ou na comunidade em estudo.

\subsection{Hipótese}

\section{H1: A temperatura foliar está correlacionada com as características micro- meteorológicas do ambiente e biofísicas dos indivíduos.}

As características biofísicas são determinadas nos indivíduos através de suas respostas aos fatores ambientais. Por exemplo, tamanho e massa foliar estão associados à quantidade de energia a que o indivíduo é exposto. Assim, folhas mais expostas, como as do dossel florestal, desenvolverão características para interagir com as condições de dossel. 
H2: A temperatura foliar é o fator determinante do processo de fotossíntese em folhas do dossel florestal.

O aumento de temperatura pode: alterar a estrutura das enzimas envolvidas no processo de carboxilação, aumentar a fluidez das membranas do cloroplasto e diminuir a condutância estomática, afetando diretamente a fotossíntese. Desta forma, o processo bioquímico e de condução do $\mathrm{CO}_{2}$ do ar é afetado pelo aumento da temperatura foliar. 


\section{REVISÃO DE LITERATURA}

\subsection{Mudanças globais e as florestas tropicais}

A percepção das alterações ambientais em escala global como resultado das ações antropogênicas é uma preocupação que se iniciou na década de 1960, chamando a atenção do mundo todo e em diferentes âmbitos sociais (Grace, 2004). Dentre outras coisas, estas mudanças globais têm afetado os ciclos biogeoquímicos, particularmente, o ciclo do carbono (Petit et al., 1999; Grace 2004; Clark, 2004).

O aumento da concentração dos gases do efeito estufa na atmosfera tem causado alterações climáticas, interferindo diretamente: na quantidade $e$ qualidade de luz que chega na biosfera; no aumento da temperatura global da ordem de 0,6 $\pm 0,2^{\circ} \mathrm{C}$; e na freqüência do fenômeno "El Niño" onde nas regiões das florestas tropicais úmidas este aumento de temperatura tem sido acompanhado de precipitações anuais menores (Clark, 2004; Malhi e Wright, 2004; Schöngart et al., 2004; Cole, 2001; Laurance e Williamson, 2001).

O ciclo do carbono nas regiões de florestas tropicais tem recebido atenção especial, pois $60 \%$ do aquecimento global está relacionado com o aumento da concentração de dióxido de carbono na atmosfera e as florestas tropicais compreendem um significativo estoque e podem funcionar como dreno de carbono (Grace, 2004; Clark, 2004; Chambers et al., 2001).

As florestas tropicais apresentam grande parte do carbono na forma de biomassa, contendo mais de $75 \%$ do C terrestre armazenado (Grace et al., 
2001). São caracterizadas por uma alta taxa de produtividade primária, podendo-se conseqüentemente atribuir a estas florestas uma grande fração da produtividade global ( Baldochi e Meyes, 1991; Grace et al., 2001). Field et al. (1998) encontrou que em termos globais estas florestas apresentam uma produtividade primária liquida (PPL) de $17,8 \mathrm{Pg}$ de $\mathrm{C}$, aproximadamente $31 \%$ do PPL global, sendo a Amazônia corresponde a cerca de 40 \% deste tipo de floresta em todo mundo (FRA FAO, 2001).

A floresta tropical da Amazônia é um ecossistema complexo e de delicado equilíbrio ecológico (Clark et al., 2003). Esta floresta está entre os ecossistemas terrestres mais quentes do planeta e espera-se que seja um dos primeiros a diminuir a sua produção em função do aquecimento global. As temperaturas nestas regiões são relativamente altas para os processos fisiológicos nos vegetais (Saxe et al., 2001; Clark, 2004), e Ayeneh et al. (2002) concluíram que o excesso de calor é o fator mais comum de estresse abiótico para a floresta amazônica.

\subsection{Temperatura do dossel florestal}

Todos os organismos interagem com o seu ambiente físico através das trocas de energia. A temperatura é de fundamental importância afetando toda a atividade metabólica das plantas (Elhringer, 1989), sendo um dos principais fatores que determinam a distribuição das espécies de plantas nos diferentes ecossistemas do mundo. O estabelecimento das espécies de plantas depende diretamente de fatores como a temperatura mínima, média e máxima (Bassow et al., 1994).

A temperatura do dossel é um dos indicadores das interações entre biosfera e ambiente, pois integra todos os mecanismos de absorção e dissipação de energia que atuam na zona do dossel florestal. A temperatura foliar $\left(T_{\text {fol }}\right)$ resulta de como a planta com suas características morfológicas e 
fisiológicas, consegue controlar o balanço de energia absorvida, o fluxo de calor sensível, o fluxo de calor latente ou alguma combinação destes fatores (Ferguson et al., 1973; Gates, 1964).

Segundo Gates (1964), a temperatura da planta é um parâmetro com o qual se pode inferir sobre processos fisiológicos da planta. Assim, quando a $T_{\text {fol }}$ fica mais elevada, próxima da temperatura letal, a capacidade de dissipação de energia da folha pode significar a diferença entre a manutenção ou paralisação dos processos ou até mesmo a destruição dos tecidos.

Pequenas diferenças de temperatura dos órgãos podem fazer grandes diferenças sobre taxas fotossintéticas, respiratórias e outras atividades bioquímicas da folha da planta, podendo significar a preservação ou a extinção de uma espécie (Bazzaz, 1998; Gates, 1964).

Freqüentemente, a radiação solar nas regiões tropicais eleva a $T_{\text {fol }}$ no meio do dia a valores maiores que $40^{\circ} \mathrm{C}$ (Koch et al., 1994; Ishida et al., 1999; Kitao et al., 2000) e a diferença entre $T_{\text {fol }}$ e temperatura do $\operatorname{ar}\left(T_{\text {ar }}\right)$ pode exceder freqüentemente a $7^{\circ} \mathrm{C}$ (Ishida et al., 1999).

\subsection{Temperatura foliar e assimilação de $\mathrm{CO}_{2}$}

A assimilação de $\mathrm{CO}_{2}$ nas plantas dos trópicos é o resultado final de um conjunto de processos que são regulados por fatores intrínsecos e extrínsecos a planta. As altas temperaturas foliares têm sido apontadas por muitos autores, como o principal fator que afeta a fixação de carbono nas diversas etapas do processo (Atkin et al., 2000; Medlyn et al., 2002b; Medlyn et al., 2002a; Bernacchi et al., 2001; Griffin et al., 2002).

A fotossíntese é um dos processos fisiológicos mais sensíveis ao calor, visto que temperaturas entre 35 a $45{ }^{\circ} \mathrm{C}$ tendem a inibir a taxa fotossintética, embora as plantas apresentem consideráveis amplitudes entre suas temperaturas ótimas e seus limites toleráveis (Berry e Björkman, 1980). 
Nas situações mais extremas, dependendo da quantidade de calor na folha e quanto tempo este indivíduo é exposto, a temperatura pode causar danos na maquinaria fotossintética, tanto a nível enzimático, desestruturando ou desnaturando as enzimas envolvidas no processo de fixação do $\mathrm{CO}_{2}$, como no nível dos fotossistemas, ocasionando a fotoinibição ou fotodestruição (Medlyn et al. 2002a; Medlyn et al. 2002b; Bernacchi et al., 2001; Bassow et al., 1994; Schöngart et al., 2004; Siebke et al., 2002).

O efeito da alta temperatura sobre a atividade da ribulose 1,5 bisfosfato carboxilase/oxigenase (Rubisco) tem sido muito discutido. Ishida et al. (1999) verificaram que há um fator genético que propicia a maior ou menor tolerância desta enzima ao calor. Outros autores têm mostrado que a Rubisco é uma enzima que mantêm atividade mesmo em temperaturas relativamente mais altas que o ponto de temperatura ótima da fotossíntese (Bernacchi et al., 2001; medlyn et al., 2002b; Medlyn et al., 1999).

Elevadas $\mathrm{T}_{\text {fol }}$ propiciam mudanças na solubilidade de $\mathrm{CO}_{2}$ e $\mathrm{O}_{2}$ sobre as propriedades cinéticas da Rubisco, afetando a taxa assimilatória líquida $(A)$, favorecendo o aumento da solubilidade de oxigênio na câmara subestomática e fazendo com que aumente a função oxigenase da Rubisco, a fotorespiração, contribuindo assim para uma menor taxa de $\mathrm{CO}_{2}$ fixado nestas horas (Husic et al., 2002; Vargas-Luna et al., 2003; Leakey et al., 2003). Schrader et al. (2004) verificaram que a fotorespiração faz parte de uma estratégia de dissipação de energia que é importante para manutenção dos fotossistemas.

Os fotossistemas são muito sensíveis a variação de temperatura, pois estão dispostos na membrana do tilacóide (Badretdinov et al., 2002) e para Niinemets et al. (1999) pequenos aumentos da temperatura, podem refletir em maior fluidez destas membranas ocasionando desorganização no aparato fotoquímico.

Trabalhando com Gossypium barbadense, Schrader et al. (2004) verificaram que nas condições de temperaturas moderadamente mais elevadas estas plantas apresentavam mecanismos de fotoinibição, que pode estar 
associado a uma tentativa da planta em paralisar a atividade da Rubisco, principalmente a atividade de oxigenação, para evitar a presença de compostos tóxicos da via fotorespiratória (Husic et al., 2002).

Células crescendo sobre condições de estresse térmico criam mecanismos para se adaptar a essa condição, apresentando estratégias de manutenção das estruturas dos fotossistemas, entretanto estas estratégias podem não significar a continuação do transporte de elétrons nestas condições e sim a economia de ter que reestruturar a maquinaria fotoquímica (Inoue et al., 2001).

A resposta da capacidade de transporte de elétrons a elevação da temperatura, pode variar muito entre as espécies, grupos funcionais e ambientes em que a folha se desenvolve (Medlyn et al., 1999). Leakey et al. (2003) mostraram que temperaturas foliares maiores que $34{ }^{\circ} \mathrm{C}$ podem causar diminuição da capacidade de transporte de elétrons, gerando menores quantidades de energia para os processos de fixação de $\mathrm{CO}_{2}$ e regeneração da ribulose 1,5 bisfosfato.

O mecanismo de controle da condutância estomática (gs) ainda é tema de muitas discussões, no entanto, o movimento estomático tem sido freqüentemente associado a fatores ambientais, principalmente aqueles que podem promover aumentos nas diferenças do déficit de vapor entre o ar e a folha (Leakey et al., 2003; wan et al., 2004; Uddling et al., 2004; Angelocci et al., 2004). Trabalhando com florestas tropicais Pitman (1996) mostrou que a variável ambiental mais importante é o potencial hídrico do solo, seguido da temperatura que tem um efeito menor, mas também importante na abertura estomática.

A resposta da condutância estomática ao aumento da temperatura do ar $\left(T_{\text {ar }}\right)$ é descrita como uma redução dos seus valores (Poons e Welschen, 2003; Leakey et al., 2003), no entanto, nas condições de altas $\mathrm{T}_{\text {ar }}$ é difícil separar o efeito da temperatura do ar e do déficit de pressão de vapor do ar (DPV) (Udding et al., 2004), já Angelocci et al. (2004) mostraram que a supressão da 
abertura estomática está muito mais relacionada ao DPV que aos aumentos de $\mathrm{T}_{\mathrm{ar}}$.

Para Bassow et al. (1994) outro fator que corrobora para a diminuição da assimilação de $\mathrm{CO}_{2}$ nas condições de altas temperaturas do ar é a condutância do $\mathrm{CO}_{2}$ no mesofilo. Bernacchi et al. (2001) afirmaram que a difusão de $\mathrm{CO}_{2}$ não obedece a um padrão de resposta ao acréscimo de $T_{\mathrm{ar}}$, sugerindo que este fluxo interno de $\mathrm{CO}_{2}$ está mais correlacionado com a abertura e fechamento estomático.

A transpiração $(E)$ é muito importante para a planta por manter a temperatura das folhas de sol dentro do limite letal, pequenas taxas de $\mathrm{E}$ podem significar uma diferença de alguns graus na temperatura foliar que pode, em condições quentes, significar a diferença entre sobrevivência e morte do tecido. Uma taxa de transpiração de $1,84 \mathrm{mmol} \cdot \mathrm{H}_{2} \mathrm{O} \cdot \mathrm{m}^{-2} \cdot \mathrm{s}^{-1}$ pode causar uma diminuição da temperatura foliar em até $5{ }^{\circ} \mathrm{C}$ (Gates, 1964).

Entendendo a taxa de assimilação de $\mathrm{CO}_{2}$, como o balanço de entrada e saída de carbono, a respiração tem papel primordial quando se discute os efeitos do aumento da temperatura, pois este processo metabólico apresenta respostas de aumentos de forma exponencial (Clark, 2004; Atkin et al. 2000). Chambers et al. (2004) trabalhando com a floresta tropical na Amazônia central, mostraram que aumentos da taxa respiratória das folhas estão relacionados com aumentos da temperatura.

A respiração $(R)$ é um processo sensível as mudanças de temperatura variando conforme as flutuações sazonais e diárias de temperatura. O aumento de respiração, quando ocorre aumento de $10{ }^{\circ} \mathrm{C}$ na temperatura $\left(Q_{10}\right)$, pode variar de 1,5 a 4,1 (Clark, 2004; Meir et al., 2001; Loveys et al., 2003).

Ryan et al. (1994) trabalhando com respiração do caule de duas espécies de árvores de dossel em uma floresta tropical da Costa Rica, verificaram que o $Q_{10}$ (o aumento proporcional do processo metabólico com o aumento de $10{ }^{\circ} \mathrm{C}$ na temperatura) foi de 2,1 , indicando que a respiração do caule aumentou em $8 \%$ e $24 \%$ com aumento de 1 e $3{ }^{\circ} \mathrm{C}$, respectivamente. $\mathrm{O}$ 
valor de $Q_{10}$ para as folhas foi geralmente maior que aqueles observados para os troncos (Ryan et al., 1994).

Vários estudos caracterizam a fotossíntese e respiração em sub-bosque nas florestas tropicais (Mulkey et al., 1996; Swaine, 1996; Ryan et al., 1994), mas poucos focalizam as características das folhas do dossel (Zotz e Winter, 1993; Zotz e Winter, 1996) e segundo Rijkers et al. (2000), os que existem referem-se a um número reduzido de espécies.

Não obstante, vários atributos destes processos estão fortemente correlacionados com parâmetros (temperatura foliar, área específica foliar, concentração de nitrogênio) que apresentam menores dificuldades de quantificação nas folhas do dossel e que podem ser utilizados para estimar a produtividade primária líquida de um sistema biológico com precisão razoável (Reich et al., 1997).

\subsection{Teoria do modelo}

Estudos têm sido desenvolvidos para estimar a resposta da fotossíntese líquida $(A)$, às variações ambientais, assumindo que a razão $\left(C_{i} / C_{a}\right)$ entre a concentração de $\mathrm{CO}_{2}$ na câmara subestomática $\left(C_{i}\right)$ e no ambiente $\left(C_{a}\right)$, detalha a taxa de assimilação de $\mathrm{CO}_{2}$, que é calculada sob condições de saturação de luz e que é também regulada pela regeneração da ribulose 1,5 bisfosfato (RuBP), ou pela atividade catalítica de ribulose 1,5 bisfosfato carboxilase/oxigenase (Rubisco), quando a concentração de RuBP no cloroplasto está próxima a saturação (Katul et al., 2000; Medlyn et al., 2002a; Schrader et al., 2004; Ninements et al., 1999 e Pons e Welschen, 2003).

Modelos desenvolvidos por Farquhar (Farquhar et al., 1980; Farquhar e Sharkey, 1982; De Pury e Farquhar, 1997), com recentes modificações realizadas por Harley et al. (1992) e Medlyn et al. (1999), têm sido amplamente utilizados para simular a fotossíntese. Os parâmetros chaves nestes modelos 
de fotossíntese são calculados ajustando curvas de resposta da fotossíntese (A) a variação de $C_{i}$.

O modelo utilizado para ajustar os dados das curvas de resposta de $A$ variando $C_{i}\left(A-C_{i}\right)$ foi proposto por De Pury e Farquhar (1997) com recentes modificações realizadas por Medlyn et al. (1999), onde a fotossíntese (A) é determinada pelo limite mínimo de atividade da rubisco $\left(P_{\vee}\right)$ e por reações limitadas por elétron $\left(P_{J}\right)$, menos a respiração, podendo ser descrita por:

$$
\begin{aligned}
& A=\min \left\{P_{V}, P_{J}\right\}-R_{f o l} \\
& P_{j}=\mathrm{J}\left(C_{i}-\Gamma^{\star}\right) /\left(4 C_{i}+8 \Gamma^{\star}\right) \\
& \mathrm{P}_{\mathrm{v}}=\mathrm{V}_{\mathrm{cmax}}\left(C_{i}-\Gamma^{\star}\right) /\left(C_{i}+k_{r}\right)
\end{aligned}
$$

onde,

$R_{\text {fol }}$ é respiração da folha na incidência de luz; J é a taxa de transporte de elétrons; $V_{c m a x}$ é a taxa de máxima atividade de Rubisco; $C_{i}$ é a concentração intercelular de $\mathrm{CO}_{2} ; \Gamma^{*}$ é o ponto de compensação de $\mathrm{CO}_{2}$ na ausência de respiração foliar sob incidência de luz; $k_{r}$ é a constante efetiva de MichaelisMenten para a Rubisco nas reações de carboxilação e oxigenação.

$J$ é modelado como uma função da radiação fotossinteticamente ativa efetivamente absorvida (RFA) dada por:

$$
\theta J^{2}-\left(I_{\mathrm{e}}+\mathrm{J}_{\max }\right) \mathrm{J}+I_{\mathrm{e}} \mathrm{J}_{\max }
$$

onde,

$\theta$ é a curvatura da resposta de transporte de elétron a radiação; $J_{\max }$ é a taxa potencial máxima de transporte de elétrons; $l_{\mathrm{e}}$ é a RFA que foi efetivamente absorvida pelo fotossistema II (PSII) (Medlyn et al. 1999).

Nestes modelos, a resposta da fotossíntese à radiação fotossinteticamente ativa (A-RFA) provê dados para calcular a $\theta$, que é a convexidade da curva A-RFA para regeneração da ribulose-1,5-bisfosfato (Leith e Reynolds, 1987). Há uma tendência dos valores de $\theta$ diminuírem sob baixos níveis de luz quando a fotossíntese passa a ser limitada pelo transporte de 
elétron $\left(P_{\mathrm{J}}\right)$ e também pela atividade da Rubisco $\left(P_{\mathrm{V}}\right)$ (Cannell e Thornley, 2000).

A (Eq. 4) é usada para obter $\theta$ a partir das curvas de resposta da fotossíntese a luz. Determina-se $J_{\max }$ ajustando a curva $A-C_{i}$ e substituindo-se a solução da Eq (4) para J na Eq (2).

Os valores de $\mathrm{V}_{\text {cmax }}$ e $\mathrm{R}_{\mathrm{fol}}$ são calculados solucionando a Eq (3) apenas na porção linear da resposta da curva $A-C_{i}$ onde $C_{i}$ é limitado. Pelas relações entre temperatura e $J_{\max }, V_{c \max }$ e $R_{f o l}$, é possível estabelecer comparações com as relações estabelecidas por Medlyn et al. (1999).

Os valores de $I_{e}$ podem ser determinados pela equação:

$$
I_{e}=[(1-f) / 2] \alpha I_{0}
$$

onde,

$f$ é o fator de correção espectral $(0,15)$; $\alpha$ é capacidade da folha em absorver luz (assumido como 0,85); e $I_{0}$ é a radiação fotossinteticamente ativa incidente (Medlyn et al. 1999).

Os valores de $\Gamma^{*}$ e $\mathrm{k}_{\mathrm{r}}$ são funções complexas dependentes da temperatura e são descritos nas equações:

$$
\begin{aligned}
& \Gamma^{\star}=0,036(\mathrm{~T}-25)^{2}+1,88(\mathrm{~T}-25)+36,9 \\
& \mathrm{k}_{\mathrm{r}}=\mathrm{k}_{\mathrm{c}}\left(1+\mathrm{O} / \mathrm{k}_{\mathrm{o}}\right)
\end{aligned}
$$

onde,

T é a temperatura da folha; $k_{c}$ é a constante de Michaelis-Menten para Rubisco na função carboxilase; $O$ é pressão parcial intercelular do oxigênio (assumida como 0,21 mol.mol ${ }^{-1}$ de $\mathrm{O}_{2}$; e $\mathrm{k}_{\circ}$ é a constante de Michaelis-Menten para Rubisco na função oxigenase (Medlyn et al., 1999).

Os valores de $\mathrm{k}_{\mathrm{c}}$ e $\mathrm{K}_{\mathrm{o}}$ são determinados pelas equações:

$$
\mathrm{K}_{\mathrm{c}}=404 \exp (59,4(\mathrm{~T}-25) /(298 \mathrm{R}(\mathrm{T}+273)))
$$




$$
\mathrm{K}_{\mathrm{o}}=2,48 \cdot 10^{5} \cdot \exp (36(\mathrm{~T}-25) /(298 \mathrm{R}(\mathrm{T}+273)))
$$

onde,

T é a temperatura da folha; e exp é a função exponencial na base 10.

Há ainda outras importantes respostas a explorar como correlações entre $A$ e $T_{\text {fol }}$ (fotossíntese em função da temperatura foliar), A e RFA (fotossíntese em função da radiação fotossinteticamente ativa), A e DPV (fotossíntese em função do déficit de pressão de vapor do ar) e $A$ e $u_{e}$ (fotossíntese em função taxa de fluxo de ar turbulento).

Para Meinzer e Goldstein (1996) uma das dificuldades implícitas é a mudança dos fluxos de ar junto a folha, o que pode aumentar as dificuldades de se extrapolar medidas de troca gasosa em folhas isoladas para árvores inteiras.

Outros estudos mostraram que altos valores de déficit de pressão de vapor (DPV), causaram diminuições na fotossíntese e condutância estomática $\left(g_{s}\right)$ (Siebke et al., 2002; Pons e Welschen, 2003). Ishida et al. (1999) verificaram que o balanço de $\mathrm{CO}_{2}$ apresenta decréscimos nos horários próximos ao meio-dia sugerindo que este declínio esteja relacionado ao aumento das taxas de respiração $(R)$, aumento da temperatura foliar favorecendo a reação oxigenase da ribulose-1,5-bisfosfato carboxilase oxigenase (Rubisco) e a diminuição da condutância de $\mathrm{CO}_{2}$ no mesofilo $\left(\mathrm{g}_{\mathrm{c}}\right)$ que é uma variável chave, pois é determinante da razão $C_{i} / C_{a}$ (Farquhar e Sharkey, 1982). 


\section{MATERIAL E MÉTODOS}

Este trabalho foi desenvolvido na Amazônia Central, na Estação Experimental de Silvicultura Tropical (núcleo ZF-2), área de pesquisa da Coordenação de Pesquisa de Silvicultura Tropical (CPST) do Instituto Nacional de Pesquisas da Amazônia (INPA), e está localizada nas coordenadas $2^{\circ} 36^{\prime} \mathrm{S}$, $60^{\circ} 12^{\prime}$ W e a $90 \mathrm{~m}$ de altitude em relação ao nível do mar.

Este trabalho foi realizado para atender as necessidades de respostas sobre padrões das variações fisiológicas do dossel florestal na Amazônia central e contou com o apoio dos projetos "Large Biosphere and Atmosphere" (LBA), Manejo Florestal na ZF-2 (PICULUS) e Pesquisas da Floresta Amazônica Brasileira (JACARANDA).

O LBA é um projeto de colaboração internacional de grande escala e caráter multidisciplinar que tem como objetivo entender o funcionamento do ecossistema amazônico no cenário das mudanças globais e mudanças do uso da terra na região.

O PICULUS é um projeto de manejo sustentado da floresta que tem como objetivo organizar as ações necessárias para ordenar os fatores de produção, combinando a exploração sustentada com a preservação da floresta.

E o JACARANDA é um programa de colaboração em pesquisa sobre a Amazônia brasileira entre o governo Brasileiro e o Japão e foi direcionado com o objetivo maior de atingir o uso sustentável dos recursos florestais, buscando 
aumentar os conhecimentos biológico e ecológico, para aperfeiçoar as tecnologias para a conservação da floresta amazônica e a recuperação de suas áreas já degradadas.

\subsection{Caracterização da área}

\subsubsection{Clima}

De acordo com a classificação de Köppen, o clima da região é do tipo "Amw", caracterizado como quente e úmido e denominado também de tropical chuvoso, pois apresenta temperaturas, umidades e precipitações elevadas. A temperatura média anual é de $26,7^{\circ} \mathrm{C}$, com valores de mínima e máxima de $23,5{ }^{\circ} \mathrm{C}$ e $31,2{ }^{\circ} \mathrm{C}$ respectivamente, sendo a umidade relativa média anual de $84 \%$.

A precipitação anual média medida entre 1961 e 1990 é de 2.285 mm. Há dois períodos sazonais distintos quanto ao regime pluviométrico, que resultam do movimento anual de zona da convergência intertropical causando na região um período seco e um chuvoso (Marengo e Nobre, 2001).

Tomando como base uma série histórica do período de 1971 a 2000, a época seca é caracterizada por uma precipitação em torno de $125 \mathrm{~mm}$.mês ${ }^{-1}$ se estendendo geralmente pelos meses de julho a outubro, enquanto a estação chuvosa é caracterizada por meses com precipitações superiores a este valor, apresentando médias mensais em torno de $258 \mathrm{~mm} . \mathrm{mês}^{-1}$ entre os meses de novembro a junho (Figura 1).

O período seco pode se estender mais ou menos a cada ano e para Sombroek, 2001; e Chambers et al., 2004 ele pode ser caracterizado por épocas onde a precipitação mensal seja próxima de $100 \mathrm{~mm} \cdot \mathrm{mês}^{-1}$. 


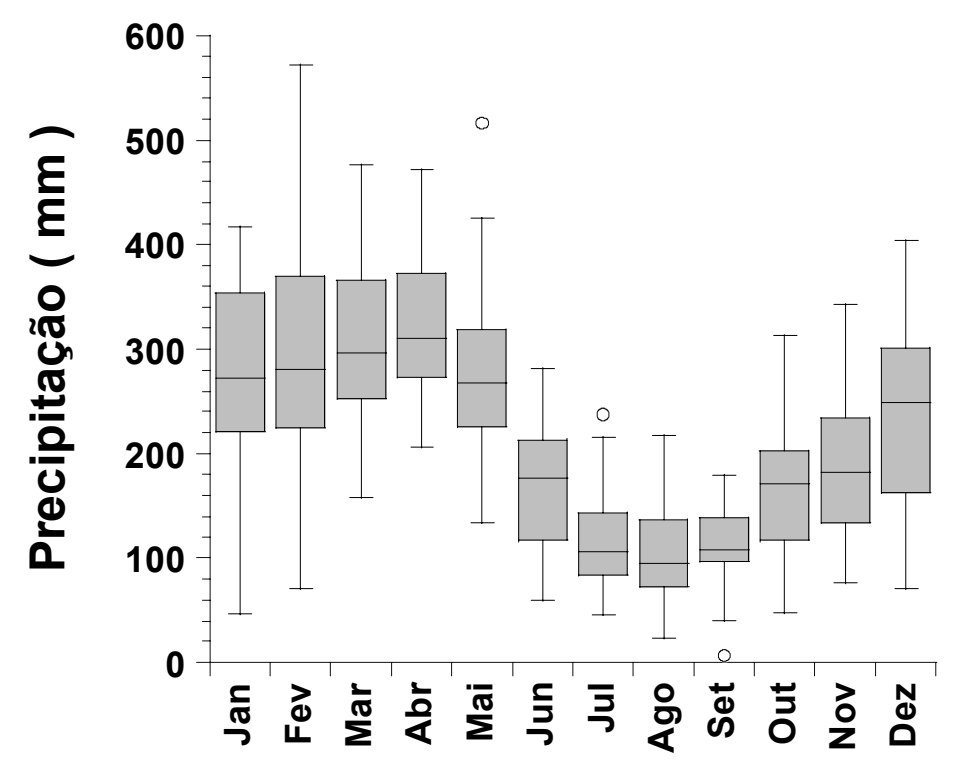

Figura 1 - Precipitação na região de Manaus no período histórico de 1971 a 2000. Dados obtidos da estação meteorológica da Empresa Brasileira de Pesquisa Agropecuária (EMBRAPA/CPAA)

O balanço hídrico da região em uma série histórica no período de 1961 a 1990 mostra que a região apresentou um déficit de água no solo para os meses de junho a novembro, enquanto nos meses de dezembro a maio há um excedente de água como mostra a Figura 2 (Sentelhas et al., 2005). 


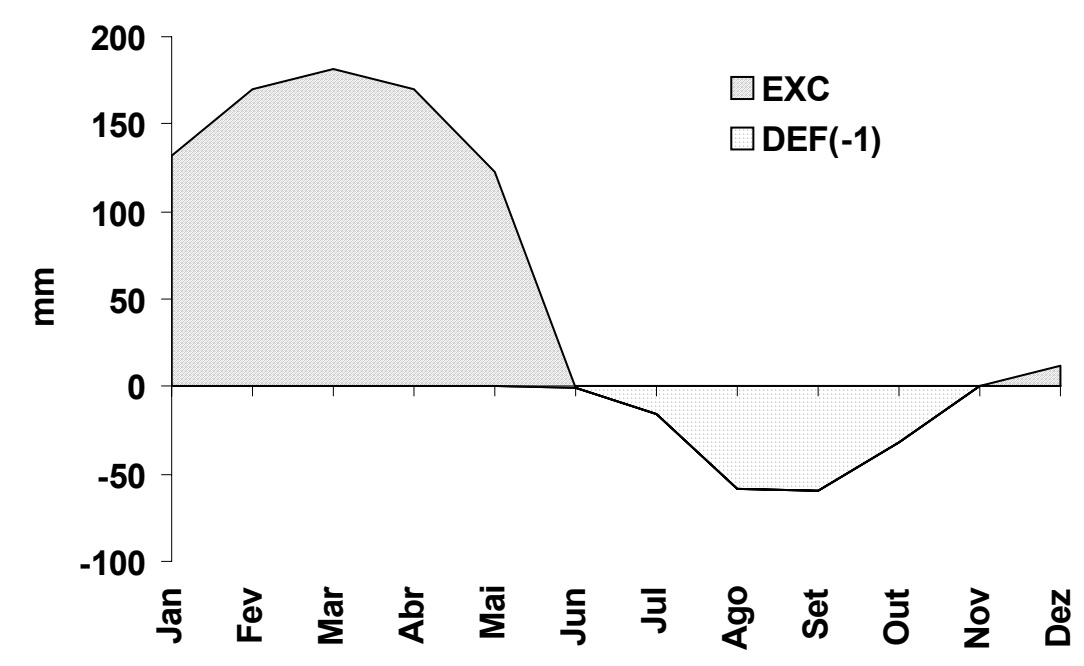

Figura 2 - Balanço hídrico da região na Manaus no período histórico de 1961 a 1990. Dados obtidos do Instituto Nacional de Meteorologia (INMET) segundo Sentelhas et al. (2005)

\subsubsection{Solo}

O solo mais bem representado nas bacias hidrográficas da ZF-2 é o Latossolo Amarelo Álico, argiloso, que ocupa a superfície dos platôs, cuja fase de referência sob floresta é caracterizado pela presença de um horizonte médio, poroso, situado entre dois horizontes pouco porosos e que este solo é composto pelos sedimentos terciários do Grupo Barreiras, que são constituídos de minerais resistentes a alteração, tais como a caolinita, o quartzo, os óxidos e hidróxidos de ferro e o alumínio (Chauvel,1982).

$\mathrm{Na}$ região a topografia apresenta seqüências de platôs, encostas e baixios. Ferraz et al. (1998) relatam que os solos dos platôs apresentaram textura argilosa; nas encostas, variaram de argilo-arenosos próximos aos platôs e areno-argilosos próximos aos baixios e, os solos nas áreas de baixio, apresentaram textura arenosa. Os solos foram classificados em três tipos: 
Latossolo amarelo nos platôs; Podzólicos-Amarelo nas encostas e Arenossolos hidromórficos nos baixios.

O padrão de distribuição vertical dos teores dos nutrientes trocáveis $\mathrm{K}$, $\mathrm{Ca}$ e $\mathrm{Mg}$ indicam que é na camada mais próxima a cobertura vegetal onde se processa com maior intensidade a ciclagem de nutrientes. A conservação da matéria orgânica nesses solos é fator importante para a manutenção da fertilidade dos solos. A disponibilidade de nutrientes para as plantas é baixa, e os solos podem ser classificados como distróficos (Ferraz et al., 1998).

As maiores concentrações dos micronutrientes $\mathrm{Fe}, \mathrm{Mn}$ e $\mathrm{Cu}$ estão nos solos dos platôs, o que pode ser associados a textura argilosa desses solos. A oferta de $\mathrm{Fe}$ e $\mathrm{Zn}$ para as plantas nos solos arenosos é provavelmente reduzida, devido aos maiores teores desses nutrientes estarem abaixo da zona principal de enraizamento das plantas (Ferraz et al., 1998).

\subsubsection{Vegetação}

A área de estudo é coberta por uma floresta tropical úmida densa de terra firme, típica da parte central da região amazônica (Higuchi et al., 1997). Segundo Radam-Brasil (1978) tomando como base a geomorfologia esta região, ela é denominada de sub-região dos Platôs da Amazônia e tomando como base o levantamento florístico de inventários florestais, denomina-se como Macro-ambiente de Relevo Tabular, no qual a cobertura vegetal densa é freqüentemente alterada por manchas de floresta aberta, onde os estratos arbustivos e herbáceos são compostos por regeneração natural das espécies arbóreas, palmeiras e plantas não vasculares.

A composição florística da área é bastante heterogênea, o índice de Shannon-Wiener para duas parcelas de inventário permanente foi de 4,39 e 4,59 (Higuchi et al., 1998). De acordo com Carneiro (2004), trabalhando em 
cerca de 10 ha, a composição florística da região estudada nas topografias tipo platô e baixio apresentaram 737 espécies, pertencentes a 238 gêneros e 59 famílias.

As famílias que apresentaram maior número de indivíduos foram: Lecythidaceae com quinhentos e cinco (505) indivíduos, Sapotaceae (498), Arecaceae (343), Euphorbiaceae (306), Burseraceae (291), Chrysobalanaceae (258), Fabaceae (255), Caesalpiniaceae (240), Lauraceae (136), Mimosaceae (134), Myristicaceae (126), Annonaceae e Moraceae (114) cada uma, Bombacaceae (108) e Humiriaceae (70), somando $80,1 \%$ do total dos indivíduos amostrados. As famílias mais ricas em espécies foram: Sapotaceae (61 espécies), Lecythidaceae (36) e Burseraceae (27) (Carneiro, 2004).

\subsection{Local de coleta dos dados}

O acesso às copas no dossel florestal, que estava aproximadamente entre 18 e 30 metros de altura do nível do solo, se deu através de 4 torres situadas nos quilômetros $(\mathrm{km})$ 14, 23, 33 e 34 da estrada que leva à Estação Experimental de Silvicultura Tropical (ZF-2). Duas destas torres já estavam instaladas na área da ZF-2, uma no quilômetro 14 com as coordenadas 02 $35,348^{\prime}$ Sul (S), 6006,916' Oeste (O) e $141 \mathrm{~m}$ de altitude em relação ao nível do mar (Atl) chamada de T14 e a outra no quilômetro 34 com as coordenadas $02^{\circ} 63,538^{\prime} \mathrm{S}, 60^{\circ} 12,431^{\prime}$ O e $140 \mathrm{~m}$ Alt chamada de T34.

As outras duas foram instaladas no decorrer do trabalho com o apoio dos projetos LBA, PICULUS e JACARANDA, sendo que uma delas foi instalada na área do projeto BIONTE no quilômetro 23 da estrada que leva à ZF-2 localizadas nas coordenadas $02^{\circ} 37,867^{\prime} \mathrm{S}, 60^{\circ} 09,262^{\prime} \mathrm{O}$ e $137 \mathrm{~m}$ Alt chamada BBL4 e outra no quilômetro 33 instalada na parcela permanente do projeto 
JACARANDA, sob as coordenadas de 02³5,909'S, 60¹2,431'O e $129 \mathrm{~m}$ Alt chamada de TN-S.

\subsection{Variáveis climatológicas}

As condições micro-meteorológicos das áreas de estudo foram obtidas utilizando-se estações meteorológicas automáticas modelo LI-1401 (LI-COR, Inc., Lincoln, NE, USA). As variáveis medidas foram: temperatura do ar, umidade relativa do ar, radiação fotossinteticamente ativa e precipitação. Os dados foram armazenados em um datalogger LI-1400 (LI-COR, Inc., Lincoln, NE, USA). A compilação dos dados foi feita com software LI-1400 (LI-COR, Inc., Lincoln, NE, USA). Os dados médios foram registrados a cada 15 minutos durante.

\subsection{Material vegetal estudado}

Avaliaram-se as características biofísicas, fisiológicas e temperaturas de folhas completamente expandidas (maduras) na parte superior do dossel ao redor das quatro torres. O critério de seleção das folhas observada no estudo foi aleatório. Na T14 foram alcançadas 9 plantas entre 20 e $31 \mathrm{~m}$ de altura, na BBL4 foram outras 8 plantas entre 18 e $30 \mathrm{~m}$ de altura, na TN-S foram estudadas 5 plantas entre 18 e 35 m de altura e na T34 foram 7 entre 18 e $31 \mathrm{~m}$ de altura, as quais foram identificadas botanicamente conforme Tabela 1. 
Tabela 1. Torres, identificações de campo (ID) e identificações botânicas das plantas utilizadas no estudo

\begin{tabular}{|c|c|c|c|}
\hline Local & ID & Família & Espécie \\
\hline T14 & 1 & Caesalpiniaceae & Peltogine excelsa \\
\hline T14 & 2 & Leg: Mimosoideae & Inga sp. \\
\hline T14 & 3 & Moraceae & Brosimum parinarioides ssp. parinarioides \\
\hline T14 & 4 & Bignoniaceae & Jacaranda copaia \\
\hline T14 & 5 & Burseraceae & Protium apiculatum \\
\hline T14 & 6 & Burseraceae & Protium sp. \\
\hline T14 & 7 & Meliaceae & Guarea sp. \\
\hline T14 & cipó 1 & Menispermaceae & Abuta cf. panurensis \\
\hline T14 & cipó 2 & Fabaceae & Macherium sp. \\
\hline T14 & cipó 3 & Dilleniaceae & Tetracera amazonica \\
\hline BBL4 & 183 & Clusiaceae & Caraipa grandifolia \\
\hline BBL4 & 184 & Lauraceae & Licaria martiniana \\
\hline BBL4 & 185 & Sapotaceae & Pouteria macrophylla \\
\hline BBL4 & 186 & Rubiaceae & Capirona cf. decorticans \\
\hline BBL4 & 187 & Humiriaceae & Vantanea parviflora \\
\hline BBL4 & $x 38$ & Anisophylleaceae & Anisophyllea manausensis \\
\hline BBL4 & x39 & Sapotaceae & Pouteria reticulate \\
\hline BBL4 & $x 40$ & Euphorbiaceae & Micrandropsis scleroxylon \\
\hline TN-S & 560 & Leg: Mimosoideae & Zygia racemosa \\
\hline TN-S & 561 & Sapotaceae & Micropholis guyanensis ssp duckeana \\
\hline TN-S & 565 & Sapotaceae & Pouteria anomala \\
\hline TN-S & 567 & Sapotaceae & Pouteria williamii \\
\hline TN-S & 568 & Lauraceae & Licania octandra \\
\hline TN-S & 570 & Lecythidaceae & Eschweilera wachenheimii \\
\hline T34 & 1 & Sapotaceae & Pouteria anomala \\
\hline T34 & 2 & Sapotaceae & Micropholis guyanensis ssp duckeana \\
\hline T34 & 3 & Sapotaceae & Pouteria cf. erythrochrysa \\
\hline T34 & 4 & Chrysobalanaceae & Couepia longipendula \\
\hline T34 & 5 & Lecythidaceae & Eschweilera coriacea \\
\hline T34 & 6 & Lecythidaceae & Eschweilera cf. micrantha \\
\hline T34 & 7 & Quiinaceae & Quiina cf. negrensis \\
\hline T34 & cipó 1 & Não identificada & Planta não identificada \\
\hline
\end{tabular}

Obs: A identificação botânica foi feita no departamento de botânica do Inpa - SAPECA. 


\subsection{Avaliações biofísicas}

As seguintes características biofísicas foram avaliadas: área específica foliar (AEF), massa específica foliar (MEF), temperatura foliar $\left(T_{\text {fol }}\right)$, teor de nitrogênio $(N)$ teor de carbono $(C)$ e composição isotópica de carbono $\left(\delta^{13} C\right)$ e do nitrogênio $\left(\delta^{15} \mathrm{~N}\right)$ dos tecidos foliares estudados.

Área específica foliar (AEF) dada em $\mathrm{cm}^{2} \cdot \mathrm{g}^{-1}$ e massa específica foliar (MEF) dada em g.m ${ }^{-2}$ foram obtidas pelas relações de área foliar (AF) e massa seca foliar (MS). Para determinar a área foliar $\left(\mathrm{cm}^{2}\right)$ foi utilizado um integrador de área foliar LI-3000 (LI-COR, Inc., Lincoln, NE, USA). Após a determinação de área foliar o material foi levado para estufa com temperatura de $75^{\circ} \mathrm{C}$ por 72 horas, para determinação da massa seca em gramas (g) com auxilio de uma balança analítica 4800 pm (Mettler-Toledo, Inc.).

As concentrações de $\mathrm{C}$ e $\mathrm{N}$ foram expressas em relação a MEF $\left(\mathrm{g} \cdot \mathrm{m}^{-2}\right)$, e foram determinadas através de um analisador elementar (Carlo Erba) acoplado a um espectrômetro de massa (Finnigan Mat - Delta plus) no Laboratório de Ecologia Isotópica do CENA/USP, Piracicaba, SP, Brasil

\subsection{Medida da temperatura foliar}

Determinou-se a temperatura foliar $\left(T_{\text {fol }}\right)$ em dois períodos sazonais, estação seca e chuvosa. Para o desenvolvimento do trabalho considerou-se que os dados obtidos nas torres TN-S entre 26-07-03 e 27-08-03 e T14 entre 28-10-03 e 17-12-03 observando-se 25 folhas em cada torre, como dados coletados no período seco, pois a maior precipitação local no período de 31 dias foi de $103 \mathrm{~mm}$. O período chuvoso foi caracterizado por uma precipitação maior que $400 \mathrm{~mm}$ por mês. Neste período determinou-se a $\mathrm{T}_{\text {fol }}$ nas torres T34 
e BBL4, onde foram coletados entre 20-12-03 a 04-02-04 com 22 folhas amostradas e entre 13-02-04 e 23-03-04 com 24 folhas amostradas, respectivamente.

A $\mathrm{T}_{\text {fol }}$ foi monitorada a cada 15 minutos com a utilização de 25 termopares (TC) (cobre-constantan, 0,08 mm, AWG40, Omega Engineering, Stanford, CT, USA). Os TC foram mantidos em contato com as folhas utilizando-se fitas adesivas com micro-poros (surgical tape 1538-0, 3M ${ }^{\mathrm{TM}}$ Company, USA), colocados na porção abaxial de folhas completamente expandidas.

Para armazenamento e coleta dos dados foi utilizado um datalogger modelo CR10X, um armazenador de dados do modelo SM4M e um multiplexador modelo AM25T (Campbell Scientific, Inc.). O programa utilizado para interface entre datalogger e o computador foi o PC208W (Campbell Scientific, Inc.).

Em cada um destes locais e períodos de coleta de dados, foi instalada uma estação micro-meteorológica com horários de coletas sincronizados para controle das condições climáticas locais.

\subsection{Avaliações fisiológicas}

Avaliou-se as respostas da respiração das folhas $\left(R_{\mathrm{fol}}\right)$ e da fotossíntese (A) às variações de radiação fotossinteticamente ativa (RFA), temperatura foliar $\left(T_{\text {fol }}\right)$ e concentração de $\mathrm{CO}_{2}$ na câmara subestomática $\left(C_{i}\right)$, desenvolvendo-se curvas de respostas entre $\mathrm{A}$ e $\mathrm{Ci}$ em diferentes temperaturas foliares.

As trocas gasosas (respiração foliar e fotossíntese) foram quantificadas nas mesmas plantas em que se quantificou o crescimento, utilizando um analisador de gás infravermelho (IRGA) modelo LI-6400 (LI-COR, Inc., Lincoln, NE, USA), que inclui uma fonte de luz azul/vermelho LI-6400-02B (LI-COR), 
controlador da concentração de $\mathrm{CO}_{2}$ e de temperatura. As medições só foram realizadas quando o coeficiente combinando as variações de gás carbônico, água e fluxo de $\operatorname{ar}\left(\Delta \mathrm{CO}_{2}, \Delta \mathrm{H}_{2} \mathrm{O}\right.$ e $\Delta \mathrm{u}_{\mathrm{e}}$, respectivamente) apresentou-se abaixo de $1,0 \%$.

Para cada folha obteve-se uma curva de resposta da fotossíntese à radiação fotossinteticamente ativa (A-RFA) e quatro curvas de respostas da fotossíntese em relação a concentração interna de $\mathrm{CO}_{2}\left(A-C_{i}\right)$ em diferentes temperaturas foliares: entre 25 e $29^{\circ} \mathrm{C}$; 30 e $34{ }^{\circ} \mathrm{C}$; 34 e $38^{\circ} \mathrm{C}$; e uma última nas temperaturas superiores a $39{ }^{\circ} \mathrm{C}$. As curvas foram realizadas entre os horários das 07:00 às 14:00 horas. 


\section{RESULTADOS}

\subsection{Caracterização micro-meteorológica}

A radiação fotossinteticamente ativa (RFA) foi diferente nos dois períodos sazonais. No período seco a média diurna foi de $718,7 \mu \mathrm{mol} \cdot \mathrm{m}^{-2} \cdot \mathrm{s}^{-1}$, com valores máximos de $2400 \mu \mathrm{mol} \cdot \mathrm{m}^{-2} \cdot \mathrm{s}^{-1}$. A estação chuvosa foi caracterizada por uma RFA média de 527,7 $\mu \mathrm{mol} \cdot \mathrm{m}^{-2} \cdot \mathrm{s}^{-1}$, com taxas de fluxo de fótons de até $2200 \mu \mathrm{mol} \cdot \mathrm{m}^{-2} \cdot \mathrm{s}^{-1}$. A Figura 3 mostra a variação média da RFA ao longo do dia nos períodos seco e chuvoso. Estes valores de RFA são correspondentes aos horários em que não ocorreram eventos de precipitação.

Quando ocorre um evento de precipitação, mesmo que de apenas $1 \mathrm{~mm}$ em 15 minutos, não foi detectada diferenças estatisticamente significativas para as médias de RFA nas duas épocas e valores os médios passaram para a ordem de $112,3 \pm 50 \mu \mathrm{mol} . \mathrm{m}^{-2} \cdot \mathrm{s}^{-1}$ na estação seca e $82,8 \pm 30 \mu \mathrm{mol} . \mathrm{m}^{-2} \cdot \mathrm{s}^{-1}$ na estação chuvosa. 

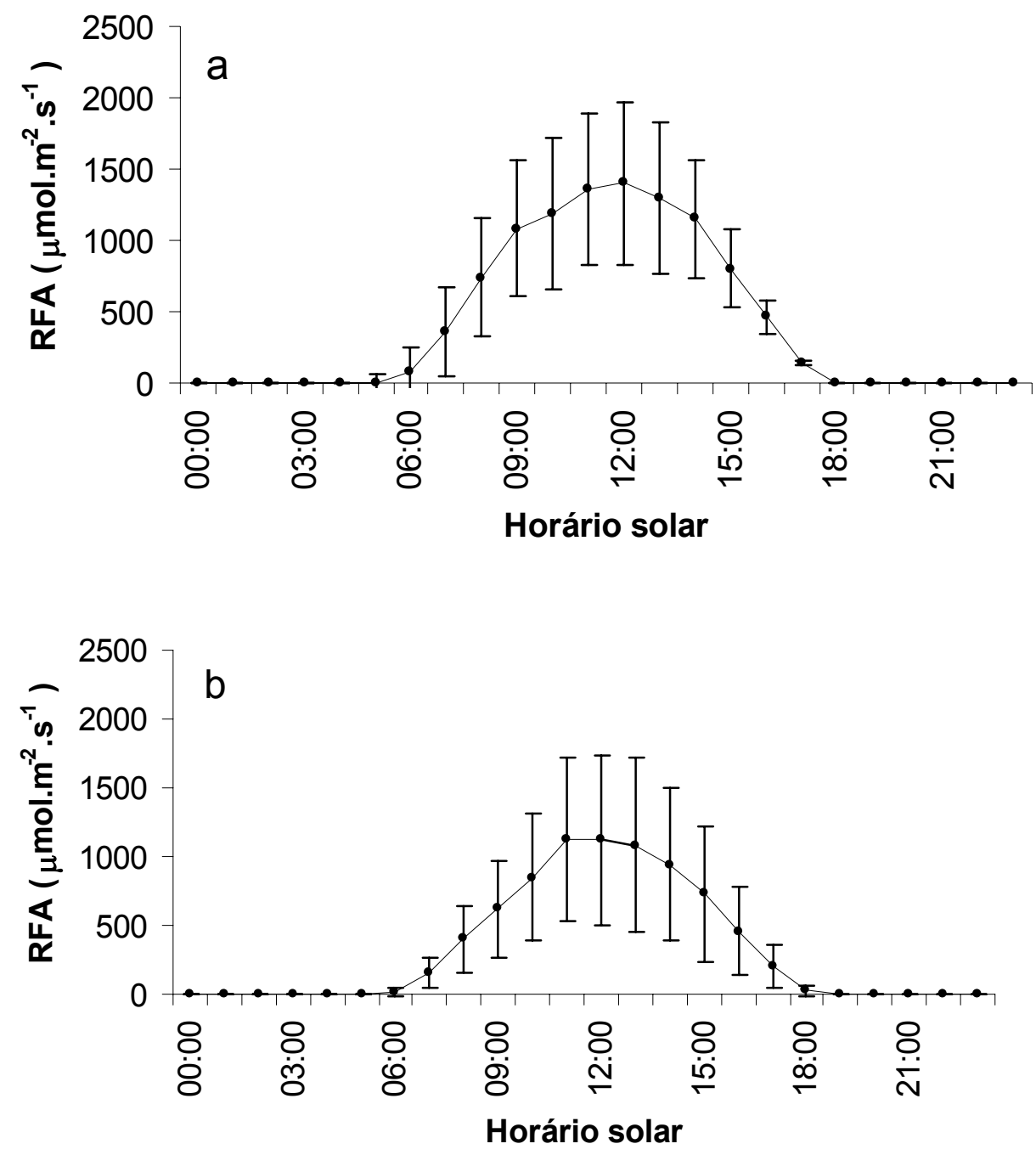

Figura 3 - Distribuição diurna média da radiação fotossinteticamente ativa (RFA), nos períodos seco (a) e chuvoso (b)

No período chuvoso, verificaram-se temperaturas médias do ar $\left(T_{\mathrm{ar}}\right)$ menores que aquelas verificadas no período seco, quando a $T_{\text {ar }}$ foi de $28,4 \pm$ $0,1{ }^{\circ} \mathrm{C}$, enquanto no período chuvoso a $\mathrm{T}_{\text {ar }}$ foi de $27,1 \pm 0,1^{\circ} \mathrm{C}$. A Figura 4 ilustra a variação da temperatura média do ar para o ciclo diurno nas duas épocas sazonais. Considerando os horários de chuvas, o mesmo observado 
para RFA também acontece com $\mathrm{T}_{\mathrm{ar}}$, ou seja, as médias nas duas épocas são semelhantes, quando se verificou valores médios de $23,8 \pm 0,4{ }^{\circ} \mathrm{C}$.
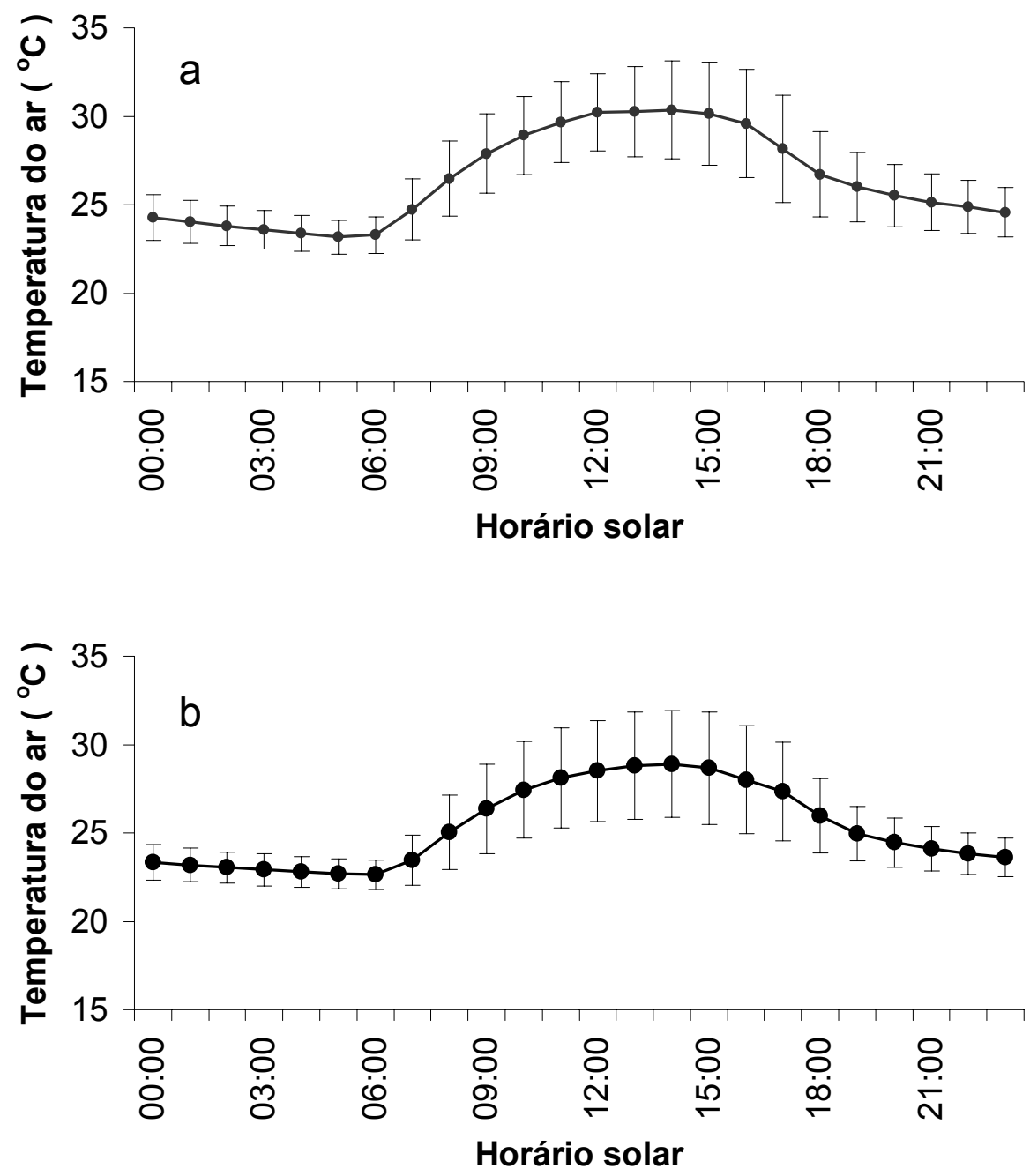

Figura 4 - Distribuição diurna média da temperatura do ar nos períodos seco (a) e chuvoso (b)

A umidade relativa do ar (UR) também foi distinta nos dois períodos sazonais com médias de $73,8 \pm 0,5 \%$ no seco e $82,8 \pm 0,5 \%$ no chuvoso. Com a presença de chuva a UR média diária aumentou para 96,0 $\pm 1,8 \%$ e 77,8 \pm 
0,4 \% nos períodos chuvoso e seco, respectivamente. O déficit de saturação de vapor (DSV) apresentou valores de 0,43 kPa na época chuvosa e 0,73 kPa para a seca, na presença de precipitação os valores passaram a 0,14 e 0,31 kPa, respectivamente. A Figura 5 ilustra que no intervalo entre 11:00 e 17:00 horas há uma maior indisponibilidade de água no ar atmosférico nos dois períodos sazonais.

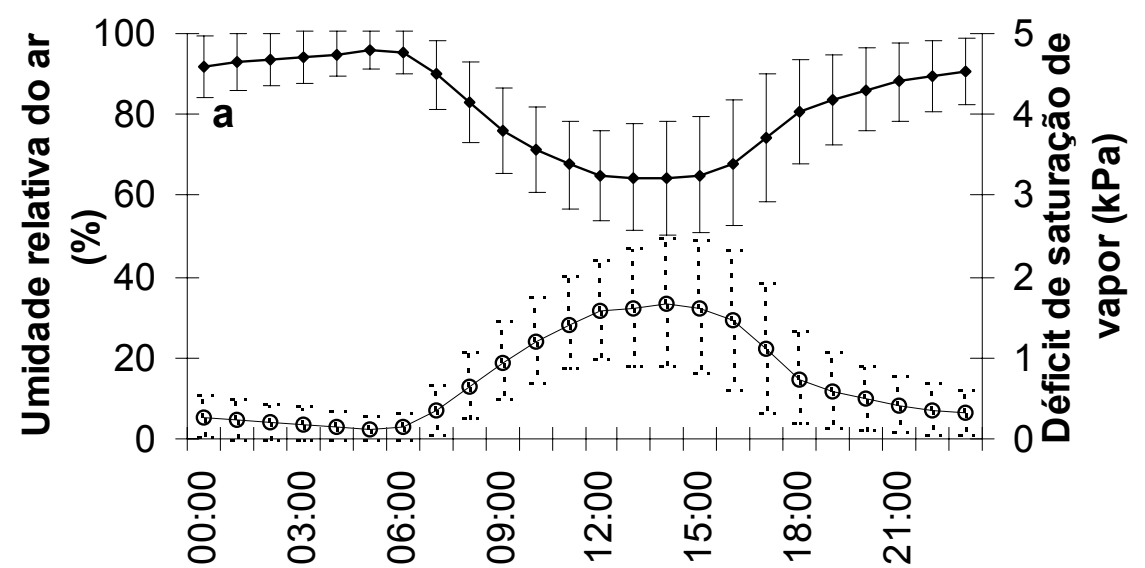

Horário solar

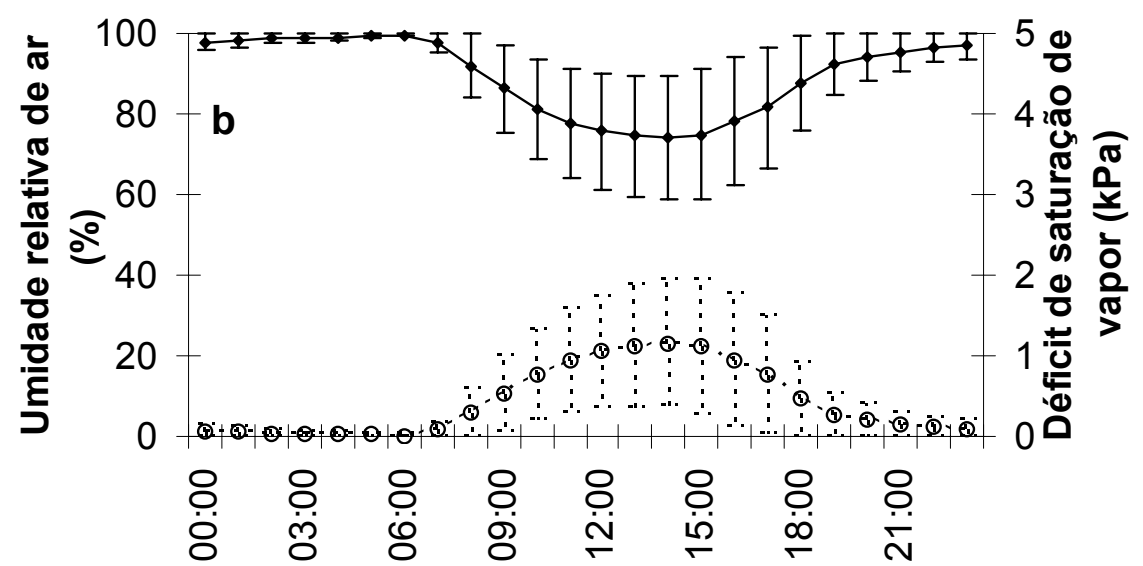

Horário solar

Figura 5 - Distribuição diurna média da umidade relativa do ar (UR, - •- ) e do déficit de saturação de vapor (DSV, - o - ) nos períodos seco (a) e chuvoso (b) 
A precipitação (Prec) foi de $40 \mathrm{~mm}$ na TN-S no período de 26-07-03 a 2708-03. Na T14 o período de coleta foi de 28-10-03 a 17-12-03 e apresentou uma Prec de $174 \mathrm{~mm}$. Como a precipitação mensal nestas duas áreas foi menor que $105 \mathrm{~mm}$ e os períodos de avaliação estão na maior parte do tempo no período de déficit no balanço hídrico regional, considerou-se estes dois representativos do período seco. Nas demais torres a precipitação mensal foi superior a $400 \mathrm{~mm} \cdot \mathrm{mês}^{-1}$ caracterizando uma estação chuvosa. Na T34 a Prec foi de $421 \mathrm{~mm}$ no período de 20-12-03 a 04-02-04 e na BBL4 onde as medições foram realizadas entre 13-02-04 e 18-03-04 a Prec foi de 456 mm. A Figura 6 apresenta a distribuição da precipitação nos diferentes períodos de avaliação.
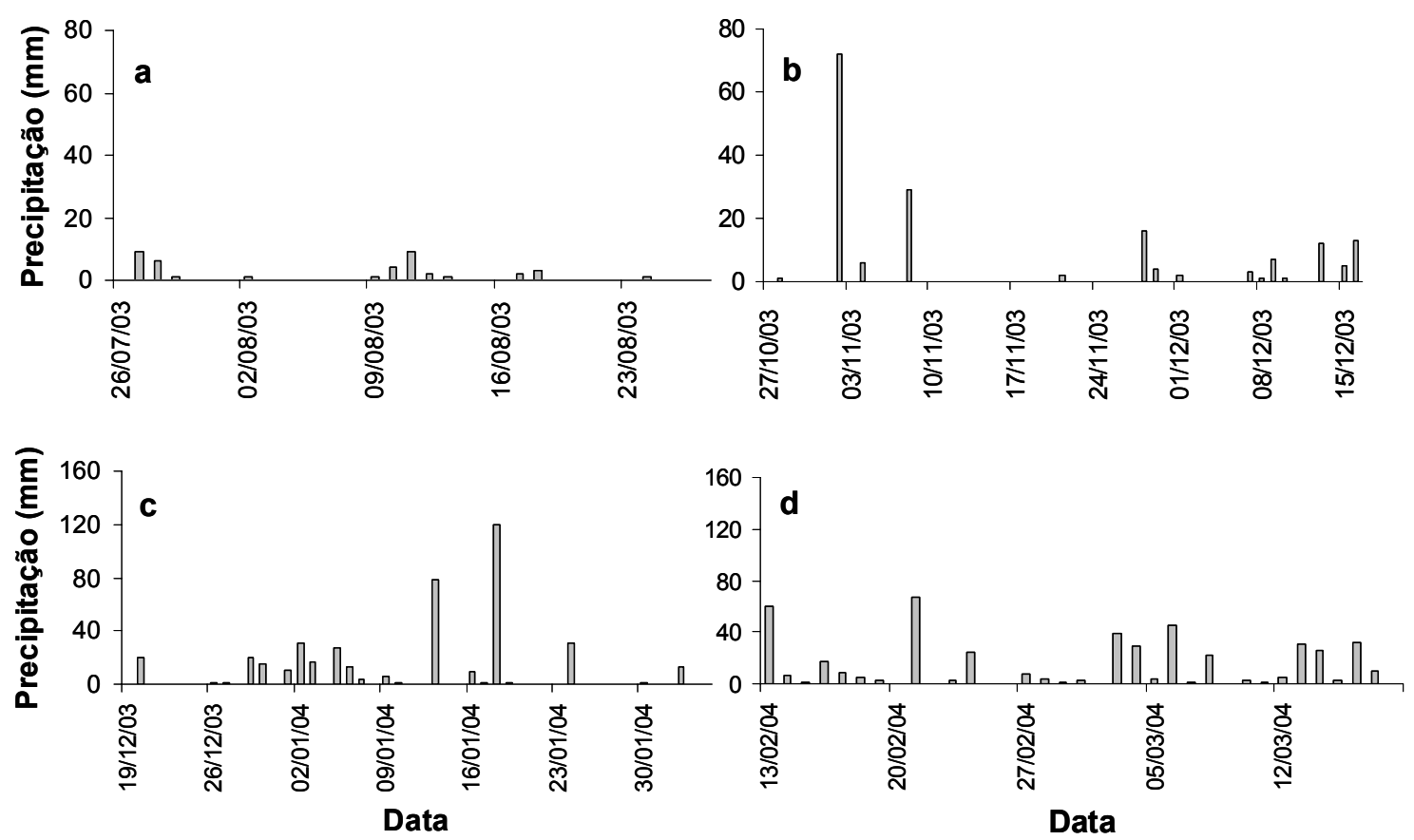

Figura 6 - Distribuição da precipitação para os períodos de avaliação da temperatura foliar, (a) no período de 26-07 a 27-08-03 na TN-S, (b) de 28-10 a 17-12-03 na T14, (c) de 20-12-03 a 04-02-04 na T34 e (d) de 13-02 a 23-03-04 na BBL4; as figuras (a) e (b) representam a precipitação do período de seco e (c) e (d) do período chuvoso 


\subsection{Temperatura foliar}

Analisando os dados de temperatura foliar $\left(T_{\text {fol }}\right)$ foram verificadas interações entre esta variável e as características meteorológicas locais. Os valores médios para a $T_{\text {fol }}$ foram de $34,4 \pm 1,8{ }^{\circ} \mathrm{C}$ no período seco e $33,1 \pm 2,2$ ${ }^{\circ} \mathrm{C}$, no período chuvoso. Em média a $\mathrm{T}_{\text {fol }}$ foi $6{ }^{\circ} \mathrm{C}$ superior a temperatura do ar $\left(\mathrm{T}_{\mathrm{ar}}\right)$ para ambos os períodos.

As características biofísicas estiveram pouco relacionadas com a $T_{\text {fol }}$, área foliar, área específica foliar e massa específica foliar apresentando baixos coeficientes de correlação $\left(r^{2}\right)$, todos menores que 0,11 . Nos casos em que as temperaturas das folhas estiveram mais elevadas, a altura em que a folha se encontrava no dossel florestal foi a característica biofísica que apresentou melhor correlação com $\mathrm{T}_{\text {fol }}\left(r^{2}=0,24\right.$ e probabilidade $\left.(P)<0,0001\right)$. Desta forma as folhas que se encontravam na porção superior do dossel foram aquelas com os maiores valores de $T_{\text {fol }}$ (Figura 7 ). Não se verificou relação entre as $T_{\text {fol }}$ médias e mínimas com as características biofísicas.

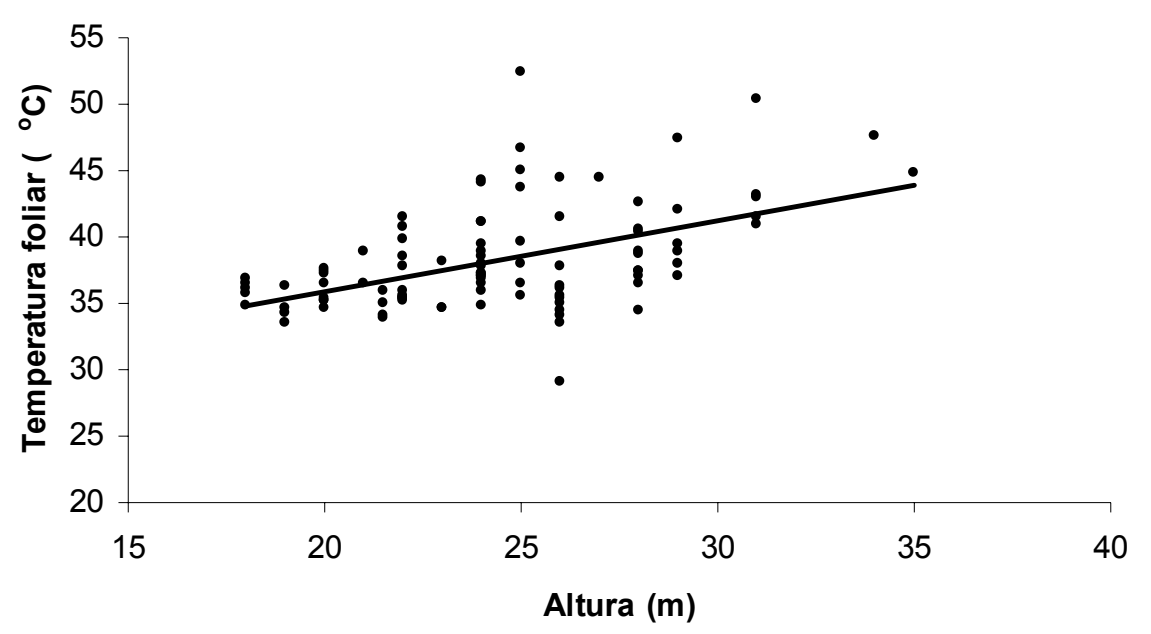

Figura 7 - Variação da temperatura foliar máxima em função da altura em que a folha se encontrava no dossel florestal 
As altas temperaturas foliares estiveram associadas com altas taxas de radiação fotossinteticamente ativa (RFA) e a baixos valores de umidade relativa do ar (UR), enquanto que, para as horas em que as condições ambientais eram de baixas taxas de RFA e altas UR, foram verificadas as menores $T_{\text {fol. }}$ Com base neste fato, observado nos dados de campo, foi criado um modelo empírico médio, correlacionando-se em uma regressão múltipla, $\mathrm{T}_{\text {fol }}$ como respostas das variações de RFA e UR, encontrando-se uma equação que descreve a variação de $T_{\text {fol }}$ que é dada por:

$1 / T_{\text {fol }}=2,48 \exp ^{-06} U R^{2}-1,82 \exp ^{-04} U R-1,83 \exp ^{-06} R F A+0,0363$

onde,

$\mathrm{T}_{\text {fol }}$ é a temperatura foliar; exp é o símbolo da exponencial na base 10; UR é a umidade relativa do ar (\%); e RFA é a radiação fotossinteticamente ativa $\left(\mu \mathrm{mol} \cdot \mathrm{m}^{-2} \cdot \mathrm{s}^{-1}\right)$. Esta equação média de regressão múltipla apresentou um $\mathrm{r}^{2}=$ 0,86 e $P<0,0001$, com $n=97$ folhas amostradas.

Para descrever as variações de $T_{\text {fol }}$ que ocorrem nas folhas durante 0 ciclo diurno, criou-se respostas, fornecendo ao modelo empírico de cada folha as condições de alta UR e baixa RFA (100 \% e $50 \mu \mathrm{mol} . \mathrm{m}^{-2} \mathrm{~s}^{-1}$, respectivamente), para determinar os valores de $T_{\text {fol }}$ quando a folha teria as menores temperaturas ( $T_{\text {min }}$ ), e também sob a condição inversa, quando ocorre baixa UR e alta RFA (45 \% de UR e RFA de $2000 \mu \mathrm{mol} . \mathrm{m}^{-2} \mathrm{~s}^{-1}$ ) encontrando-se os maiores valores para a temperatura foliar $\left(T_{\max }\right)$.

Observando os dados gerados a partir do modelo empírico verificou-se que nas horas em que as folhas estavam sob a condição de $T_{\min }$, a temperatura máxima encontrada foi de $24,9 \pm 2,3^{\circ} \mathrm{C}$, podendo chegar a temperaturas de no mínimo $21,4 \pm 1,6{ }^{\circ} \mathrm{C}$. Nas horas de $\mathrm{T}_{\max }$ a variação observada foi bem maior, sendo que a média para temperatura máxima foi de $38,4^{\circ} \mathrm{C}$ variando entre 26,9 e $52,5{ }^{\circ} \mathrm{C}$. As Tabelas 2, 3, 4 e 5 mostram os valores encontrados pela 
utilização do modelo para cada folha amostrada das torres TN-S, T14, T34 e BBL4, respectivamente.

Tabela 2. Valores referentes à identificação de campo (Planta), o intercepto com o eixo dos $Y$ da correlação entre o inverso da temperatura foliar (y-int) e RFA, UR e $U^{2}{ }^{2}$ são os valores das constantes que multiplicam os respectivos parâmetros micro-meteorológicos. Máxima, corresponde aos valores de $T_{\text {fol }}$ nas condições de baixa UR e alta RFA (45 \% e $2000 \mu \mathrm{mol} . \mathrm{m}^{-2} \mathrm{~s}^{-1}$ ), Mínima, são os valores de $\mathrm{T}_{\text {fol }}$ nas condições de alta UR e baixa RFA $\left(100 \%\right.$ e $\left.50 \mu \mathrm{mol} . \mathrm{m}^{-2} \mathrm{~s}^{-1}\right)$ e Amp é a diferença entre a maior e menor temperatura foliar. Dados relativos às observações de temperatura foliar na TN-S no período de 26-07-03 a 27-08-03

\begin{tabular}{|c|c|c|c|c|c|c|c|}
\hline \multirow[b]{2}{*}{ Planta } & \multirow[b]{2}{*}{$y$-int } & \multicolumn{3}{|c|}{ Constantes de $f\left(1 / T_{f o l}\right)$} & \multicolumn{3}{|c|}{ Temperatura foliar } \\
\hline & & RFA & UR & $\mathbf{U R}^{2}$ & Máxima & Mínima & Amp \\
\hline 560 & 0,025 & $-1,1 E^{-06}$ & $1,0 \mathrm{E}^{-04}$ & $1,2 \mathrm{E}^{-06}$ & 39,4 & 20,6 & 18,8 \\
\hline 560 & 0,027 & $-1,7 E^{-06}$ & $1,0 \mathrm{E}^{-04}$ & $1,1 \mathrm{E}^{-06}$ & 38,9 & 20,6 & 18,3 \\
\hline 560 & 0,028 & $-8,7 E^{-07}$ & $1,1 \mathrm{E}^{-05}$ & $1,7 \mathrm{E}^{-06}$ & 36,4 & 20,8 & 15,6 \\
\hline 568 & 0,028 & $-9,1 \mathrm{E}^{-07}$ & $-2,4 E^{-08}$ & $1,8 \mathrm{E}^{-07}$ & 37,0 & 20,5 & 16,5 \\
\hline 568 & 0,028 & $-1,3 E^{-06}$ & $8,1 \mathrm{E}^{-06}$ & $1,7 \mathrm{E}^{-06}$ & 37,5 & 20,7 & 16,8 \\
\hline 568 & 0,029 & $-1,6 E^{-06}$ & $1,7 \mathrm{E}^{-05}$ & $1,8 \mathrm{E}^{-06}$ & 38,7 & 20,4 & 18,3 \\
\hline 565 & 0,030 & $-1,7 E^{-06}$ & $-3,8 E^{-05}$ & $2,0 \mathrm{E}^{-04}$ & 40,3 & 20,2 & 20,1 \\
\hline 565 & 0,029 & $-2,1 \mathrm{E}^{-06}$ & $-9,2 E^{-06}$ & $1,9 \mathrm{E}^{-06}$ & 42,5 & 19,5 & 23,0 \\
\hline 565 & 0,018 & $-1,4 E^{-06}$ & $3,0 \mathrm{E}^{-04}$ & $2,6 \mathrm{E}^{-07}$ & 44,4 & 19,8 & 24,6 \\
\hline 567 & 0,024 & $-2,3 E^{-06}$ & $2,0 \mathrm{E}^{-04}$ & $5,7 \mathrm{E}^{-07}$ & 43,2 & 20,2 & 23,0 \\
\hline 567 & 0,028 & $-3,8 E^{-06}$ & $1,0 E^{-04}$ & $9,1 \mathrm{E}^{-07}$ & 44,8 & 24,4 & 20,4 \\
\hline 567 & 0,032 & $-4,5 E^{-06}$ & $-1,1 E^{-05}$ & $1,6 \mathrm{E}^{-06}$ & 47,6 & 19,8 & 27,8 \\
\hline 561 & 0,023 & $-1,5 E^{-06}$ & $1,0 E^{-04}$ & $8,1 \mathrm{E}^{-07}$ & 41,0 & 20,3 & 20,7 \\
\hline 561 & 0,020 & $-2,1 \mathrm{E}^{-06}$ & $3,0 \mathrm{E}^{-04}$ & $-1,6 E^{-07}$ & 42,9 & 20,4 & 22,5 \\
\hline 561 & 0,029 & $-2,3 E^{-06}$ & $-9,7 E^{-06}$ & $1,8 \mathrm{E}^{-07}$ & 41,5 & 19,9 & 21,6 \\
\hline 565 & 0,025 & $-1,5 E^{-06}$ & $1,0 \mathrm{E}^{-04}$ & $1,1 \mathrm{E}^{-06}$ & 39,4 & 20,5 & 18,9 \\
\hline 565 & 0,026 & $-9,8 E^{-07}$ & $1,0 \mathrm{E}^{-04}$ & $9,6 \mathrm{E}^{-07}$ & 36,4 & 21,0 & 15,4 \\
\hline 565 & 0,027 & $-1,1 E^{-06}$ & $1,0 \mathrm{E}^{-04}$ & $1,1 \mathrm{E}^{-06}$ & 36,5 & 20,7 & 15,8 \\
\hline 568 & 0,024 & $-1,2 E^{-06}$ & $1,0 \mathrm{E}^{-04}$ & $7,7 \mathrm{E}^{-07}$ & 37,8 & 20,5 & 17,3 \\
\hline 568 & 0,028 & $-7,6 \mathrm{E}^{-07}$ & $8,3 \mathrm{E}^{-06}$ & $1,7 \mathrm{E}^{-06}$ & 36,1 & 20,6 & 15,5 \\
\hline 570 & 0,026 & $-1,3 E^{-06}$ & $1,0 \mathrm{E}^{-04}$ & $1,1 \mathrm{E}^{-06}$ & 37,5 & 20,4 & 17,1 \\
\hline 560 & 0,025 & $-1,6 E^{-06}$ & $1,0 \mathrm{E}^{-04}$ & $9,6 \mathrm{E}^{-07}$ & 38,9 & 20,1 & 18,8 \\
\hline 565 & 0,024 & $-1,2 E^{-06}$ & $1,0 \mathrm{E}^{-04}$ & $7,1 \mathrm{E}^{-07}$ & 38,1 & 20,4 & 17,7 \\
\hline 560 & 0,027 & $-1,1 E^{-06}$ & $1,0 E^{-04}$ & $1,1 \mathrm{E}^{-06}$ & 36,4 & 20,6 & 15,8 \\
\hline 560 & 0,026 & $-9,0 E^{-07}$ & $1,0 \mathrm{E}^{-04}$ & $1,0 \mathrm{E}^{-06}$ & 36,0 & 20,6 & 15,4 \\
\hline
\end{tabular}


Tabela 3. Valores referentes à identificação de campo (Planta), o intercepto com o eixo dos $Y$ da correlação entre o inverso da temperatura foliar (y-int) e RFA, UR e $U^{2}$ são os valores das constantes que multiplicam os respectivos parâmetros micro-meteorológicos. Máxima, corresponde aos valores de $\mathrm{T}_{\text {fol }}$ nas condições de baixa UR e alta RFA (45\% e $2000 \mu \mathrm{mol} . \mathrm{m}^{-2} \mathrm{~s}^{-1}$ ), Mínima, são os valores de $\mathrm{T}_{\text {fol }}$ nas condições de alta UR e baixa RFA $\left(100 \%\right.$ e $\left.50 \mu \mathrm{mol} . \mathrm{m}^{-2} \mathrm{~s}^{-1}\right)$ e Amp é a diferença entre a maior e menor temperatura foliar. Dados relativos às observações de temperatura foliar na T14 no período de 28-10-03 a 17-12-03

\begin{tabular}{|c|c|c|c|c|c|c|c|}
\hline \multirow[b]{2}{*}{ Planta } & \multirow[b]{2}{*}{$y$-int } & \multicolumn{3}{|c|}{ Constantes de $f\left(1 / T_{\text {fol }}\right)$} & \multicolumn{3}{|c|}{ Temperatura foliar } \\
\hline & & RFA & UR & $\mathrm{UR}^{2}$ & Máxima & Mínima & Amp \\
\hline Cipó 1 & 0,039 & $-1,3 E^{-06}$ & $-2,6 \mathrm{E}^{-04}$ & $3,0 \mathrm{E}^{-06}$ & 34,9 & 21,9 & 13,0 \\
\hline Cipó 1 & 0,036 & $-1,3 E^{-06}$ & $-1,7 E^{-04}$ & $2,5 \mathrm{E}^{-06}$ & 36,9 & 21,4 & 15,5 \\
\hline Cipó 1 & 0,051 & $5,2 \mathrm{E}^{-07}$ & $-7,7 \mathrm{E}^{-04}$ & $6,9 \mathrm{E}^{-06}$ & 37,3 & 20,5 & 16,8 \\
\hline 4 & 0,035 & $-1,1 E^{-06}$ & $-2,0 E^{-04}$ & $2,5 \mathrm{E}^{-06}$ & 37,2 & 21,7 & 15,5 \\
\hline 4 & 0,042 & $-3,1 E^{-06}$ & $-3,7 E^{-04}$ & $3,8 \mathrm{E}^{-06}$ & 44,0 & 20,9 & 23,1 \\
\hline 4 & 0,041 & $-3,2 E^{-06}$ & $-2,7 E^{-04}$ & $3,0 \mathrm{E}^{-06}$ & 41,1 & 21,1 & 20,0 \\
\hline 6 & 0,035 & $-1,7 E^{-06}$ & $-1,9 E^{-04}$ & $2,8 \mathrm{E}^{-06}$ & 39,8 & 21,5 & 18,3 \\
\hline 6 & 0,035 & $-2,4 E^{-06}$ & $-1,8 E^{-04}$ & $2,6 \mathrm{E}^{-06}$ & 41,4 & 21,1 & 20,3 \\
\hline 6 & 0,035 & $-1,8 E^{-06}$ & $-1,9 E^{-04}$ & $2,7 \mathrm{E}^{-06}$ & 38,6 & 21,6 & 17,0 \\
\hline 3 & 0,034 & $-2,8 E^{-06}$ & $-1,7 E^{-04}$ & $2,7 \mathrm{E}^{-06}$ & 44,4 & 21,3 & 23,1 \\
\hline 3 & 0,040 & $-1,1 E^{-06}$ & $-2,6 E^{-04}$ & $3,1 \mathrm{E}^{-06}$ & 35,5 & 21,7 & 13,8 \\
\hline 3 & 0,036 & $-8,2 E^{-07}$ & $-2,3 E^{-04}$ & $3,0 \mathrm{E}^{-06}$ & 36,3 & 21,8 & 14,5 \\
\hline Cipó 2 & 0,043 & $-1,4 E^{-06}$ & $-4,1 E^{-04}$ & $4,3 \mathrm{E}^{-06}$ & 37,7 & 21,4 & 16,3 \\
\hline Cipó 2 & 0,034 & $-8,6 E^{-07}$ & $-1,8 E^{-04}$ & $2,8 \mathrm{E}^{-06}$ & 37,0 & 21,7 & 15,3 \\
\hline Cipó 2 & 0,036 & $-7,4 E^{-07}$ & $-2,2 E^{-04}$ & $3,0 \mathrm{E}^{-06}$ & 36,0 & 21,8 & 14,2 \\
\hline 7 & 0,035 & $-7,0 E^{-07}$ & $-2,0 E^{-04}$ & $2,9 \mathrm{E}^{-06}$ & 36,0 & 21,6 & 14,4 \\
\hline 7 & 0,034 & $-7,3 E^{-07}$ & $-1,5 E^{-04}$ & $2,4 \mathrm{E}^{-06}$ & 35,3 & 21,8 & 13,5 \\
\hline 7 & 0,034 & $-8,5 E^{-07}$ & $-1,4 E^{-04}$ & $2,3 \mathrm{E}^{-06}$ & 35,5 & 21,8 & 13,7 \\
\hline 5 & 0,036 & $-1,3 E^{-06}$ & $-1,9 E^{-04}$ & $2,7 \mathrm{E}^{-06}$ & 36,5 & 21,7 & 14,8 \\
\hline 5 & 0,035 & $-8,5 E^{-07}$ & $-1,8 E^{-04}$ & $2,6 \mathrm{E}^{-06}$ & 35,2 & 21,9 & 13,3 \\
\hline 5 & 0,039 & $-1,6 E^{-06}$ & $-2,8 E^{-04}$ & $3,3 \mathrm{E}^{-06}$ & 37,6 & 21,5 & 16,1 \\
\hline Cipó 3 & 0,031 & $-8,1 \mathrm{E}^{-07}$ & $-1,3 E^{-04}$ & $2,5 \mathrm{E}^{-06}$ & 38,6 & 21,6 & 17,0 \\
\hline Cipó 3 & 0,039 & $-1,2 E^{-06}$ & $-3,0 E^{-04}$ & $3,5 \mathrm{E}^{-06}$ & 37,0 & 21,7 & 15,3 \\
\hline Cipó 3 & 0,032 & $-1,1 E^{-06}$ & $-1,6 E^{-04}$ & $2,6 \mathrm{E}^{-06}$ & 41,2 & 21,2 & 20,0 \\
\hline 2 & 0,031 & $-2,2 E^{-06}$ & $-1,3 E^{-04}$ & $2,5 \mathrm{E}^{-06}$ & 44,2 & 21,2 & 23,0 \\
\hline
\end{tabular}


Tabela 4. Valores referentes à identificação de campo (Planta), o intercepto com o eixo dos $Y$ da correlação entre o inverso da temperatura foliar (y-int) e RFA, UR e $U^{2}$ são os valores das constantes que multiplicam os respectivos parâmetros micro-meteorológicos. Máxima, corresponde aos valores de $\mathrm{T}_{\text {fol }}$ nas condições de baixa UR e alta RFA ( $45 \%$ e $2000 \mu \mathrm{mol} . \mathrm{m}^{-2} \mathrm{~s}^{-1}$ ), Mínima, são os valores de $\mathrm{T}_{\text {fol }}$ nas condições de alta UR e baixa RFA $\left(100 \%\right.$ e $\left.50 \mu \mathrm{mol} . \mathrm{m}^{-2} \mathrm{~s}^{-1}\right)$ e Amp é a diferença entre a maior e menor temperatura foliar. Dados relativos às observações de temperatura foliar na T34 no período de 20-12-03 a 04-02-04

\begin{tabular}{lccccccc}
\hline & \multicolumn{3}{c}{ Constantes de $\mathrm{f}\left(1 / \mathrm{T}_{\mathrm{fo}}\right)$} & \multicolumn{3}{c}{ Temperatura foliar } \\
Planta & y-int & RFA & UR & UR $^{2}$ & Máxima & Mínima & Amp \\
\hline 5 & 0,039 & $-2,3 \mathrm{E}^{-06}$ & $-2,3 \mathrm{E}^{-04}$ & $2,6 \mathrm{E}^{-06}$ & 37,9 & 22,1 & 15,8 \\
5 & 0,030 & $-1,9 \mathrm{E}^{-06}$ & $-2,0 \mathrm{E}^{-05}$ & $1,3 \mathrm{E}^{-06}$ & 38,9 & 22,6 & 16,3 \\
5 & 0,055 & $-5,1 \mathrm{E}^{-06}$ & $-6,2 \mathrm{E}^{-04}$ & $4,9 \mathrm{E}^{-06}$ & 46,7 & 21,2 & 25,5 \\
3 & 0,038 & $-3,7 \mathrm{E}^{-06}$ & $-3,0 \mathrm{E}^{-04}$ & $3,5 \mathrm{E}^{-06}$ & 52,5 & 21,3 & 31,2 \\
3 & 0,043 & $-2,5 \mathrm{E}^{-06}$ & $-3,2 \mathrm{E}^{-04}$ & $3,2 \mathrm{E}^{-06}$ & 37,9 & 22,1 & 15,8 \\
3 & 0,045 & $-3,1 \mathrm{E}^{-06}$ & $-3,8 \mathrm{E}^{-04}$ & $3,5 \mathrm{E}^{-06}$ & 39,6 & 21,9 & 17,7 \\
2 & 0,052 & $-4,1 \mathrm{E}^{-06}$ & $-5,9 \mathrm{E}^{-04}$ & $4,9 \mathrm{E}^{-06}$ & 43,7 & 21,8 & 21,9 \\
2 & 0,050 & $-4,0 \mathrm{E}^{-06}$ & $-5,4 \mathrm{E}^{-04}$ & $4,7 \mathrm{E}^{-06}$ & 45,0 & 21,6 & 23,4 \\
2 & 0,040 & $-2,4 \mathrm{E}^{-06}$ & $-3,2 \mathrm{E}^{-04}$ & $3,5 \mathrm{E}^{-06}$ & 41,4 & 21,9 & 19,5 \\
Cipó 1 & 0,041 & $-1,5 \mathrm{E}^{-06}$ & $-2,9 \mathrm{E}^{-04}$ & $3,0 \mathrm{E}^{-06}$ & 35,1 & 22,2 & 12,9 \\
Cipó 1 & 0,036 & $-1,0 \mathrm{E}^{-06}$ & $-1,5 \mathrm{E}^{-04}$ & $2,2 \mathrm{E}^{-06}$ & 34,7 & 22,3 & 12,4 \\
1 & 0,059 & $-2,7 \mathrm{E}^{-06}$ & $-8,0 \mathrm{E}^{-04}$ & $6,3 \mathrm{E}^{-06}$ & 38,8 & 21,7 & 17,1 \\
1 & 0,039 & $-1,6 \mathrm{E}^{-06}$ & $-2,8 \mathrm{E}^{-04}$ & $3,1 \mathrm{E}^{-06}$ & 37,5 & 22,2 & 15,3 \\
1 & 0,038 & $-2,5 \mathrm{E}^{-06}$ & $-2,3 \mathrm{E}^{-04}$ & $2,7 \mathrm{E}^{-06}$ & 40,5 & 22,0 & 18,5 \\
4 & 0,040 & $-2,0 \mathrm{E}^{-06}$ & $-2,9 \mathrm{E}^{-04}$ & $3,0 \mathrm{E}^{-06}$ & 37,7 & 22,1 & 15,6 \\
4 & 0,040 & $-2,8 \mathrm{E}^{-06}$ & $-2,8 \mathrm{E}^{-04}$ & $3,0 \mathrm{E}^{-06}$ & 40,7 & 21,9 & 18,8 \\
4 & 0,036 & $-1,2 \mathrm{E}^{-06}$ & $-1,5 \mathrm{E}^{-04}$ & $2,1 \mathrm{E}^{-06}$ & 35,4 & 22,3 & 13,1 \\
Cipó 1 & 0,036 & $-1,2 \mathrm{E}^{-06}$ & $-1,4 \mathrm{E}^{-04}$ & $2,1 \mathrm{E}^{-06}$ & 35,3 & 22,2 & 13,1 \\
6 & 0,037 & $-1,0 \mathrm{E}^{-06}$ & $-1,8 \mathrm{E}^{-04}$ & $2,3 \mathrm{E}^{-06}$ & 34,8 & 22,2 & 12,6 \\
6 & 0,034 & $-1,0 \mathrm{E}^{-06}$ & $-1,4 \mathrm{E}^{-04}$ & $2,2 \mathrm{E}^{-06}$ & 36,4 & 22,1 & 14,3 \\
7 & 0,034 & $-9,1 \mathrm{E}^{-07}$ & $-1,2 \mathrm{E}^{-04}$ & $2,0 \mathrm{E}^{-06}$ & 35,7 & 22,3 & 13,4 \\
7 & 0,042 & $-1,8 \mathrm{E}^{-06}$ & $-3,4 \mathrm{E}^{-04}$ & $3,4 \mathrm{E}^{-06}$ & 36,8 & 22,1 & 14,7 \\
\hline
\end{tabular}


Tabela 5. Valores referentes à identificação de campo (Planta), o intercepto com o eixo dos $Y$ da correlação entre o inverso da temperatura foliar (y-int) e RFA, UR e $U^{2}$ são os valores das constantes que multiplicam os respectivos parâmetros micro-meteorológicos. Máxima, corresponde aos valores de $T_{\text {fol }}$ nas condições de baixa UR e alta RFA (45\% e $2000 \mu \mathrm{mol} . \mathrm{m}^{-2} \mathrm{~s}^{-1}$ ), Mínima, são os valores de $\mathrm{T}_{\text {fol }}$ nas condições de alta UR e baixa RFA $\left(100 \%\right.$ e $\left.50 \mu \mathrm{mol} . \mathrm{m}^{-2} \mathrm{~s}^{-1}\right)$ e Amp é a diferença entre a maior e menor temperatura foliar. Dados relativos às observações de temperatura foliar na BBL4 no período de 13-02-04 a 23-03-04

\begin{tabular}{|c|c|c|c|c|c|c|c|}
\hline \multirow[b]{2}{*}{ Planta } & \multirow[b]{2}{*}{$y$-int } & \multicolumn{3}{|c|}{ Constantes de $f\left(1 / T_{\text {fol }}\right)$} & \multicolumn{3}{|c|}{ Temperatura foliar } \\
\hline & & PAR & UR & $\mathbf{U R}^{2}$ & Máximo & Mínimo & Amp \\
\hline 186 & 0,047 & $-2,2 E^{-06}$ & $-4,0 E^{-04}$ & $3,6 \mathrm{E}^{-06}$ & 34,5 & 21,8 & 12,7 \\
\hline 186 & 0,044 & $-1,9 E^{-06}$ & $-3,3 E^{-04}$ & $3,2 \mathrm{E}^{-06}$ & 34,4 & 22,0 & 12,4 \\
\hline$\times 40$ & 0,033 & $-7,8 \mathrm{E}^{-07}$ & $-5,3 E^{-05}$ & $1,3 \mathrm{E}^{-06}$ & 33,6 & 22,0 & 11,6 \\
\hline$\times 40$ & 0,032 & $-8,3 E^{-07}$ & $-3,7 E^{-05}$ & $1,5 \mathrm{E}^{-06}$ & 34,7 & 21,9 & 12,8 \\
\hline$\times 40$ & 0,034 & $-1,0 E^{-06}$ & $-7,0 E^{-05}$ & $1,6 \mathrm{E}^{-06}$ & 34,2 & 21,9 & 12,3 \\
\hline 187 & 0,039 & $-1,5 E^{-06}$ & $-2,0 E^{-04}$ & $2,4 \mathrm{E}^{-06}$ & 34,6 & 22,0 & 12,6 \\
\hline 187 & 0,038 & $-1,5 E^{-06}$ & $-1,8 E^{-04}$ & $2,4 \mathrm{E}^{-06}$ & 34,7 & 21,7 & 13,0 \\
\hline 187 & 0,045 & $-2,2 E^{-06}$ & $-3,6 E^{-04}$ & $3,4 \mathrm{E}^{-06}$ & 35,1 & 21,5 & 13,6 \\
\hline$\times 39$ & 0,047 & $-2,3 E^{-06}$ & $-3,9 E^{-04}$ & $3,6 \mathrm{E}^{-06}$ & 35,0 & 21,5 & 13,5 \\
\hline$\times 39$ & 0,041 & $-1,3 E^{-06}$ & $-2,7 E^{-04}$ & $2,9 \mathrm{E}^{-06}$ & 33,8 & 21,8 & 12,0 \\
\hline$\times 39$ & 0,047 & $-1,9 E^{-06}$ & $-4,0 \mathrm{E}^{-04}$ & $3,6 \mathrm{E}^{-06}$ & 34,0 & 21,7 & 12,3 \\
\hline 184 & 0,053 & $-2,2 E^{-06}$ & $-5,6 E^{-04}$ & $4,6 \mathrm{E}^{-06}$ & 34,1 & 21,4 & 12,7 \\
\hline 184 & 0,048 & $-1,8 E^{-06}$ & $-4,3 E^{-04}$ & $3,8 \mathrm{E}^{-06}$ & 33,5 & 21,8 & 11,7 \\
\hline 184 & 0,046 & $-2,5 E^{-06}$ & $-3,4 E^{-04}$ & $3,1 \mathrm{E}^{-06}$ & 35,5 & 21,3 & 14,2 \\
\hline 183 & 0,045 & $-2,1 \mathrm{E}^{-06}$ & $-3,9 E^{-04}$ & $3,6 \mathrm{E}^{-06}$ & 38,0 & 21,5 & 16,5 \\
\hline 183 & 0,046 & $-4,3 E^{-06}$ & $-3,4 E^{-04}$ & $3,0 \mathrm{E}^{-07}$ & 42,0 & 21,1 & 20,9 \\
\hline 183 & 0,040 & $-4,3 E^{-06}$ & $-2,4 E^{-04}$ & $2,7 \mathrm{E}^{-06}$ & 47,4 & 20,8 & 26,6 \\
\hline 185 & 0,043 & $-1,5 E^{-06}$ & $-3,2 E^{-04}$ & $3,2 \mathrm{E}^{-06}$ & 35,0 & 22,0 & 13,0 \\
\hline 185 & 0,039 & $-1,2 E^{-06}$ & $-2,4 E^{-04}$ & $2,8 \mathrm{E}^{-06}$ & 35,3 & 21,8 & 13,5 \\
\hline 185 & 0,054 & $-3,3 E^{-06}$ & $-5,9 E^{-04}$ & $4,7 \mathrm{E}^{-06}$ & 37,0 & 21,6 & 15,4 \\
\hline$\times 38$ & 0,032 & $-1,9 E^{-06}$ & $-2,6 E^{-04}$ & $1,4 \mathrm{E}^{-06}$ & 37,3 & 21,6 & 15,7 \\
\hline$\times 38$ & 0,036 & $-1,8 \mathrm{E}^{-06}$ & $-1,3 E^{-04}$ & $2,0 \mathrm{E}^{-06}$ & 36,3 & 21,6 & 14,7 \\
\hline$\times 38$ & 0,034 & $-1,4 \mathrm{E}^{-06}$ & $-6,0 \mathrm{E}^{-05}$ & $1,5 \mathrm{E}^{-06}$ & 36,1 & 21,5 & 14,6 \\
\hline 186 & 0,043 & $-4,3 \mathrm{E}^{-06}$ & $-3,6 E^{-04}$ & $3,5 \mathrm{E}^{-06}$ & 50,4 & 21,0 & 29,4 \\
\hline
\end{tabular}


Em todos os locais e épocas de coleta, os valores mínimos de $T_{\text {fol }}$ foram semelhantes (média de $21,4 \pm 0,7{ }^{\circ} \mathrm{C}$ ), contudo o valor máximo de $\mathrm{T}_{\text {fol }}$ apresentou grande variação $(P<0,04)$ nos dois períodos sazonais (Tabela 2, 3, 4 e 5). Valores médios de $T_{\text {fol }}$ máxima foram de $38,5 \pm 1,0{ }^{\circ} \mathrm{C}$ e $37,2 \pm 0,9{ }^{\circ} \mathrm{C}$ para os períodos seco e chuvoso, respectivamente. Observaram-se diferenças elevadas entre $T_{a r}$ e $T_{\text {fol }}$ sendo que muitas vezes foram verificados valores superiores a $10{ }^{\circ} \mathrm{C}$ (Figura $8 \mathrm{a}, 8 \mathrm{~b}, 8 \mathrm{c}$ e $\left.8 \mathrm{~d}\right)$.
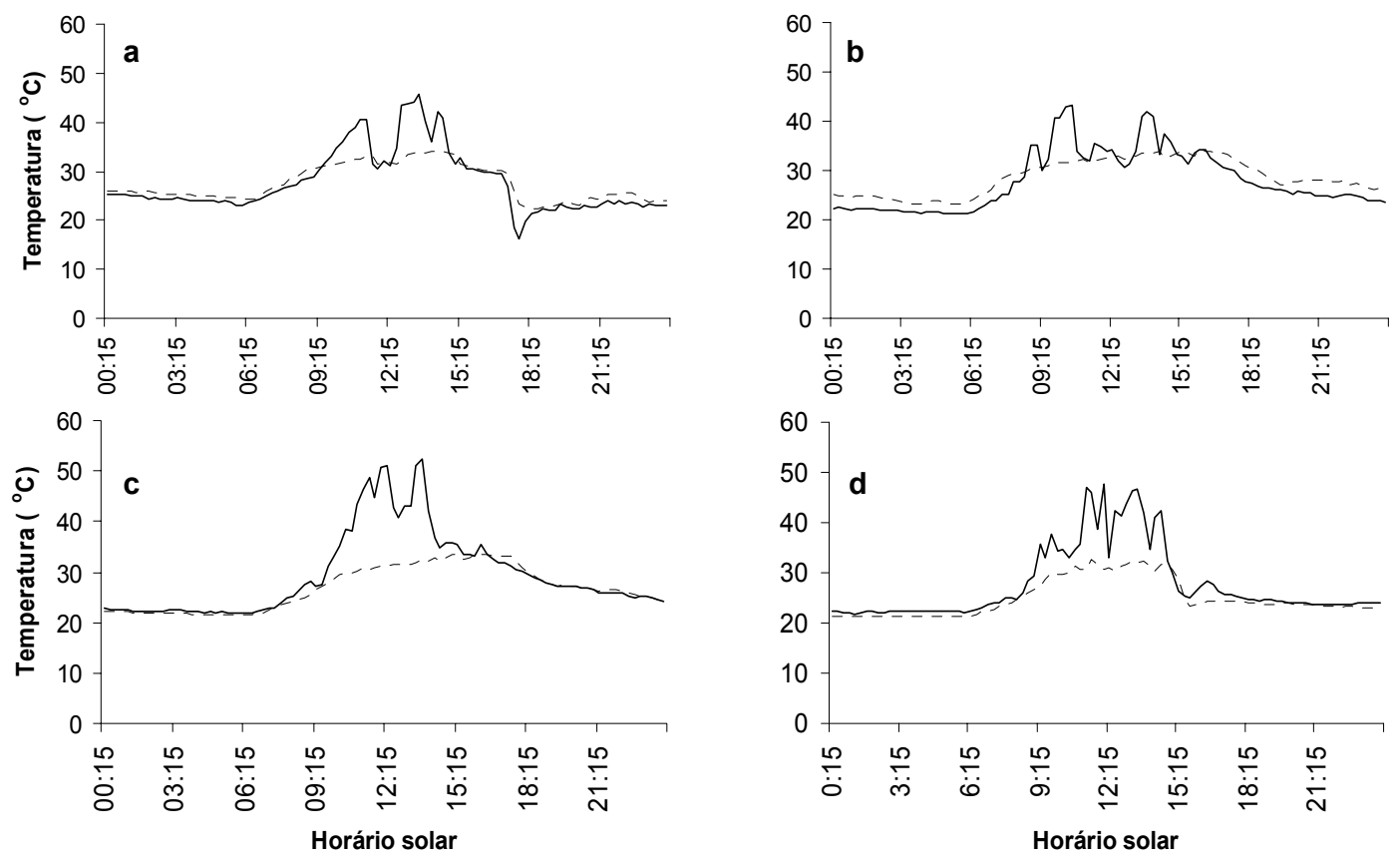

Figura 8 - Variação diurna da temperatura foliar $\left(\mathrm{T}_{\text {fol }} \longrightarrow\right.$ ) e da temperatura do ar ( $\left.\mathrm{T}_{\mathrm{ar}}----\right)$, (a) para o dossel de Pouteria williamii na TN-S no dia 24-08-03; (b) para o dossel de Brosimum parinarioides ssp. Parinarioides no dia 06-11-03, ambos (a e b) no período seco; (c) para o dossel de Pouteria cf. erythorchrosa na T34 no dia 25-01-04; e (d) para o dossel de Capirona cf. decorticans na BBL4 no dia 1003-04, estas duas últimas (c e d) no período chuvoso 
A precipitação foi responsável por uma diminuição em média de aproximadamente $4{ }^{\circ} \mathrm{C}$ na $\mathrm{T}_{\text {fol }}$ tanto no período seco (Figuras 9a, 9b, 9c e 9d) quanto para o período chuvoso (Figuras 10a, 10b, 10c e 10d). Contudo algumas vezes a presença de precipitação não diminuiu a temperatura foliar, principalmente no período seco (Figuras 9b e 9c).
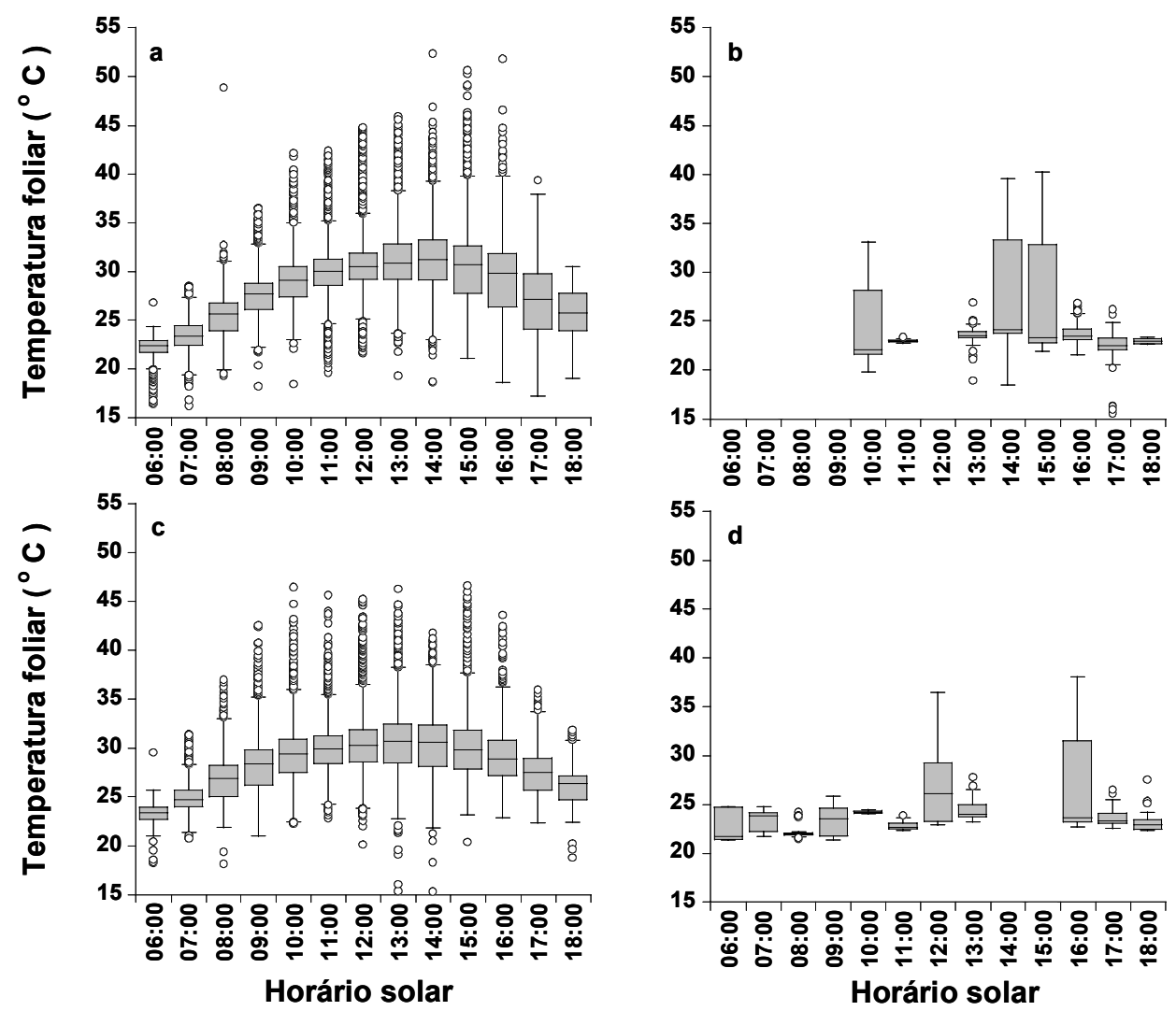

Figura 9 - Variação da temperatura foliar no ciclo diurno durante as horas sem precipitação (a e c) e nas horas com precipitação (b e d). Dados coletados entre 26-07-03 e 27-08-03 na TN-S (a e b) e entre 28-1003 e 17-12-03 na T14 (c e d) 

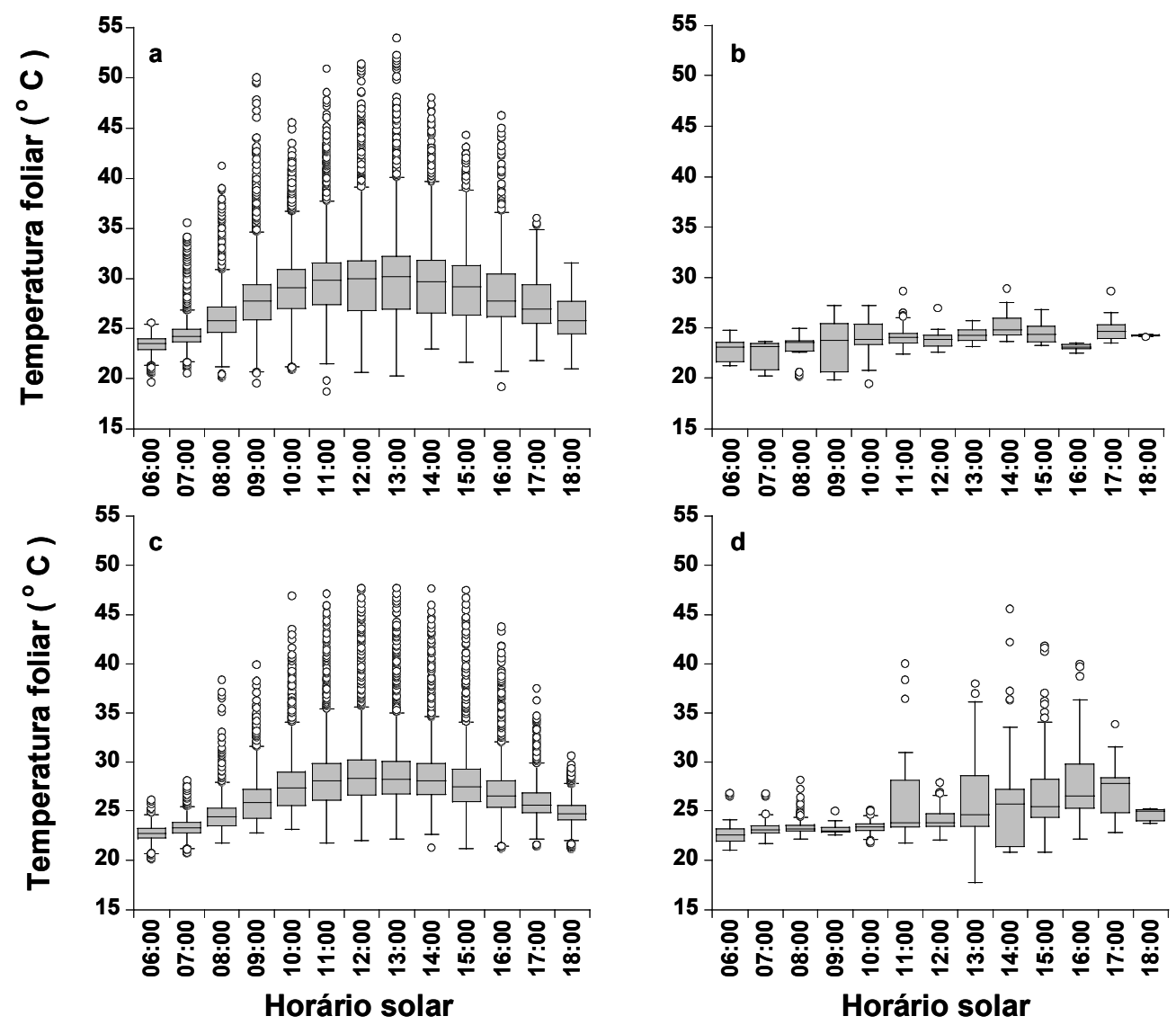

Figura 10 - Variação da temperatura foliar no ciclo diurno durante as horas sem precipitação (a e c) e nas horas com precipitação (b e d). Dados coletados entre 20-12-03 e 04-02-04 na T34 (a e b) e entre 13-0204 e 23-03-04 na BBL4 (c e d)

Nas horas em que foram verificadas precipitações a $T_{\text {fol }}$ média foi sempre em torno de $23{ }^{\circ} \mathrm{C}$ para os dois períodos sazonais durante todas as horas do dia (Figuras 9b, 9d, 10b e 10d). Nas horas sem registros de precipitação, a $T_{\text {fol }}$ apresentou aumentos dos seus valores médios até as 13:00 horas e após as 16:00 horas começava a diminuir. No intervalo entre 13:00 e 16:00 horas freqüentemente a $\mathrm{T}_{\text {fol }}$ se elevou a valores superiores a $35^{\circ} \mathrm{C}$ (Figuras $9 \mathrm{a}, 9 \mathrm{c}$, 10a,e 10c). 


\subsection{Fotossíntese}

A média da temperatura ótima média $\left(T_{\text {ot }}\right)$ para a fotossíntese das plantas observadas foi de $31,1^{\circ} \mathrm{C}$ e apresentou uma variação de $2,6{ }^{\circ} \mathrm{C}$. Não foi verificada relação entre $A_{\max }$ e $T_{\text {ot }}$ (Figura 11). Individualmente, a fotossíntese máxima $\left(A_{\max }\right)$ na temperatura ótima das 29 plantas estudadas, apresentou grande amplitude de valores conforme o Tabela 6 e Figura 11, onde o valor médio de $A_{\max }$ foi de $7,63 \mu \mathrm{mol} . \mathrm{m}^{-2} \cdot \mathrm{s}^{-1}$ apresentando um desvio padrão de 2,39 $\mu \mathrm{mol} \cdot \mathrm{m}^{-2} \cdot \mathrm{s}^{-1}$.

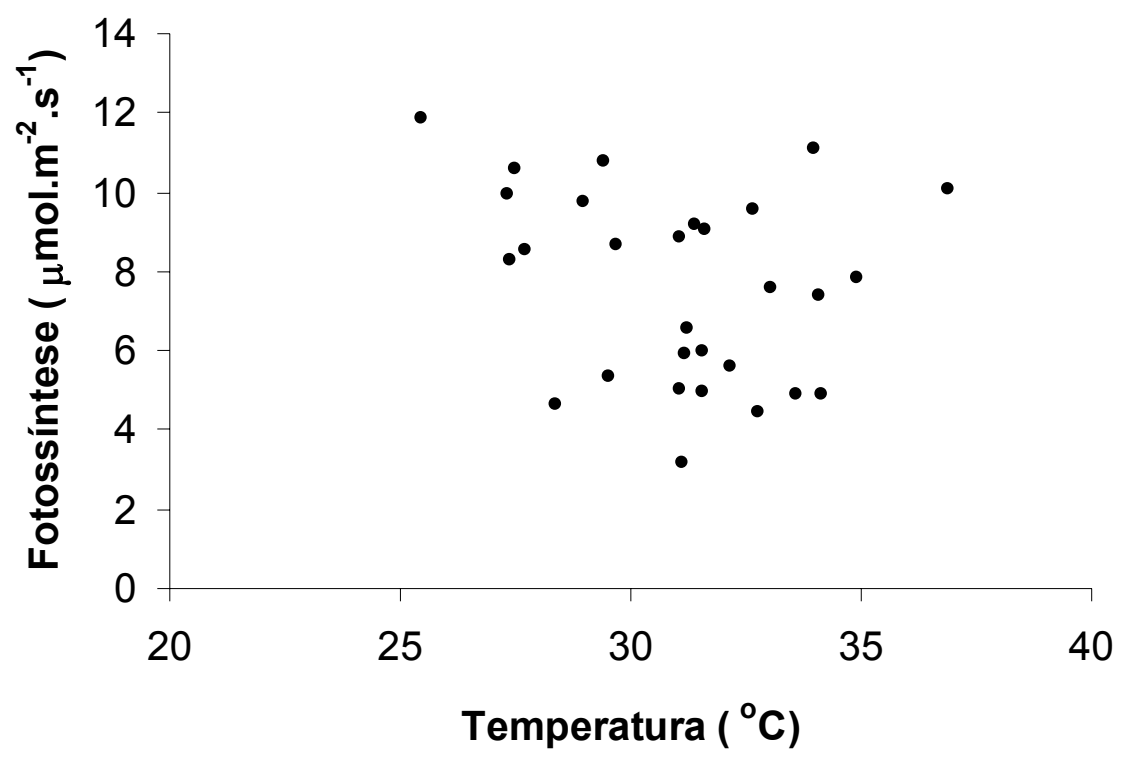

Figura 11 - Distribuição da fotossíntese máxima $\left(A_{\max }\right)$ por temperatura ótima $\left(\mathrm{T}_{\mathrm{ot}}\right)$ para 29 indivíduos 
Tabela 6. Dados de trocas gasosas em cada local de coleta (Torre) para cada indivíduo (Planta), condição de exposição da folha a luz (Folha), de temperatura ótima $\left(\mathrm{T}_{\mathrm{ot}}\right)$, curvatura $(\theta)$, capacidade máxima de transporte de elétrons $\left(\mathrm{J}_{\max }\right)$, velocidade máxima de carboxilação $\left(V_{c \max }\right)$, fotossíntese máxima $\left(A_{\max }\right)$, respiração mitocondrial $(R d)$ e condutância estomática na temperatura de $31^{\circ} \mathrm{C}$ (gs)

\begin{tabular}{llcllccccc}
\hline Torre & Planta & Folha & $\mathbf{T}_{\text {ot }}$ & $\boldsymbol{\theta}$ & $\mathbf{J}_{\max }$ & $\mathbf{V}_{\mathbf{c m a x}}$ & $\mathbf{A}_{\max }$ & $\mathbf{R d}$ & $\mathbf{g s}$ \\
\hline T14 & 1 & Sol & 27,7 & 0,97 & 60,3 & 30,0 & 8,6 & 1,8 & 0,234 \\
T14 & 2 & Sombra & 31,1 & 0,64 & 35,1 & 24,4 & 5,1 & 2,5 & 0,036 \\
T14 & 3 & Sol & 27,4 & 0,98 & 68,5 & 31,1 & 8,3 & 0,9 & 0,313 \\
T14 & 4 & Sol & 31,0 & 0,83 & 77,9 & 40,0 & 8,9 & 3,0 & 0,071 \\
T14 & 5 & Sombra & 34,1 & 0,89 & 61,7 & 41,5 & 7,4 & 1,5 & 0,042 \\
T14 & 6 & Sombra & 28,4 & 0,68 & 32,6 & 15,9 & 4,7 & 0,8 & 0,041 \\
T14 & cipó 1 & Sol & 27,3 & 0,75 & 83,4 & 32,1 & 10,0 & 0,9 & 0,334 \\
T14 & cipó 2 & Sombra & 33,9 & 0,75 & 79,9 & 28,1 & 7,9 & 2,2 & 0,029 \\
T14 & cipó 3 & Sol & 32,7 & 0,75 & 82,0 & 32,3 & 9,6 & 1,3 & 0,111 \\
BBL4 & 183 & Sombra & 32,7 & 0,92 & 38,7 & 14,3 & 4,5 & 1,2 & 0,057 \\
BBL4 & 184 & Sol & 27,5 & 0,69 & 77,7 & 61,7 & 10,8 & 0,3 & 0,099 \\
BBL4 & 185 & Sol & 33,0 & 0,74 & 68,2 & 29,5 & 7,6 & 0,7 & 0,047 \\
BBL4 & 186 & Sol & 33,9 & 0,91 & 77,3 & 33,1 & 11,1 & 0,6 & 0,071 \\
BBL4 & 187 & Sombra & 33,6 & 0,74 & 53,1 & 19,3 & 4,9 & 2,0 & 0,016 \\
BBL4 & X38 & Sombra & 31,6 & 0,26 & 70,3 & 19,5 & 9,1 & 0,5 & 0,086 \\
BBL4 & X39 & Sombra & 29,0 & 0,79 & 67,0 & 35,0 & 9,8 & 0,2 & 0,081 \\
BBL4 & X40 & Sombra & 31,2 & 0,77 & 63,0 & 23,8 & 6,6 & 1,0 & 0,087 \\
TN-S & 560 & Sombra & 31,6 & 0,75 & 42,5 & 17,8 & 5,0 & 1,1 & 0,032 \\
TN-S & 561 & Sol & 29,7 & 0,85 & 76,5 & 30,7 & 8,7 & 0,6 & 0,118 \\
TN-S & 565 & Sombra & 31,2 & 0,89 & 61,6 & 29,6 & 5,9 & 1,6 & 0,091 \\
TN-S & 567 & Sol & 31,7 & 0,89 & 86,0 & 32,3 & 5,1 & 1,9 & 0,089 \\
TN-S & 568 & Sol & 29,4 & 0,47 & 95,9 & 37,9 & 10,8 & 1,3 & 0,225 \\
T34 & 1 & Sol & 31,4 & 0,60 & 74,3 & 25,9 & 9,5 & 1,1 & 0,185 \\
T34 & 2 & Sol & 25,5 & 0,75 & 67,9 & 36,5 & 11,9 & 1,4 & 0,198 \\
T34 & 3 & Sol & 36,8 & 0,87 & 57,9 & 23,9 & 10,1 & 1,1 & 0,26 \\
T34 & 4 & Sombra & 32,1 & 0,75 & 77,7 & 34,2 & 5,7 & 1,6 & 0,042 \\
T34 & 5 & Sombra & 29,5 & 0,75 & 38,7 & 24,9 & 5,3 & 0,7 & 0,035 \\
T34 & 6 & Sombra & 34,1 & 0,40 & 30,3 & 27,5 & 4,9 & 2,6 & 0,069 \\
T34 & 7 & Sombra & 31,1 & 0,99 & 37,4 & 22,0 & 3,2 & 1,3 & 0,038 \\
\hline
\end{tabular}


Observando os dados de $A_{\max }$ e $T_{\text {ot }}$ sem uma classificação previa das folhas estudadas, não foram verificadas relações entre as características biofísicas como área específica foliar (AEF), razão isotópica do carbono 13 $\left(\delta^{13} \mathrm{C}\right)$ e razão carbono e nitrogênio $(\mathrm{C}: \mathrm{N})$ e estas variáveis. Entretanto, classificando as folhas de acordo com a exposição à luz, folhas de sol e aquelas que eventualmente estavam na sombra verificou-se que $A_{\max }$ foi maior para as folhas expostas a luz apresentando valores de $9,41 \pm 1,49 \mu \mathrm{mol} \cdot \mathrm{m}^{-2} \cdot \mathrm{s}^{-1}$, enquanto para as folhas em que eram sombreadas se verificou que a $A_{\max }$ foi de $5,73 \pm 1,55 \mu \mathrm{mol} \cdot \mathrm{m}^{-2} \cdot \mathrm{s}^{-1}$. No entanto, mesmo quando se considerou as classes de folhas de sol e sombra a $\mathrm{T}_{\text {ot }}$ foi semelhante para as duas classes de exposição da folha a luz. $\mathrm{E}$ as características biofísicas de AEF, $\delta^{13} \mathrm{C}$ e $\mathrm{C}: \mathrm{N}$ aumentam o coeficiente de correlação $\left(r^{2}\right)$ em relação a $A_{\max }$ apresentando valores de 0,61, 0,59 e 0,51, respectivamente (Figura 12a, 12b e 12c).
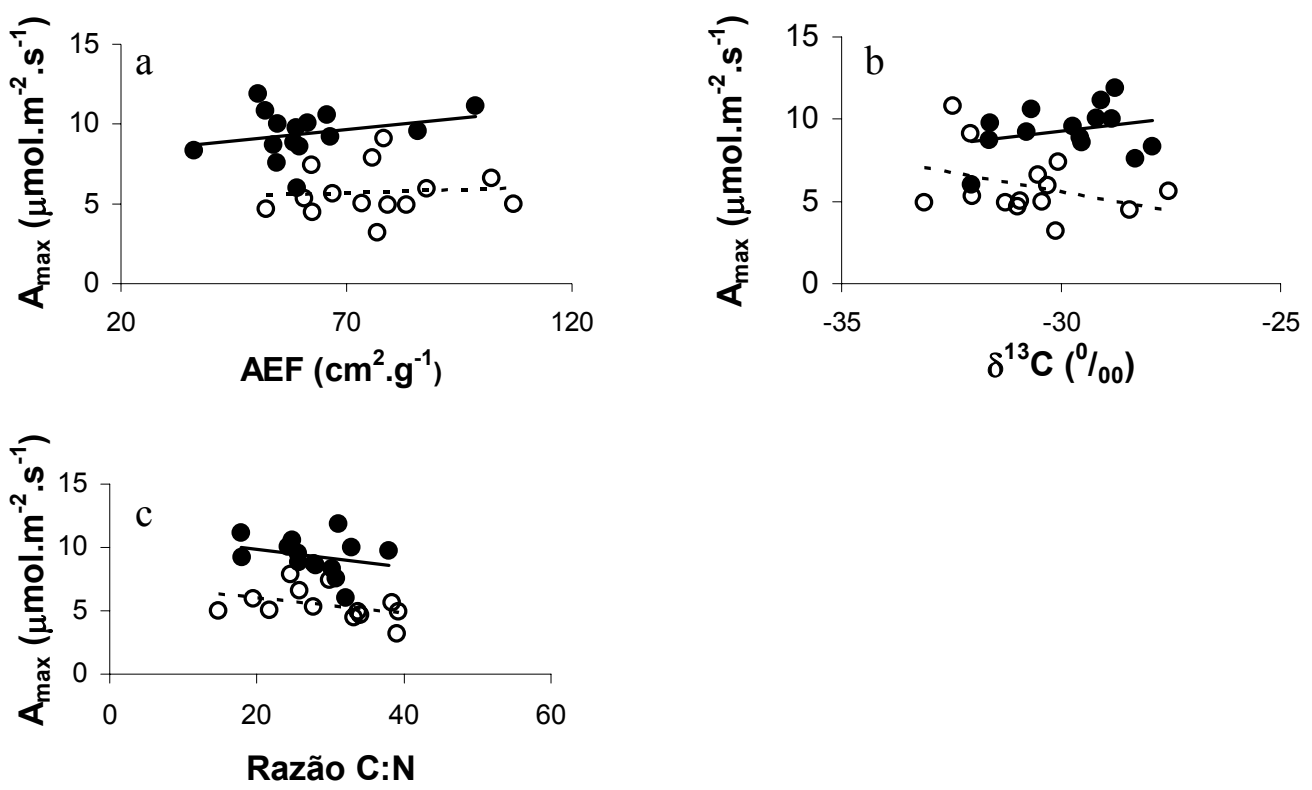

Figura 12 - Relações da fotossíntese máxima $\left(A_{\max }\right)$ de folhas de sol $(\bullet,-)$ e de sombra (०. - - -) com as características biofísicas das folhas, área específica foliar (a), composição isotópica do carbono 13 (b) e razão entre carbono e nitrogênio (c) 
As respostas de $A_{\max }$ em função da temperatura foliar estiveram separadas pelo tipo de exposição a que a folha se desenvolveu (Figura 13a e $13 \mathrm{~b})$, onde aquelas que se expunham ao sol apresentaram em média valores de $A_{\max }$ superiores até a temperatura de $31,2{ }^{\circ} \mathrm{C}$, e a partir deste ponto as médias tenderam a se igualar. De modo geral, temperaturas foliares maiores que $36{ }^{\circ} \mathrm{C}$ ocasionaram decréscimos nas taxas fotossintéticas tanto para folhas de sol como de sombra.

O efeito negativo da elevação da temperatura foliar foi mais evidente para as folhas de sombra, na temperatura de $42{ }^{\circ} \mathrm{C}$ quando se verificou uma redução média na $A_{\max }$ da ordem de $64 \%$ quando comparada com $\mathrm{T}_{\text {ot }}$, apresentando valor de $2,5 \mu \mathrm{mol} . \mathrm{m}^{-2} . \mathrm{s}^{-1}$, enquanto a diminuição dos valor para as folhas de sol foi na ordem de $3,4 \mu \mathrm{mol} . \mathrm{m}^{-2} \cdot \mathrm{s}^{-1}$ ou $37 \%$ a menos que o valor na $T_{\text {ot }}$ destas folhas.

Apenas 6 espécies mantiveram a taxa fotossintética acima de $5 \mu \mathrm{mol} . \mathrm{m}^{-}$ ${ }^{2} . \mathrm{s}^{-1}$ quando a temperatura foliar foi de $42{ }^{\circ} \mathrm{C}$, sendo que destas quatro estavam expostas ao sol; Pouteria anomla, Capirona cf. decorticans, Pouteria cf. erythrochrysa e Peltogine excelsa, e duas plantas a sombra; Macherium sp e Protium apiculato, enquanto que os efeitos mais negativos do aumento de temperatura foram verificados para Microphollis guyanensis spp duckeana e Brosimum parinarioides spp parinarioides entre as folhas de sol e Licania octandra, Couepia longipendulata, Caraipa grandifolia e Anisophyllea manauensis dentre as plantas de sombra (Figura 13a e 13b). 

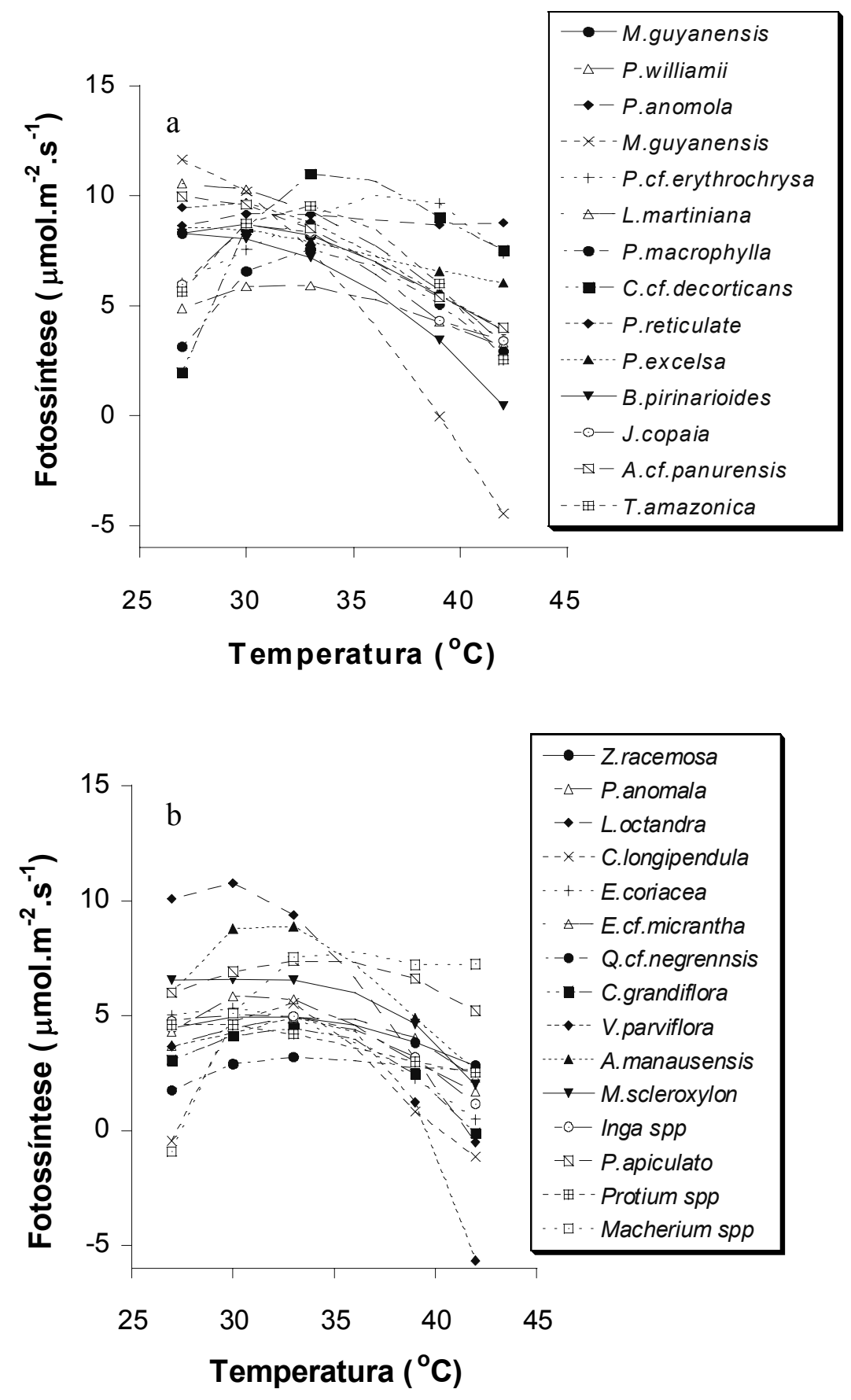

Figura 13 - Resposta da fotossíntese máxima $\left(A_{\max }\right)$ de cada espécie em função da variação da temperatura foliar $\left(T_{\text {fol }}\right)$ para folhas expostas ao sol (a) e para as folhas de sombra (b) 
Partindo dos valores médios de velocidade de carboxilação $\left(\mathrm{V}_{\mathrm{cmax}}\right)$, capacidade máxima de transporte de elétrons $\left(\mathrm{J}_{\max }\right)$ e respiração $(R d)$ de cada indivíduo nas diferentes temperaturas, observou-se que os valores de $A_{\max }$ para os dois grupos de folhas da comunidade, estão descritos na Figura 14, onde verifica-se que folhas de sol apresentam valor médio de $9,45 \mu \mathrm{mol} . \mathrm{m}^{-2} \cdot \mathrm{s}^{-1}$ para $A_{\max }$ enquanto para as folhas de sombra apresentaram $A_{\max }$ médio de 6,81 $\mu \mathrm{mol} . \mathrm{m}^{-2}$. $\mathrm{s}^{-1}$. A $\mathrm{T}_{\text {ot }}$ para os dois grupos de folhagem foi de $30,9{ }^{\circ} \mathrm{C}$. A Figura 14 mostra ainda as respostas médias da assimilação de $\mathrm{CO}_{2}$ em função da variação da temperatura foliar $\left(\mathrm{T}_{\mathrm{fol}}\right)$, as respostas médias de folhas de sol (Eq. 11) e de sombra (Eq. 12) são descritos através das funções quadráticas:

Folhas de sol $A_{\max }=-0,0326\left(T_{\text {fol }}\right)^{2}+1,8917\left(T_{\text {fol }}\right)-19,333$

Folhas de sombra $A_{\max }=-0,0363\left(T_{\text {fol }}\right)^{2}+2,2483\left(T_{\text {fol }}\right)-28,415$

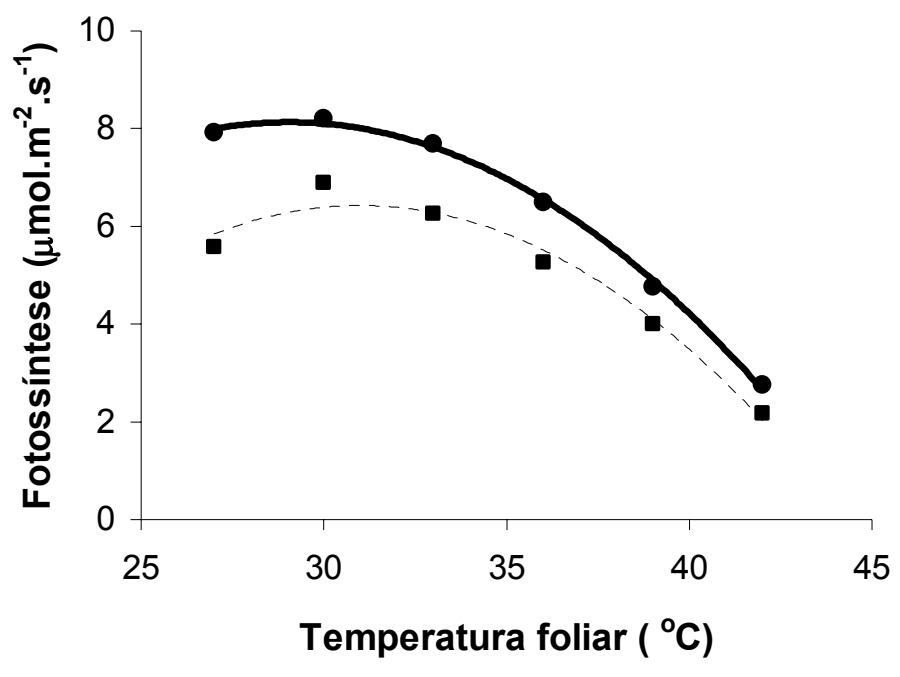

Figura 14 - Curvas de respostas da fotossíntese máxima $\left(A_{\max }\right)$ ao aumento da temperatura foliar $\left(\mathrm{T}_{\mathrm{fol}}\right)$ de folhas de sol $\left(\bullet,-{ }_{-}\right)$e folhas de sombra $(\square,----)$ Valores obtidos a partir das médias: da capacidade máxima de transporte de elétrons $\left(\mathrm{J}_{\max }\right)$, velocidade máxima de carboxilação $\left(V_{c \max }\right)$ e respiração mitocondrial $(R d)$ de cada planta nas diferentes temperaturas foliares 
As curvas de resposta da taxa potencial de transporte de elétrons para regeneração de RUBP $\left(\mathrm{J}_{\max }\right)$ e taxa máxima de atividade carboxilase da Rubisco $\left(V_{c \max }\right)$ em diferentes temperaturas, também apresentaram um padrão de resposta parabólica semelhante a $A_{\max }$, como se verifica na Figura 15a e $15 b$, onde $J_{\max }$ é descrito para folhas de sol e sombra através das equações:

Folhas de sol $\mathrm{J}_{\max }=-0,2561\left(\mathrm{~T}_{\mathrm{fol}}\right)^{2}+18,316 \mathrm{~T}_{\text {fol }}-243,41$

Folhas de sombra $J_{\max }=-0,3539\left(T_{\text {fol }}\right)^{2}+24,904 T_{\text {fol }}-374,68$

enquanto, $V_{\text {cmax }}$ nos dois grupos de folhas ficou correlacionada a $T_{\text {fol }}$ através das equações:

$$
\begin{aligned}
& \text { Folha de sol } \mathrm{V}_{\mathrm{cmax}}=-0,107\left(\mathrm{~T}_{\mathrm{fol}}\right)^{2}+7,2904 \mathrm{~T}_{\mathrm{fol}}-91,73 \\
& \text { Folha de sombra } \mathrm{V}_{\mathrm{cmax}}=-0,055\left(\mathrm{~T}_{\mathrm{fol}}\right)^{2}+3,6516 \mathrm{~T}_{\mathrm{fol}}-35,582
\end{aligned}
$$

A partir das derivadas destas funções de resposta de $J_{\max }$ e $V_{c \max }$ em relação a variação de temperatura, chegou-se aos valores de temperatura ótima $\left(T_{o t}\right)$ média de $\mathrm{J}_{\max }$ para as folhas de sol de $35,8{ }^{\circ} \mathrm{C}$ enquanto para as de sombra foi de $35,2{ }^{\circ} \mathrm{C}$. Entretanto, para o $\mathrm{V}_{\mathrm{cmax}}$ a $\mathrm{T}_{\text {ot }}$ para o primeiro grupo de folhas foi de $34,0{ }^{\circ} \mathrm{C}$ e para o segundo foi de $33,2^{\circ} \mathrm{C}$. A partir destas temperaturas ótimas, conforme se verifica nas Figuras $15 a$ e $15 b, V_{c m a x}$ para as folhas de sol foi mais sensível a variação de temperatura que $J_{\max }$ enquanto para as folhas de sombra foi verificado $V_{c \max }$ foi mais resistente ao aumento de temperatura que $J_{\max }$. 

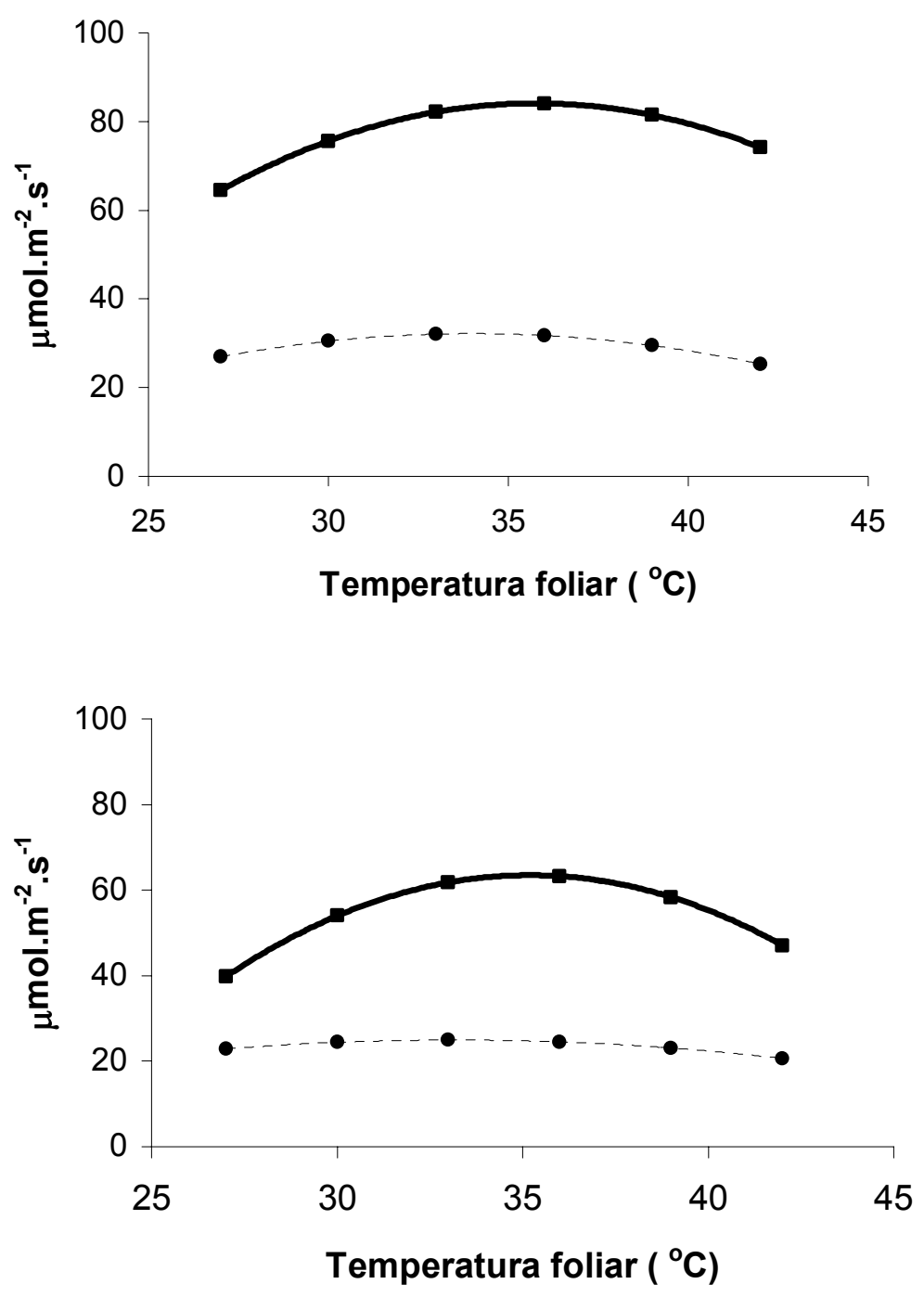

Figura 15 - Curvas de resposta média da capacidade máxima de transporte de elétrons $\left(\mathrm{J}_{\max }, \mu \mathrm{mol}\right.$ é. $\left.\mathrm{m}^{-2} \mathrm{~s}^{-1}\right)$ e velocidade máxima de carboxilação $\left(\mathrm{V}_{\mathrm{cmax}}, \mu \mathrm{mol} \mathrm{CO}_{2} \cdot \mathrm{m}^{-2} \cdot \mathrm{s}^{-1}\right)$ em função da variação da temperatura foliar na comunidade estudada 
Estes valores de temperaturas ótimas para $J_{\max }$ e $V_{c \max }$ são superiores ao verificado para fotossíntese máxima $\left(A_{\max }\right)$ indicando que isolados, estes fatores só explicam a redução de $A_{\max }$ a partir de $33,2{ }^{\circ} \mathrm{C}$ para folhas de sombra e $34,0{ }^{\circ} \mathrm{C}$ para folhas de sol.

As respostas de $J_{\max }$ e $V_{c \max }$ podem ser interpretadas também observando a razão entre estas duas variáveis $\left(\mathrm{J}_{\max }: \mathrm{V}_{\mathrm{cmax}}\right)$ onde se verifica um aumento desta razão com o aumento de temperatura para as folhas de sol, como pode ser observado na Tabela 7. Assim, dentro do intervalo de temperatura estudado o acréscimo na $T_{\text {fol }}$ leva a maiores valores de $J_{\max }$ para que ocorra a mesma quantidade do processo de carboxilação, nas folhas mais superficiais do dossel.

Tabela 7. Razão $\left(\mathrm{J}_{\max }: \mathrm{V}_{\mathrm{cmax}}\right)$, correlação da taxa de $\mathrm{J}_{\max }: \mathrm{V}_{\mathrm{cmax}}$, coeficiente de determinação $\left(r^{2}\right)$ e probabilidade da equação de correlação nas diferentes temperaturas estudadas nas folhas de sol

\begin{tabular}{lclll}
\hline $\begin{array}{l}\text { Temperatura } \\
\text { foliar }\end{array}$ & $\mathrm{J}_{\max }: \mathrm{V}_{\mathrm{cmax}}$ & Equação de correlação & $\mathrm{r}^{2}$ & $\mathrm{P}>\mathrm{F}$ \\
\hline $27^{\circ} \mathrm{C}$ & $2,39 \pm 1,58$ & $\mathrm{~V}_{\mathrm{cmax}}=0,57 \mathrm{~J}_{\max }+49,04$ & 0,15 & 0,113 \\
$30^{\circ} \mathrm{C}$ & $2,48 \pm 0,44$ & $\mathrm{~V}_{\mathrm{cmax}}=1,61 \mathrm{~J}_{\max }+26,49$ & 0,34 & 0,001 \\
$33^{\circ} \mathrm{C}$ & $2,56 \pm 0,42$ & $\mathrm{~V}_{\mathrm{cmax}}=1,47 \mathrm{~J}_{\max }+34,86$ & 0,16 & 0,092 \\
$36{ }^{\circ} \mathrm{C}$ & $2,65 \pm 0,62$ & $\mathrm{~V}_{\mathrm{cmax}}=0,02 \mathrm{~J}_{\max }+30,87$ & 0,02 & 0,887 \\
$39^{\circ} \mathrm{C}$ & $2,76 \pm 0,79$ & $\mathrm{~V}_{\text {cmax }}=0,04 \mathrm{~J}_{\max }+26,30$ & 0,02 & 0,712 \\
$42{ }^{\circ} \mathrm{C}$ & $2,93 \pm 1,93$ & $\mathrm{~V}_{c \max }=0,14 \mathrm{~J}_{\max }+14,83$ & 0,19 & 0,103 \\
\hline
\end{tabular}

As folhas de sombra, no entanto aumentaram os valores da razão $\mathrm{J}_{\max }: \mathrm{V}_{\mathrm{cmax}}$ até a temperatura de $36{ }^{\circ} \mathrm{C}$. A partir deste ponto para esta variável foi verificado um declínio de seus valores, conforme verifica-se na Tabela 8 , mostrando que estes tipos de folhas nas temperaturas mais altas apresentam uma maior eficiência do uso de elétrons para a carboxilação. 
Tabela 8. Razão ( $\left.\mathrm{J}_{\max }: \mathrm{V}_{\text {cmax }}\right)$, correlação da taxa de $\mathrm{J}_{\max }: \mathrm{V}_{\mathrm{cmax}}$, coeficiente de determinação $\left(r^{2}\right)$ e probabilidade da equação de correlação nas diferentes temperaturas estudadas nas folhas de sombra

\begin{tabular}{lclll}
\hline $\begin{array}{l}\text { Temperatura } \\
\text { foliar }\end{array}$ & $\mathrm{J}_{\max }: \mathrm{V}_{\mathrm{cmax}}$ & Equação de correlação & $\mathrm{r}^{2}$ & $\mathrm{P}>\mathrm{F}$ \\
\hline $27^{\circ} \mathrm{C}$ & $1,74 \pm 0,95$ & $\mathrm{~V}_{\mathrm{cmax}}=0,14 \mathrm{~J}_{\max }+17,14$ & 0,14 & 0,370 \\
$30^{\circ} \mathrm{C}$ & $2,10 \pm 0,65$ & $\mathrm{~V}_{\text {cmax }}=0,28 \mathrm{~J}_{\max }+9,490$ & 0,49 & 0,033 \\
$33^{\circ} \mathrm{C}$ & $2,47 \pm 0,59$ & $\mathrm{~V}_{\text {cmax }}=0,29 \mathrm{~J}_{\max }+7,137$ & 0,61 & 0,004 \\
$36{ }^{\circ} \mathrm{C}$ & $2,58 \pm 0,67$ & $\mathrm{~V}_{\text {cmax }}=0,24 \mathrm{~J}_{\max }+9,257$ & 0,51 & 0,005 \\
$39^{\circ} \mathrm{C}$ & $2,52 \pm 0,89$ & $\mathrm{~V}_{\text {cmax }}=0,17 \mathrm{~J}_{\max }+12,88$ & 0,32 & 0,026 \\
$42^{\circ} \mathrm{C}$ & $2,28 \pm 1,28$ & $\mathrm{~V}_{\text {cmax }}=0,13 \mathrm{~J}_{\max }+14,60$ & 0,20 & 0,090 \\
\hline
\end{tabular}

Outro aspecto é a inclinação das curvas geradas pela relação $\mathrm{J}_{\max }: \mathrm{V}_{\mathrm{cmax}}$ como se observa nos dados da Tabela 7 e 8 , onde observa-se que nas temperaturas de $30{ }^{\circ} \mathrm{C}$ e $33{ }^{\circ} \mathrm{C}$ para as folhas de sol e sombra, respectivamente, verifica-se os maiores valores de coeficiente angular da reta, atrelados também aos maiores coeficientes de determinação, indicando que nesta temperatura as plantas estudadas são mais eficientes quando considerados os elétrons direcionados para a regeneração de RUBP $\left(J_{\max }\right)$ e a fixação de $\mathrm{CO}_{2}$.

Outro aspecto importante a ser observado, e que também controla a assimilação de $\mathrm{CO}_{2}$ pelas folhas é a abertura estomática (gs). A Tabela 6 mostra os valores de gs para cada indivíduo na temperatura ótima da fotossíntese, onde se verifica que as folhas de sol têm, em geral, maior abertura estomática que as folhas de sombra.

A resposta da gs a variação da temperatura das folhas foi muito variável entre as espécies (Figura 16a e 16b), verificando-se que o aumento da temperatura até $36{ }^{\circ} \mathrm{C}$ não afetou a gs, mas a partir desta temperatura foliar aumentos proporcionaram uma gradativa diminuição da gs (Figura 16a e 16b). 

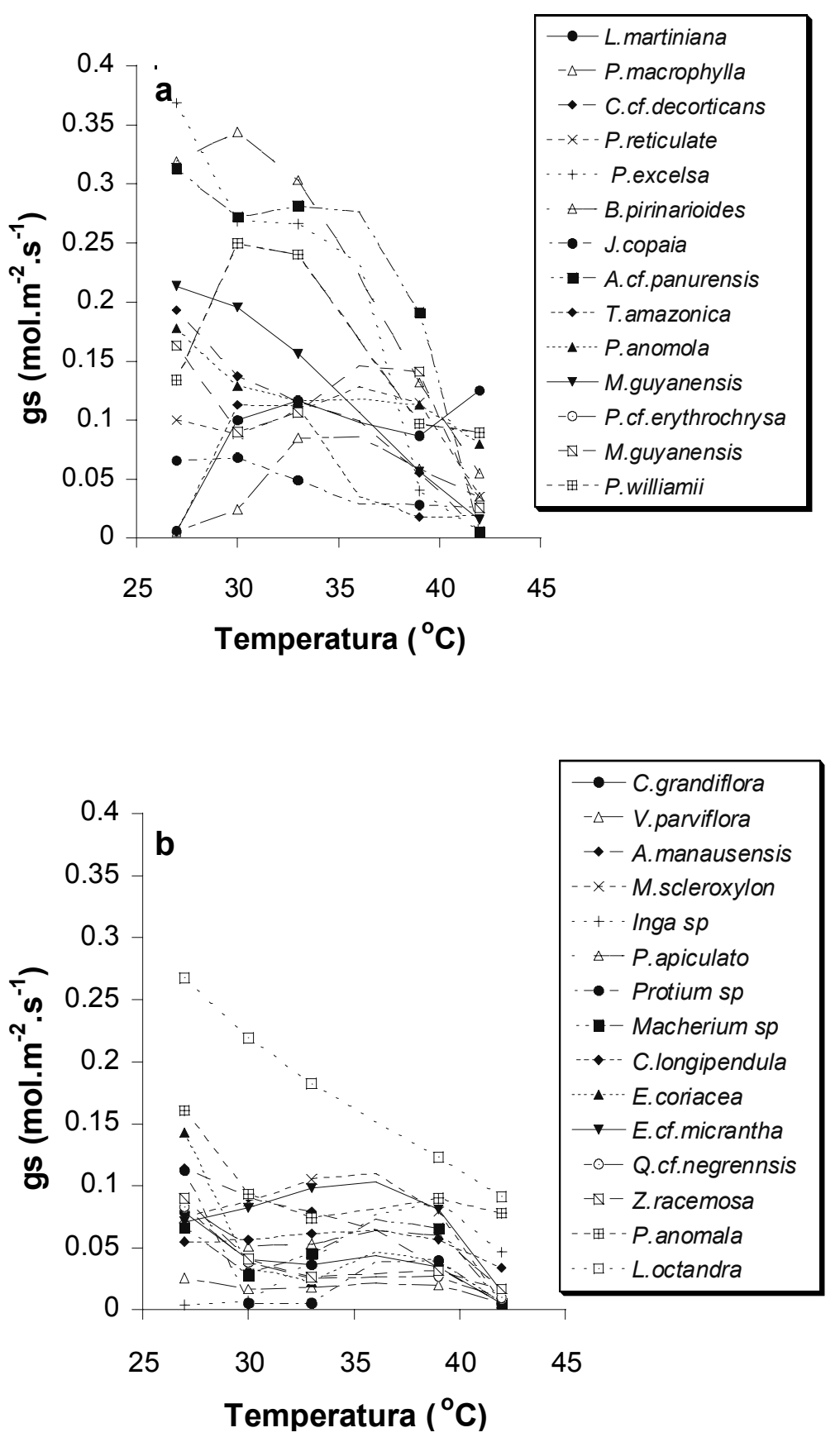

Figura 16 - Curva de resposta da condutância estomática (gs) de cada espécie em função da variação da temperatura foliar $\left(T_{\text {fol }}\right)$, para folhas de sol (a) e sombra (b) 
O efeito do aumento da $T_{\text {fol }}$ sobre a gs foi mais prejudicial para as folhas de sol que para as de sombra. Nas primeiras dentro do intervalo de temperatura estudado, verificou-se uma queda dos valores de gs, exceto para Capirona cf. decorticans, Pouteria williamii e Pouteria anomola que mantiveram seu valores próximos aqueles verificados nas temperaturas de $36{ }^{\circ} \mathrm{C}$ (Figura 16a), já para o segundo grupo, o aumento da temperatura proporcionou uma queda dos valores de gs de 27 a $30{ }^{\circ} \mathrm{C}$, passando por uma manutenção dos valores até 36 ${ }^{\circ} \mathrm{C}$, e depois deste ponto aumentos da $\mathrm{T}_{\text {fol }}$ acarretaram diminuições da condutância. Apenas a espécie Pouteria anomola manteve a abertura dos estômatos estáveis neste grupo de folhas (Figura 16b)

Partindo dos valores médios de condutância estomática a temperatura ótima as folhas de sol foi de $30,9{ }^{\circ} \mathrm{C}$ com o valor máximo de condutância estomática de $0,171 \mathrm{~mol} \cdot \mathrm{m}^{-2} \cdot \mathrm{s}^{-1}$ e a partir desta $T_{\text {fol }}$ qualquer aumento de temperatura acarretou em uma diminuição da gs (Figura 17), sendo que a resposta média das folhas de sol podem ser descrita através da equação:

Folhas de sol gs $=0,017\left(T_{\text {fol }}\right)^{3}-2,99\left(T_{\text {fol }}\right)^{2}+135,15\left(T_{\text {fol }}\right)-1661,93$

Para as folhas de sombra foi verificada uma diminuição dos valores de gs até $31,1{ }^{\circ} \mathrm{C}$, quando a gs apresenta o valor de $0,044 \mathrm{~mol} \cdot \mathrm{m}^{-2} \cdot \mathrm{s}^{-1}$, desta temperatura até $36,9{ }^{\circ} \mathrm{C}$ a gs passa um período de estabilização e posteriormente diminui seus valores (Figura 17). A resposta média da gs nas folhas de sombra é descrita pela equação:

Folhas de sombra gs $=-0,176\left(T_{\text {fol }}\right)^{3}+17,95\left(T_{\text {fol }}\right)^{2}-606,93\left(T_{\text {fol }}\right)+6839,1$ Eq. $(17)$ 


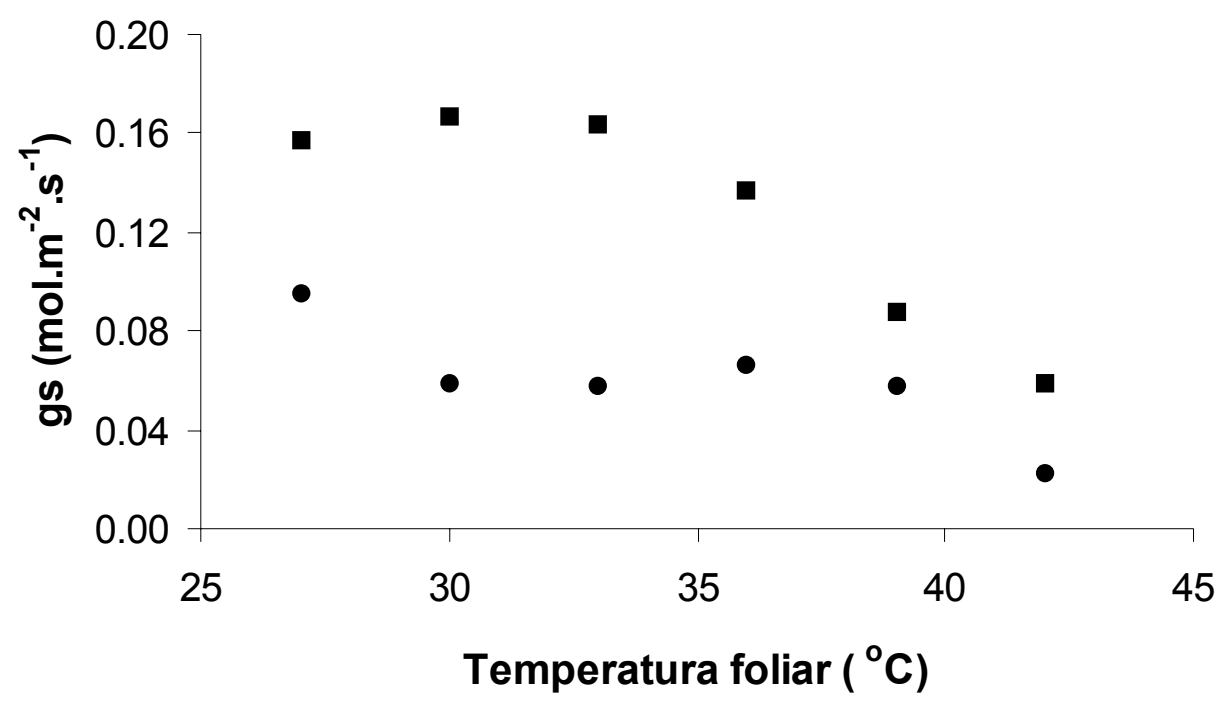

Figura 17 - Resposta da condutância estomática (gs) em média para folhas de

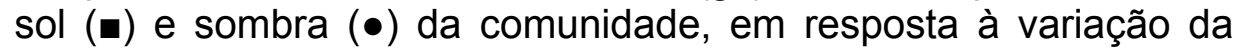
temperatura foliar

O aumento da temperatura foliar causou limitações da condutância ao $\mathrm{CO}_{2}$ (gc) no mesofilo foliar. Entre os grupos de plantas observados o mais afetado na gc foi o de folhas de sombra apresentando uma limitação de condutância do $\mathrm{CO}_{2}$ no mesofilo ( $\mathrm{Lgc}$ ) $123 \%$ maior na temperatura mais elevada que na menor, enquanto nas folhas de sol a Lgc aumentou da menor para maior temperatura em $40 \%$. Em ambos os grupos observados foram verificados fortes correlações $\left(r^{2}=0,94\right)$ que descrevem a variação da Lgc em função da temperatura foliar na comunidade, descritas através das funções:

Folhas de sol $\operatorname{Lgs}=0,0115 \mathrm{~T}_{\text {fol }}+0,1152$

Folhas de sombra $\operatorname{Lgs}=0,0215 \mathrm{~T}_{\text {fol }}+0,2603$

Eq. (19) 


\subsection{Respiração}

Pensando no processo global de fixação do $\mathrm{CO}_{2}$, outro fator que contribui para menores valores de assimilação do carbono é a resposta individual do processo de respiração da folha $(R d)$ que na temperatura ótima $\left(T_{\text {ot }}\right)$ da fotossíntese apresentou valores com grande variação, com uma pequena tendência de ser mais alta nas $T_{\text {ot }}$ mais elevadas (Tabela 6), contudo não foi verificada diferença estatística nas respostas de $\mathrm{Rd}$ na $\mathrm{T}_{\text {ot }}$ entre os dois grupos de folhas observados, sendo que folhas de sol apresentaram um Rd médio de $1,40 \pm 0,7 \mu \mathrm{mol} \cdot \mathrm{m}^{-2} \cdot \mathrm{s}^{-1}$ e a taxa respiratória média para folhas de sombra foi de $1,25 \pm 0,6 \mu \mathrm{mol} \cdot \mathrm{m}^{-2} \cdot \mathrm{s}^{-1}$ (Figura 18).

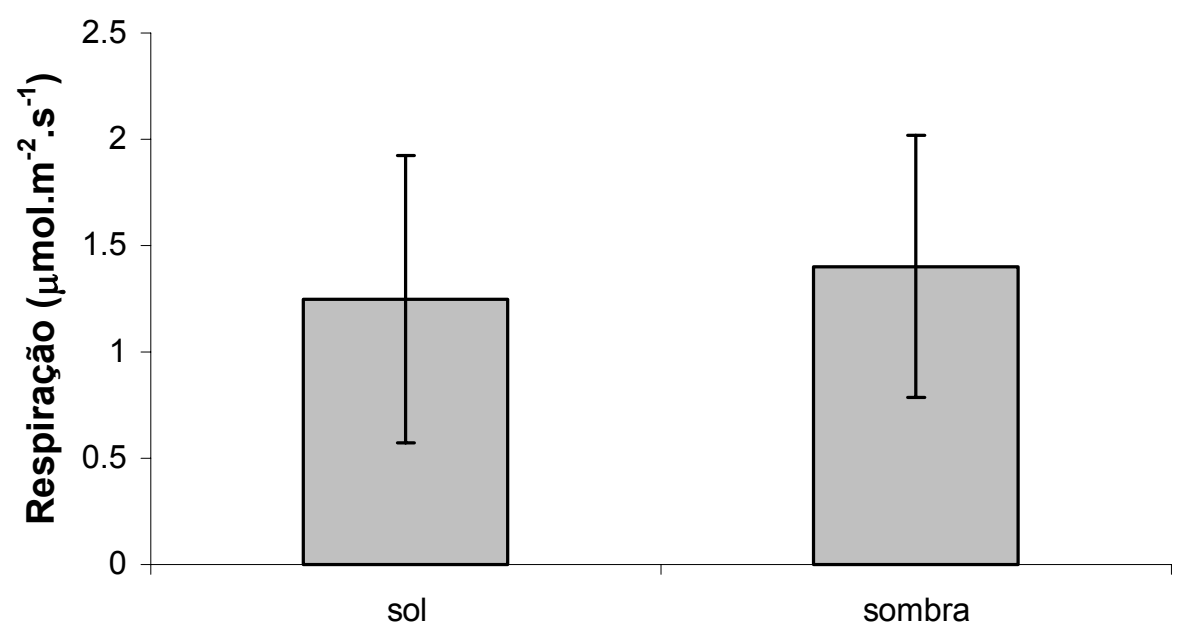

Figura 18 - Taxa respiratória $(\mathrm{Rd})$ média para folhas de sol e sombra na temperatura ótima $\left(T_{\text {ot }}\right)$ para fotossíntese máxima 
A resposta individual da respiração foliar em função da variação da temperatura foi em geral um gradativo aumento, contudo algumas espécies não apresentaram grandes aumentos. Este padrão de resposta foi verificado para plantas de folhas de sol e sombra, nas expostas à radiação solar observou-se as espécies Jacaranda copaia, Licaria martiniana, Pouteria williamii e Peltogine excelsa (Figura 19a), enquanto no grupo de folhas de sombra foi verificado para Pouteria anomola, Coupea longipendula e Macherium sp (Figura 19b).

Os maiores aumentos nas taxas de $\mathrm{Rd}$ em função da variação da $\mathrm{T}_{\text {fol }}$ foram verificados para as folhas de sombra, sendo que dentre estas as espécies Ventanea paviflora, Eschweilera cf. micrantha, Protium sp e Eschweilera coriacea apresentaram os maiores aumentos de Rd. Para as folhas de sol as espécies que responderam com maiores aumentos de Rd ao efeito do aquecimento foliar foram Micropholis guyanensis spp duckeana, Tetracera amazonica e Capirona cf. decorticans (Figuras 19a e 19b).

Observando a Figura 20 na resposta média de $\mathrm{Rd}$ das folhas de sombra da comunidade estudada à elevação a $T_{\text {fol }}$ verificou-se que o coeficiente angular da reta que descreve a sua variação média foi maior que a verificada para as folhas de sol, sendo que dentro do intervalo de temperatura foliar estudada (27 ${ }^{\circ} \mathrm{C}$ e $42{ }^{\circ} \mathrm{C}$ ), o primeiro grupo mais que dobrou a sua taxa respiratória, enquanto para as folhas de sol o acréscimo foi de $75 \%$. 

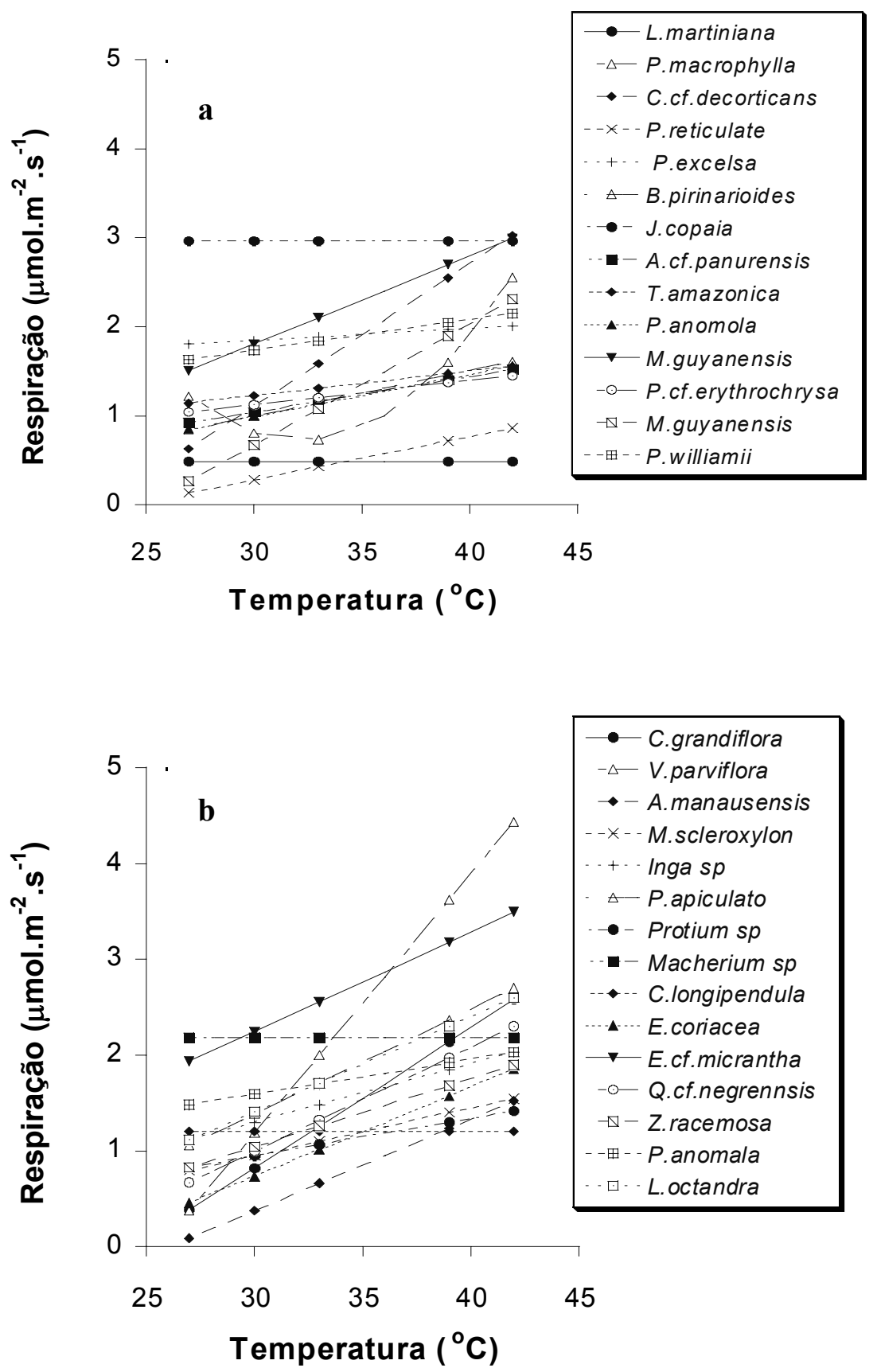

Figura 19 - Curva de resposta da respiração foliar (Rd) de cada espécie em função da variação da temperatura foliar $\left(T_{\text {fol }}\right)$ para folhas de sol (a) e sombra (b) 
Como em todas as temperaturas estudadas as respostas de $\mathrm{Rd}$ foram semelhantes nos dois grupos de folhas então se utilizou um modelo para descrever o efeito da temperatura sobre $\mathrm{Rd}$ que pode ser descrito pela equação:

$$
R d=0,071\left(T_{\text {fol }}\right)-0,889
$$

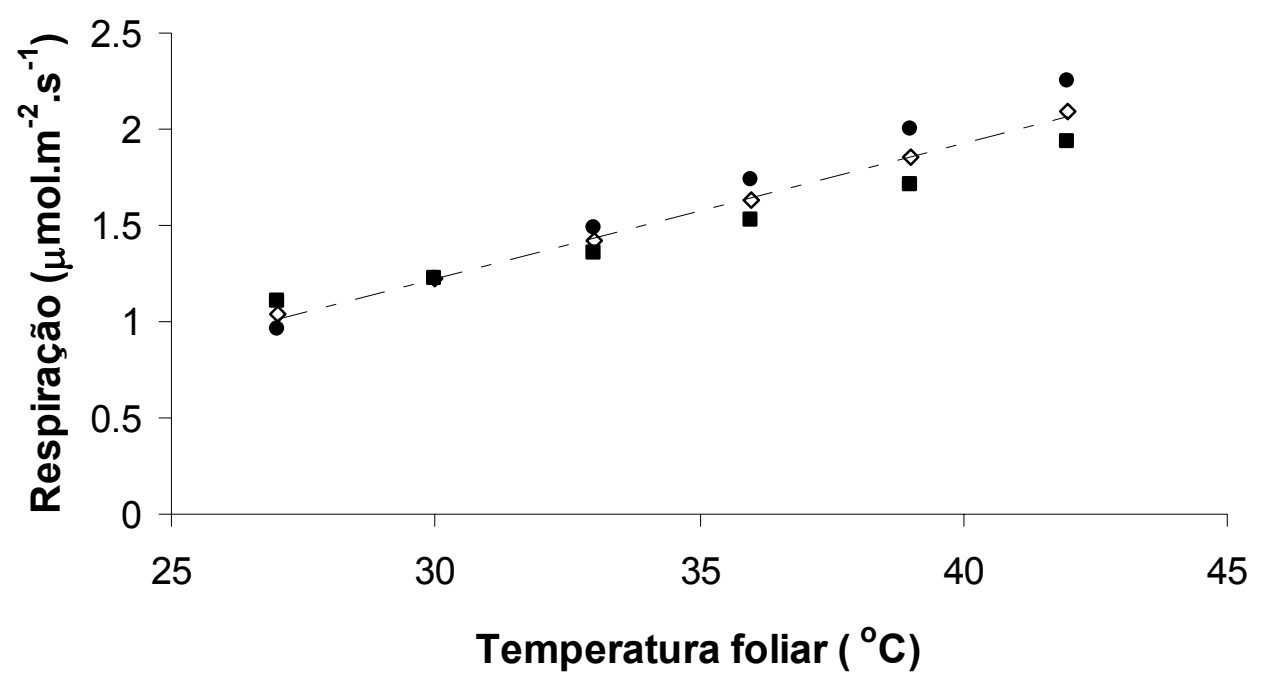

Figura 20 - Resposta da respiração foliar (Rd) em média para folhas de sol (घ), sombra (•), e o modelo médio dos grupos de folha $\left(\diamond_{,-}-\right)$da comunidade, em resposta a variação da temperatura foliar

Avaliando o efeito da temperatura no índice $Q_{10}$ (aumento proporcional para cada 10 graus de aumento na temperatura) para a $\mathrm{Rd}$, foi observado que o aumento da temperatura acarretou em diminuição do valor de $Q_{10}$, onde se verificou uma variação de 2,81 para 2,44 nas temperaturas foliares de $30^{\circ} \mathrm{C}$ e 
$40{ }^{\circ} \mathrm{C}$, isto verificando-se o efeito instantâneo do aumento de temperatura. No entanto quando se verifica o efeito da resposta a longo prazo, encontra-se que não há variação do $Q_{10}$ que apesar de apresentar um alto valor absoluto foi constante em 5,06. 


\section{DISCUSSÃO}

\subsection{Temperatura Foliar}

A temperatura foliar $\left(\mathrm{T}_{\mathrm{fol}}\right)$ esteve na maior parte do tempo $6{ }^{\circ} \mathrm{C}$ acima da temperatura do ar ( $\mathrm{T}_{\text {ar }}$ ), no entanto muitas vezes como mostrado nas Tabelas 2 , 3,4 e 5 e nas Figuras 9 e 10 , foi verificado que a $T_{\text {fol }}$ foi superior a $35^{\circ} \mathrm{C}$, e que houveram diferenças entre $T_{\text {fol }}$ e $T_{\text {ar }}$ chegando a valores superiores a $10{ }^{\circ} \mathrm{C}$ como o verificado na Figura 8. Isto indica que as folhas do dossel da floresta tem trocado energia de forma adequada com o ambiente, no entanto para algumas folhas que apresentam a $T_{\text {fol }}$ no limite da temperatura letal.

As diferenças entre as $T_{\text {fol }}$ e $T_{\text {ar }}$ podem ser substancialmente elevadas $e$ estão relacionadas com a capacidade que as folhas têm de dissipar calor pela condução ou transpiração (Niinemet et al., 1999). Em condições de estresse de déficit hídrico, o fechamento estomático determina um progressivo aumento da $T_{\text {fol. }}$. Os valores da diferença entre $T_{\text {fol }}$ e $T_{a r}$ encontrados neste trabalho são elevados (Figura 8), porém Tarnopolsky e Seginer (1999) citam que esta diferença pode chegar a $20{ }^{\circ} \mathrm{C}$, quando comparadas folhas expostas ao sol e sombreadas. Gates (1964) afirma que quando estas diferenças são grandes a transpiração não está sendo capaz de dissipar a energia da folha.

As características biofísicas dos indivíduos estudados estiveram pouco relacionadas com a temperatura foliar, no entanto quando se trata dos horários mais quentes do dia, onde verificaram-se os valores máximos de temperatura 
foliar máxima, a altura em que a folha estava posicionada no dossel foi a melhor destas características para predizer a $\mathrm{T}_{\text {fol }}$ (Figura 7) Niinemets et al., (1999), Raschke, (1960) e Gates, (1964) verificaram também, que maiores valores de $\mathrm{T}_{\text {fol }}$ estão melhores relacionados com a porção mais alta do dossel, assim folhas mais altas estão sujeitas aos maiores danos devido ao calor excessivo. Estas observações indicam que quanto mais exposta estiver a folha no dossel, maior será a interação da folha com as características que regem a variação da temperatura foliar.

$A T_{\text {fol }}$ é determinada pela quantidade de energia que chega na folha, e os mecanismos fisiológicos ou morfológicos que a folha dispõem para dissipar o calor. Neste trabalho a $\mathrm{T}_{\text {fol }}$ esteve bem correlacionada com os aspectos climáticos estudados, verificando-se uma forte relação entre radiação fotossinteticamente ativa (RFA) e umidade relativa do $\operatorname{ar}(\mathrm{UR}) \mathrm{com} \mathrm{T}_{\text {fol }}$. $\mathrm{A}$ Eq. (10) encontrada através de uma regressão múltipla, determina o valor de $T_{\text {fol }}$ com boa margem de segurança, e reflete o efeito da intensidade luminosa e da presença de água na atmosfera, como indicador das interações entre folhas e estas variáveis meteorológicas.

Aumentos na $\mathrm{T}_{\text {fol }}$ estiveram bem correlacionados com acréscimos da quantidade e tempo de RFA que chegava na superfície do dossel, o mesmo foi observado por Niinemets et al. (1999) que encontraram boas correlações entre a intensidade de radiação e $T_{\text {fol }}$ potencial máxima.

Os aumentos da $\mathrm{T}_{\text {fol }}$ neste trabalho estiveram relacionados a diminuição da umidade relativa do ar (UR). Eamus (1999) descreve vários fatores que estão associados a diminuição da UR e contribuem diretamente para o aumento da $T_{\text {fol. }}$. Para espécies não caducifólias, a ausência de chuva por períodos relativamente longos, leva a potenciais hídricos foliares mais negativos, o que ocasiona o fechamento estomático com conseqüente decréscimo da transpiração e um maior aquecimento foliar.

A diminuição da UR também proporciona o aumento do déficit de pressão de vapor (DPV) que tem sido freqüentemente relacionado ao padrão de 
resposta estomática, mostrando que aumentos de DPV estão associados a redução na abertura dos estômatos (Eamus, 1999; e Niienemet et al., 1999; Angelocci et al., 2004), o que contribui para o aumento da temperatura foliar.

As menores temperaturas foliares foram verificadas nos horários com precipitação e noturnos, onde havia maior umidade relativa do ar (UR) e ausência de radiação, momentos em que as folhas tendem a ter temperatura foliar mais próxima as temperaturas do ambiente. As precipitações, mesmo que de apenas $1 \mathrm{~mm}$ por 15 minutos, foram responsáveis pela diminuição de $4{ }^{\circ} \mathrm{C}$ na temperatura foliar Esta diminuição pode ser explicada pela diminuição de RFA com o céu encoberto por nuvens e pelo aumento de UR que são eventos que acompanham a chuva.

A variação da $T_{\text {fol }}$ discutida neste trabalho foi grande, onde verificou-se que folhas mais expostas a luz e conseqüentemente a menores UR, apresentaram $\mathrm{T}_{\text {fol }}$ que podem chegar a valores superiores a $35{ }^{\circ} \mathrm{C}$, e sob condições mais extremas foi verificado que temperaturas acima de $45{ }^{\circ} \mathrm{C}$, valores estes que indicam que o dossel florestal na sua porção mais alta, tem sido sujeito a grandes estresses de temperatura. Para Bazzaz (1998) a maior causa de estresse para as florestas tropicais é o calor excessivo.

É preciso ressaltar ainda, que a diversidade de um dossel florestal é muito grande e que cada indivíduo deve possuir um mecanismo para lidar com essas altas temperaturas das folhas, no entanto são necessários estudos mais detalhados sobres as características biofísicas, estruturas morfológicas e processos fisiológicos envolvidos na absorção e dissipação de energia, para que se possa compreender melhor os mecanismos utilizados pelas plantas para passar por elevadas $\mathrm{T}_{\text {fol }}$, ou se realmente eles existem, ou se o dossel está no limite dos aumentos de temperatura. 


\subsection{Fotossíntese}

De acordo com o mostrado na Figura 11, a fotossíntese máxima $\left(A_{\max }\right)$ e a temperatura ótima $\left(T_{\text {ot }}\right)$ entre as espécies observadas, apresentaram grande variabilidade de valores, podendo $A_{\max }$ assumir valores de 3,21 a 11,87 $\mu$ mol.m ${ }^{-}$ ${ }^{2} \cdot \mathrm{s}^{-1}$ e $\mathrm{T}_{\text {ot }}$ de 26,5 a $36,9{ }^{\circ} \mathrm{C}$ (Tabela 6). A mesma variação de valores foi encontrada para $A_{\max }$ e $T_{\text {ot }}$ em folhas de espécies florestais em zonas temperadas (Medlyn et al., 2002a; Medlyn et al., 2002b). Assim para diminuir o efeito desta diversidade, as folhas estudadas foram agrupadas em folhas de sol e sombra (Tabela 6).

Após a classificação em folhas de sol e sombra, as características biofísicas de área específica foliar (AEF), razão isotópica do carbono $13\left(\delta^{13} \mathrm{C}\right) \mathrm{e}$ a razão entre as concentrações de carbono e nitrogênio ( $C: N)$, apresentaram correlações com coeficientes de determinação $\left(r^{2}\right)$ baixos, porém significativos com $A_{\max }$ das folhas dos dois grupos. Como pode-se notar na Figura 12 o efeito de aumento destas características biofísicas pouco muda a resposta de $A_{\max }$ dentro de um dado grupo, no entanto, nota-se uma nítida separação dos grupos com efeitos semelhantes, com exceção da relação com $\delta^{13} \mathrm{C}$, em que o padrão de resposta de $A_{\max }$ difere entre os dois grupos. Estes resultados sugerem que o critério de folhas de sol e sombra é eficaz para determinar o agrupamento dos indivíduos estudados.

O padrão de respostas de $A_{\max }$ a variação de $T_{\text {fol }}$ dependeu também do tipo de folha. Aquelas sempre expostas ao sol apresentaram maiores valores de $A_{\max }$ e $T_{\text {ot }}$ (Figura 13), sendo menos sensíveis ao aumento da temperatura foliar, indicando que estas folhas estão mais aclimatadas ao calor que as folhas de sombra. No entanto $\mathrm{T}_{\text {fol }}$ maior que $36{ }^{\circ} \mathrm{C}$ causa a queda da taxa assimilatória para todos os indivíduos estudados. Estes resultados estão de acordos com os verificados por Leakey et al., (2003) que trabalhando com plantas de Shorea 
lepurosa, verificou que aquelas que se desenvolveram em maiores temperaturas eram menos afetadas pela elevação da temperatura.

As espécies em que se verificaram os piores desempenhos de $A_{\max }$ em resposta ao aumento da $\mathrm{T}_{\mathrm{fol}}$ foram: Micropholis gyanensis spp duckeana $\mathrm{e}$ Brosimum parinarioides spp parinarioides dentre as folhas de sol, e no grupo de sombra foram: Licania octandra, Coupea longipendula, Caraipa grandiflora e Anisophyllea manauensis, podendo-se esperar que se continuar o aquecimento da atmosfera, estas espécies serão as primeiras a perecer. Enquanto as que apresentaram os melhores desempenhos foram: Pouteria anomola, Capirona cf. decorticans, Pouteria cf. erythrochrysa e Peltogine excelsa no grupo de folhas de sol e Macherium sp e Protium apiculatum para as plantas observadas na sombra.

As variações interespecíficas não explicam o efeito do aumento da temperatura nos padrões de resposta da taxa assimilatória líquida (A) que pode ser limitada por fatores bioquímicos (conforme descrito na Eq. 1) e condutância ao nível dos estômatos e mesofilo foliar (Long e Bernacchi, 2003; Medlyn et al., 1999; Niinemets et al., 1999; e Wullschleger, 1993).

Conforme podemos verificar na Figura 14, a fotossíntese máxima $\left(A_{\max }\right)$ para os dois grupos estudados foi diminuída pelo menos a metade, quando comparadas a temperatura ótima e a temperatura de $42{ }^{\circ} \mathrm{C}$, indicando que a temperatura afetou um dos estágios do processo fotossintético. Resultados mostrando a fotossíntese sendo afetada pelo aumento da temperatura são conhecidamente descritos na literatura: afetando o processo bioquímico, podendo causar danos no aparato fotoquímico, desestruturando enzimas envolvidas na fixação e redução, diminuindo a difusão de $\mathrm{CO}_{2}$ ao nível do mesofilo foliar e promovendo o aumento da resistência ao nível dos estômatos (Pons e Welschen, 2003; Medlyn et al., 2002b; Medlyn et al., 2002a; Bernacchi et al., 2001; e Hikosaka, 1997).

Para a melhor compreensão dos efeitos do aumento da temperatura foliar é necessária a análise separada dos fatores que afetam a fotossíntese. 
Quando se faz um estudo de curvas $A-C_{i}$, as limitações referentes a condutância estomática são eliminadas, fazendo com que o padrão de resposta da fotossíntese verificada seja causada por processos que ocorrem no mesofilo foliar (Long e Bernacchi, 2003; e Medlyn et al., 1999), ou seja, o transporte de elétrons $\left(P_{\mathrm{J}}\right)$ e a capacidade de carboxilação $\left(P_{\mathrm{V}}\right)$.

Neste trabalho a capacidade máxima de transporte de elétrons destinada à regeneração de RUBP $\left(\mathrm{J}_{\max }\right)$ foi afetada pelo aumento de temperatura. Entretanto, as temperaturas ótimas para $J_{\max }$ ou os pontos de máximas de Eq.(13) e Eq. (14), foram maiores que aqueles verificados para a fotossíntese (Figuras 14 e 15, e Eq. 11 e Eq. 12). A partir destes pontos de máxima indicados na Figura 15 o transporte de elétrons começa a declinar afetando a fotossíntese máxima. Padrão de resposta semelhante foi observado por Medlyn et al. (2002b), sugerindo que outros fatores podem estar influindo na queda da taxa assimilatória líquida com o aumento da temperatura. Para Scharder et al. (2004), a diminuição de $J_{\max }$ em temperaturas mais altas, pode estar relacionada a uma maior fluidez da membrana, desestruturando o fotossistema Il e a conseqüentemente menor absorção e melhor dissipação de energia luminosa.

A velocidade máxima de carboxilação $\left(\mathrm{V}_{\mathrm{cmax}}\right)$ foi pouco afetada pelo aumento da temperatura foliar, no que tange ao intervalo de $T_{\text {fol }}$ estudado (Figura 15). Essa variável apresentou uma pequena convexidade quando comparada com $\mathrm{J}_{\max }$, o que sugere que o processo de carboxilação foi pouco afetado pela temperatura. Bernacchi et al. (2001), observaram aumento progressivo para $\mathrm{V}_{\mathrm{cmax}}$ até a temperatura de $40{ }^{\circ} \mathrm{C}$.

Os valores encontrados para $J_{\max }$ e $V_{c \max }$ nas folhas de sol são maiores que os observados nas de sombra, no entanto comparando as folhas de sol e de sombra no desempenho de $J_{\max }$ e $V_{c m a x}$, usando as derivadas das equações $13,14,15$ e 16, percebe-se que altas temperaturas afetam os dois grupos diferentemente. As folhas de sombra são mais afetadas pelo transporte de elétrons que as folhas de sol, que por sua vez são mais afetas na velocidade de 
carboxilação que as de sombra. Estas mudanças na atividade de $J_{\max }$ e $V_{\text {cmax }}$ em função da condição em que se desenvolveu a folha pode ser explicada pela formação de estruturas adaptativas ao ambiente como a AEF. De acordo com Tribuzy et al. (2003) trabalhando em floresta tropical a AEF é menor nas porções mais altas do dossel, indicando que as folhas mais altas apresentam maior quantidade de massa foliar por unidade de área, o que indica que estas modificações morfo-fisiológicas possam funcionar como um mecanismo para suportar as altas temperaturas nas regiões tropicais.

Avaliando a razão entre $\mathrm{J}_{\max }: \mathrm{V}_{\mathrm{cmax}}$ na Tabela 7 percebe-se que com 0 aumento da temperatura houve um progressivo aumento nesta relação para as folhas de sol, indicando que em temperaturas mais elevadas há uma maior necessidade de energia para que a mesma quantidade de $\mathrm{CO}_{2}$ seja fixado. Esta energia produzida e não utilizada na carboxilação pode estar sendo redirecionada para um dreno alternativo dos elétrons, sendo a fotorespiração o principal (Scharder et al., 2004). No grupo das folhas de sombra (Tabela 8) verifica-se também aumento da razão $\mathrm{J}_{\max }: \mathrm{V}_{\mathrm{cmax}}$, contudo até a temperatura de $36{ }^{\circ} \mathrm{C}$ quando os valores de $\mathrm{J}_{\max }: \mathrm{V}_{\mathrm{cmax}}$ diminuem com o acréscimo da temperatura foliar, isto se deve provavelmente a uma fotoinibição devido a desestruturação do fotossistema pela maior fluidez das membranas do cloroplasto.

Outro aspecto que esta relação leva a sugerir, é que com o aumento de temperatura a planta deve criar mecanismos de desativação da atividade da Ribulose 1,5 bis-fosfato carboxilase/oxigenase (Rubisco), para evitar a atividade oxigenase e o progressivo aumento de composto tóxico da fotorespiração (Husic et al., 2002; Scharder et al., 2004) e ainda segundo estes autores a diminuição da quantidade de energia disponível para atividade da Rubisco, ou ainda, que há um redirecionamento da energia que são importantes para o desenvolvimento de outros processos.

Apesar destes fatores $\left(\mathrm{J}_{\max }\right.$ e $\mathrm{V}_{\mathrm{cmax}}$ ) estarem contribuindo para a redução da fotossíntese em altas temperaturas, o fator que parece estar mais bem 
relacionado a redução das taxas de $A_{\max }$ é a condutância estomática (gs) (Figura 16 e Figura 17). Medlyn et al. (2002a) assumem que parte da diminuição na fotossíntese em temperaturas altas é devido a limitação pelo fechamento estomático.

O padrão de resposta da gs foi muito variado na temperatura ótima para a fotossíntese $\left(T_{o t}\right)$ entre as espécies, no entanto, foi observado que as folhas de sol apresentaram valores superiores aqueles das folhas de sombra (Tabela 6). Trabalhando com Eucalyptus globulus ssp globulus provenances James e Bell (2000) verificaram que folhas menos expostas a luz apresentam menores aberturas estomáticas.

Para as temperaturas menores que $36{ }^{\circ} \mathrm{C}$ algumas espécies apresentaram aumentos dos valores de gs, e a partir desta $T_{\text {fol }}$ todas as plantas apresentaram decréscimos nos valores desta variável. As folhas de sol apresentaram na $\mathrm{T}_{\text {fol }}$ de $30,9{ }^{\circ} \mathrm{C}$ valores mais que duas vezes aqueles das folhas de sombra, sendo estatisticamente semelhantes na temperatura mais elevada. Nas folhas de sombra a gs se manteve nos níveis da $T_{\text {fol }}$ mais baixa até $36,9^{\circ} \mathrm{C}$. Quando a $\mathrm{T}_{\text {fol }}$ foi maior que este valor estas folhas aumentaram a resistência a perda de água pelos estômatos (Figura 17, Eq. 16 e Eq. 17).

Um fato que chama atenção neste trabalho e indica o nível de estresse dos estômatos nas folhas de sol e que as folhas da sombra mantêm por mais tempo a abertura estomática é a composição isotópica do carbono $\left(\delta^{13} \mathrm{C}\right)$ das folhas destes grupos. Observando a relação entre $A_{\max }$ e $\delta^{13} C$ (Figura 12b) verifica-se que as folhas sombreadas apresentam valores mais negativos de $\delta^{13} \mathrm{C}$. Indicando que este grupo discrimina mais o carbono 13 por que os estômatos estão mais próximos a sua abertura máxima, enquanto as folhas de sol por enfrentarem temperaturas mais elevadas, têm os estômatos fechados por mais tempo e por isso com valores de $\delta^{13} \mathrm{C}$ menos negativos.

Essa supressão da condutância estomática está, em geral, relacionada a fatores climáticos como luz, temperatura e déficit de pressão de vapor no ar (Pons e Welschen, 2003; e Pitman, 1996). Trabalhando com lima ácida 
Angelocci et al. (2004) mostraram que quando fixado o intervalo de temperatura. a condutância estomática é afetada pelo aumento do déficit de pressão de vapor. Outro fator que corrobora para o fechamento estomático é (Nepstad et al., 2002) o baixo potencial hídrico das folhas, nos horários próximos ao meio dia na floresta.

Tomando como base as curvas $A-C_{i}$ em diversas temperaturas desenvolvidas neste estudo, pode-se notar que valores maiores $T_{\text {fol }}$ acarretaram maior limitação estomática do $\mathrm{CO}_{2}$ no mesofilo (Lgc). A Lgc das folhas de sombras foi a mais afetada pelo aumento da $\mathrm{T}_{\text {fol }}$ como pode ser verificado derivando as Eq. 18 e Eq. 19. Dentro do intervalo de temperatura estudado a porcentagem de aumento da Lgs para folhas de sol foi 3 vezes maior que a de sombra. Resposta semelhante foi verificada por James e Bell (2000), que mostraram folhas de sombra com maiores resistências ao fluxo de carbono no mesofilo foliar. Pons e Welschen (2003) trabalhando com Eperua grandiflora afirmaram que a abertura estomática diminui com um aumento da $T_{\text {fol }}$ e que isto acarreta em diminuição da fotossíntese.

\subsection{Respiração}

Assumindo que a fotossíntese tem o papel de assimilação de $\mathrm{CO}_{2}$ e a respiração foliar $(\mathrm{Rd})$ tem o papel contrário e que ambas não podem ser quantificadas isoladamente na folha nas horas que há presença de luz, pois os processos acontecem ao mesmo tempo na folha, a resposta $\mathrm{Rd}$ aos gradativos aumentos da temperatura foliar, foi a maior liberação de carbono fixado por este processo, afetando o balanço de assimilação de $\mathrm{CO}_{2}$ dos indivíduos (Long e Bernacchi, 2003; Medlyn et al., 2002; Bernacchi et al., 2001; e Hikosaka, 1997).

Na temperatura ótima da fotossíntese a Rd apresentou grande amplitude de valores com tendência de ser maior nas $T_{\text {ot }}$ mais elevadas. Observando a 
Figura 18 verifica-se que não foram encontradas diferenças estatísticas entre as respirações das folhas de sol e de sombra. A Figura 19 mostra que Rd não apresentou diferenças entre os grupos de folhas nas diferentes $T_{\text {fol }}$, no entanto, apresenta diferença com a variação de $\mathrm{T}_{\text {fol }}$ dobrando seu valor entre a menor e maior temperatura de estudo. Trabalhando com florestas tropicais Chambers et al., (2004) afirmaram que a respiração de folha apresenta boa correlação com a $\mathrm{T}_{\text {fol. }}$

A respiração foliar é sensível aos aumentos da temperatura tornando-se, um sumidouro do $\mathrm{CO}_{2}$ assimilado pela fotossíntese. Neste trabalho foi verificado um padrão linear de resposta da $\mathrm{Rd}$ à variação de $\mathrm{T}_{\text {fol }}$ (Figura 20), no entanto, é importante ressaltar que esta é uma resposta comum da respiração a rápida variação da temperatura. Estes resultados são concordantes com aqueles descritos por Pons e Welschen, (2003) e Meir et al., (2001).

Observando o valor do índice $Q_{10}$ (aumento proporcional da respiração para cada dez graus de aumento na temperatura) quando calculado em função dos aumentos instantâneos da $\mathrm{T}_{\text {fol }}$ verificou-se que os valores deste índice diminuíram, indicando que as folhas são sensíveis e respondem com aumentos para nova situação de maior calor, mas quando se observa a resposta deste indice a adaptação para alta temperatura esta variável não apresenta variação dentro do intervalo de $\mathrm{T}_{\text {fol }}$ estudado. Este tipo de adaptação é também descrito nos trabalhos de Loveys et al. (2003), Griffin et al. (2002) e Atkin et al., (2000) que sugerem que estes fatos ocorrem devido as enzimas do processo de respiração estarem aclimatas a altas temperaturas.

\subsection{Variação da temperatura foliar e assimilação de $\mathrm{CO}_{2}$}

A variação da temperatura foliar foi grande apresentando nos horários mais quentes temperaturas que variaram entre 33 a $52{ }^{\circ} \mathrm{C}$. Considerando as equações (Eq. 11 e 12) de respostas da fotossíntese e sua temperatura ótima 
( $\left.T_{\text {ot }}\right)$ para folhas de sol e sombra chega-se aos valores de 15,1 e 12,1 tonC.ha${ }^{1}$.ano ${ }^{-1}$, respectivamente. Estes valores Assimilação estão próximos daquele verificado por Goulden et al. (2004) no período chuvoso na floresta amazônica.

É possível ainda considerar que a $\mathrm{T}_{\text {fol }}$ atinja $36{ }^{\circ} \mathrm{C}$ na média, o que não está distante da temperatura atual na época seca, nesta temperatura a produção diminui em $18 \%$ para folhas de sol e $14 \%$ para as folhas de sombra. Quando a $\mathrm{T}_{\text {fol }}$ for a $42{ }^{\circ} \mathrm{C}$ a fotossíntese será apenas $32 \%$ e $30 \%$ dos valores verificados na $T_{\text {ot, }}$, para as folhas de sol e sombra, respectivamente. Goulden et al. (2004) verificou para períodos secos valores na metade dos verificados dos que encontrou para períodos chuvosos.

As repostas de Rd indicam que nas temperaturas mais elevadas do dia há uma grande perda de $\mathrm{CO}_{2}$. Trabalhando da mesma forma os dados na $T_{\text {ot }}$ a liberação de $\mathrm{CO}_{2}$ devido a Rd fica em torno de 2,5 tonC.ha ${ }^{-1}$.ano-1 e a cada $3{ }^{\circ} \mathrm{C}$ que se elevar a $\mathrm{T}_{\text {fol }}$ serão liberados 0,4 tonC. $\mathrm{ha}^{-1}$.ano-1 a mais para atmosfera somente devido ao processo de respiração foliar. Para Griffin et al. (2002) o seqüestro de carbono ao meio dia é afetado substancialmente pela respiração dos tecidos autotróficos, principalmente as folhas devido ao aumento da temperatura. Para Chambers et al. (2004) a respiração foliar não apresenta um padrão de respostas ao horário do dia, encontrando correlação apenas com a temperatura foliar. 


\section{CONCLUSÃO}

A temperatura foliar apresentou boa correlação com as variações da radiação fotossinteticamente ativa e a umidade relativa do ar, o mesmo não foi verificado para as características biofísicas das plantas observadas.

A temperatura foliar mínima é igual nos dois períodos sazonais e está mais correlacionada às condições de altas umidades e sem radiação, nas horas que precedem o amanhecer, quando há uma tendência da temperatura do ar e foliar se igualarem.

A temperatura foliar máxima e as maiores diferenças entre temperaturas da folha e do ar estão correlacionadas com os eventos climáticos de alta radiação e baixa umidade.

A variação da temperatura foliar causou mudanças no padrão de resposta da taxa assimilatória de $\mathrm{CO}_{2}$. $\mathrm{E}$ os fatores primeiros a causar diminuição da fotossíntese máxima após a temperatura ótima são a condutância estomática e do mesofilo, adicionada a aumentos na taxa respiratória.

A temperatura ótima da fotossíntese foi de $31,1^{\circ} \mathrm{C}$ onde a comunidade apresentou uma taxa de assimilação de $\mathrm{CO}_{2}$ de $7,6 \mu \mathrm{mol} \cdot \mathrm{m}^{-2} \cdot \mathrm{s}^{-1}$, e a partir desta temperatura houve uma diminuição da fotossíntese máxima.

A capacidade máxima de transporte de elétrons destinada a regeneração de $\operatorname{RUBP}\left(\mathrm{J}_{\max }\right)$, apresentou relação negativa com a temperatura foliar a partir de $35,7^{\circ} \mathrm{C}$. A velocidade máxima de carboxilação $V_{c \max }$ foi pouco afetada pela elevação da $\mathrm{T}_{\text {fol }}$ e mostrou relação negativa depois de $34,0{ }^{\circ} \mathrm{C}$. 
A condutância estomática foi negativamente relacionada com acréscimo de $T_{\text {fol }}$, dentro do intervalo de temperatura estudado, indicando que a limitação estomática pode ser o fator que mais afeta a fotossíntese.

A respiração $(R d)$, como consumidor de fotoassimilados, contribuiu para que o balanço de carbono foliar se torne menor com o aumento da $T_{\text {fol }}$, pois $R d$ está relacionada positivamente com a temperatura foliar.

O aumento de $3{ }^{\circ} \mathrm{C}$ na temperatura foliar após a temperatura ótima da fotossíntese causa na taxa assimilatória uma diminuição de 1,3 e 07 tonC.ha${ }^{1}$.ano ${ }^{-1}$ para folhas de sol e sombra respectivamente. 


\section{REFERÊNCIAS BIBLIOGRÁFICAS}

ANGELOCCI, L. R.; MARIN, F. R.; OLIVEIRA, R. F.; RIGHI, E. Z. Transpiration, leaf diffusive conductance, and atmospheric water demand relationship in na irrigated acid lime orchard. Brasilian Journal Plant Physiology, v.16, n.1, p.53-64, 2004.

ATKIN, O.K.; EDWARDS, E. J.; LOVEYS, B. R. Response of root respiration to changes in temperature and its relevance to global warming. New Phytologist, v.147, n.1, p.141-154, 2000.

AYENEH, A.; VAN GINKEL, M.; REYNOLDS, M.P.; AMMAR, K. Comparison of leaf, spike, peduncle and canopy temperature depression in wheat under heat stress. Field Crops Research, v.79, n.2/3, p.173-184, 2002.

BEDRETDINOV ZM, GAISIN FM, DAUTOV GY, SEMICHEV AY, KRIVONOSOVA EI, MUKHAMADIYAROV KG. Some properties of a glowdischarge in a transverse flow of air. High Temperature, v.16, n.2, p.227230, 1978.

BALDOCCHI, D.D.; MEYERS, T.P. Traces gas exchange above the floor of deciduous forest,1, Evaporation and $\mathrm{CO}_{2}$ efflux. Geophys, v.96, p.72717285, 1991. 
BASSOW, S.L.; MCCONNAUGHAY, K.D.M.; BAZZAZ, F.A. The response of temperate tree seedlings grown in elevated $\mathrm{co} 2$ to extreme temperature events. Ecological Applications, v.4, n.3, p.593-603, 1994.

BAZZAZ, F.A. Tropical forest in future climate: changes in biological diversity and impact on the global carbon cycle. Climatic Change, v.39, p.317-336, 1998.

BERNACCHI C. J.; SINGSAAS E, L.; PIMENTEL C.; PORTIS, A. R.; LONG, S.P. Improved temperature response functions for models of Rubisco-limited photosynthesis. Plant Cell and Environment, v.24, n.2, p.253-259, 2001.

BERRY, J. A.; E BJÖRKMAN, O. Photosynthetic response and adaptation to temperature in higher plants. Annual Review of Plant Physiology, v.31, p.491-453, 1980.

CANNELL, M. G. R.; THORNLEY, J. H. M. Modelling the components of plant respiration: Some guiding principles. Annals of Botany, v.85, p.45-54, 2000.

CARNEIRO, V.M.C. Composição florística e análise estrutural da floresta primária de terra firme na bacia do rio Cuieiras Manaus (AM). Manaus-AM, 2004. 77p. Dissertação de (M.S.) Instituto Nacional de Pesquisa da Amazônia/Universidade do Amazonas.

CHAMBERS, J.Q.; HIGUCHI N.; TRIBUZY, E.S.; TRUMBORE, S.E. Carbon sink for a century. Nature, v.410, n.6827, p.429-429, 2001. 
CHAMBERS, J. Q.; TRIBUZY, E. S.; TOLEDO, L. C.; CRISPIN, B. F.; HIGUCHI, N.; SANTOS J. DOS; ARAÚJO, A. C.; KRUIJT, B; NOBRE, A. D.; TRUMBORE, S. E. Respiration from a tropical forest ecosystem: partitioning of sources andlow carbon use efficiency. Ecology Application, v.14, n.4 (supl.), p.s72-s88, 2004.

CHAUVEL, A. Os latossolos amarelos, álicos, argilosos, dentro dos ecossistemas das bacias experimentais do INPA e da região vizinha. Acta Amazonica, v.12, n.3, p.47-60, 1982.

CLARK, D. A. Sources or sinks? The responses of tropical forests to current and future climate and atmospheric composition. Philosophical Transactions of The Royal Society of London, v.359, n.1443, p.477-491, 2004.

CLARK, D. A.; PIPER, S. C.; KEELING, C. D.; CLARK, D. B. Tropical rain forest tree growth and atmosferic carbon dynamics linked to interannual temperature variation during 1984 - 2000. Proceedings of the National Academy of Sciences of the United States of America, v.100, n.10, p.5852-5857, 2003.

COLE, J. Paleoclimate - A slow dance for El Nino. Science, v.291, n.5508, p.1496-1497, 2001.

DE PURY, D. G. G.; FARQUHAR, G. D. Simple scaling of photosynthesis from leaves to canopies without the errors of big-leaf models. Plant Cell and Environment, v.20, p.537-557, 1997.

EAMUS, D. Ecophysiological traits of deciduos and evergreen woody species in the seasonally dry tropics. Tree, v.14, p.11-16, 1999. 
ELHERINGER, J.R. Temperature and energy budgets. In: PEARCY, R.W.; ELHERINGER, J.R.; MOONEY, H.A.; RUNDEL, P.W. (Ed.). Plant ecophysiological ecology, New York: Chapman \& Hall, 1992. cap.8, p.117135.

FARQUHAR, G. D.; SHARKEY, T. D. Stomatal conductance and photosynthesis. Annual Review of Plant Physiology, v.33, p.317-345, 1982.

FARQUHAR, G. D.; VON CAEMMERER, S.; BERRY, J. A. A biochemical model of photosynthetic $\mathrm{CO}_{2}$ assimilation in leaves of $\mathrm{C}_{3}$ species. Planta, v.149, p.78-90, 1980.

FERGUSON, H.; ESLICK, R.F.; AASE, J.K. canopy temperatures of barley as influenced by morphological characteristics Agronomy Journal, v.65, n.3, p.425-428, 1973.

FERRAZ, J.; OHTA, S.; SALLES, P.C. Distribuição dos solos ao longo de dois transectos em floresta primária ao norte de Manaus (AM). in: HIGUCHI, N.; CAMPOS, M.A.A.; SAMPAIO, P.T.B.; SANTOS, J. (Ed.). Pesquisas Florestais para Conservação da Floresta e Reabilitação de Áreas Degradadas da Amazônia. 1998. p.111-143.

FIELD, C.B.; BEHRENFELD, M.J.; RANDERSON, J.T.; FALKOWSKI, P. Primary production of the biosphere: Integrating terrestrial and oceanic components. Sience, v.281, n.5374, p.237-240, 1998.

FRA FAO. Forest resources assessment food and agriculture organization of the United Nation 2000: tropical countries. Rome, 2001, p.287-291. (FAO Forestry Paper, 140). 
GATES, D.M. Leaf temperature and transpiration. Agronomy Journal, v.56, p.273-277, 1964.

GOULDEN, M.L.; MILLER, S.D.; DA ROCHA, H.R.; MENTON, M.C.; DE FREITAS, H.C.; FIGUEIRA, A.M.E.S.; DE SOUSA, C.A.D. Diel and seasonal patterns of tropical forest $\mathrm{CO} 2$ exchange. Ecological Applications, v.14 n.4 (Supl.), s42-s54, 2004.

GRACE, J. Understanding and managing the global carbon cycle. Journal of Ecology, v.92, n.2, p.189-202, 2004.

GRACE, J.; MALHI, Y., HIGUCHI, N., MEIR, P.. Productivity of tropical rain forest. In: ROY, J.; SAUGIER, B.; MOONEY, H.A (Ed.). Terrestrial global productivity. 2001. p.401-426.

GRIFFIN, K. L.; TURNBULL, M.; MURTHY, R.; LIN, G. H.; ADAMS, J.; FARNSWORTH, B.; MAHATO, T.; BAZIN, G.; POTASNAK, M.; BERRY, J. A. Leaf respiration is differentially affected by leaf vs. stand-level night-time warming. Global Change Biology, v.8, n.5, p.479-485, 2002.

HARLEY, P. C.; THOMAS, R. B.; REYNOLDS, J. F.; STRAIN, B. R. Modelling photosynthesis of cotton grown in elevated carbon dioxide. Plant Cell and Environment, v.15, p.271-282, 1992.

HIGUCHI, N. Ciência e tecnologia e o desmatamento no Amazonas. Jornal Gazeta Mercantil Amazonas, p.20, 2000. 
HIGUCHI. N.; SANTOS.J. DOS; RIBEIRO. R.J.; FREITAS, J.V.; VIEIRA, G.; CÖIC, A.; MINETTE, L.J. Crescimento e Incremento de uma Floresta Amazônica de Terra-Firme Manejada Experimentalmente In: Biomassa de Nutrientes Florestais. INPA/DFID. 1997. 89-132p.

HIKOSAKA, K. Modelling optimal temperature acclimatation of photosynthetic apparatus in $\mathrm{C}_{3}$ plants with respect to nitrogen use. Annals of Botany, v.80, p.721-730, 1997.

HUSIC, D.W.; HUSIC, H.D.; TOLBERT, N.E. The oxidative photosynthetic carbon-cycle or c2 cycle. Critical Reviews in Plant Sciences, v.5, n.1, p.45$100,2002$.

ISHIDA, A.; TOMA, T.; MARJENAH, A. Limitation of leaf carbon gain by stomatal and photochemical processes in the top canopy of Macaranga conifera, a tropical pioneer tree. Tree Physiology, v.19, p.467-473, 1999.

JAMES, S.A.; BELL, D.T. Influence of light availability on leaf structure and growth of two Eucalyptus globulus $\mathrm{ssp}$ globulus provenances. Tree Physiology, v.20, n.15, p.1007-1018, 2000.

KATUL, G. G.; ELLSWORTH, D. S.; LAI. C. T. Modelling assimilation and intercellular $\mathrm{CO}_{2}$ from measured conductance: a synthesis of approaches. Plant Cell and Environment, v.23, p.1313-1328, 2000.

KITAJIMA, K. Relative importance of photosynthetic traits and allocation patterns as correlates of seedling shade tolerance of 13 tropical trees. Oecologia, v.98, p.419-428, 1994. 
KITAO, M.; LEI, T. T.; KOIKE, T.; TOBITA, H.; MARUYAMA, Y.; MATSUMOTO, Y.; ANG. L.-H. Temperature response and photoinhibition investigated by chlorophyll fluorescence measurements for four distinct species of dipterocarp trees. Physiologia Plantarum, v.109, p.284-290, 2000.

KOCH, G.W.; AMTHOR, J.S.; GOULDEN, M.L. Diurnal patterns of leaf photosynthesis conductance and water potential at the top of a lowland forest canopy in Cameron: measurements from the Radeau des Cines. Tree Physiology, v.14, p.347-360, 1994.

LAURANCE, W.F.; WILLIAMSON, G.B. Positive feedbacks among forest fragmentation, drought, and climate change in the Amazon. Conservation Biology, v.15 n.6, p.1529-1535, 2001.

LEAKEY, A.D.B.; PRESS, M.C.; SCHOLES, J.D.; WATLING, J.R. Relative enhancement of photosynthesis and growth at elevated $\mathrm{CO} 2$ is greater under sunflecks than uniform irradiance in a tropical rain forest tree seedling. Plant Cell and Environment, v.25, n.12, p.1701-1714, 2002.

LIETH, J. H.; REYNOLDS, J. F. The nonrectangular hyperbola as a photosynthetic light response model: geometrical interpretation and estimation of the parameter $\theta$. Photosynthetica, v.21, p.363-366, 1987.

LONG, S. P.; BERNACCHI, C. J. Gas exchange measurements, what can they tell us about the underlying limitations to photosynthesis? Procedures and sources of error. Journal of Experimental Botany, v.54, n.392, p.23932401, 2003. 
LOVEYS, B. R.; ATKINSON, L. J.; SHERLOCK, D. J.; ROBERTS, R. L.; FITTER, A. H.; ATKIN, O. K. Thermal acclimation of leaf and root respiration: an investigation comparing inherently fast- and slow-growing plant species. Global Change Biology, v.9, n.6, p.895-910, 2003.

MALHI, Y.; WRIGHT, J. Spatial patterns and recent trends in the climate of tropical rainforest regions. Philosophical Transactions of the Royal Society of London Series B-Biological Sciences, v.359, n.1443, p311329, 2004.

MARENGO, J. A.; NOBRE, C. A. General characteristics and variability of climate in the Amazon Basin and its links to the global climate system. In: MCCLAIN, M. E.; VICTORIA, R. L. RICHEY, J. E. (Ed.). The Biogeochemistry of Amazon Basin, New York: Oxford University Press, 2001. p.17-41.

MEDLYN, B. E.; BADECK, F. W.; DE PURY, D. G. G.; BARTON, C. V. M.; BROADMEADOW, M.; CEULEMANS, R.; DE ANGELIS, P.; FORSTREUTER, M.; JACH, M. E.; KELLOMAKI, S.; LAITAT, E.; MAREK, M.; PHILIPPOT, S.; REY, A.; STRASSEMEYER, J.; LAITINEN, K.; LIOZON, R.; PORTIER, B.; ROBERNTZ, P. WANG, K.; JARVIS. P. G. Effects of elevated $\left(\mathrm{CO}_{2}\right)$ on photosynthesis in European forest species: a metaanalysis of model parameters. Plant Cell and Environment, v.22, p.14751495, 1999.

MEDLYN, B. E.; LOUSTAU, D.; DELZON S. Temperature responses of parameters of a biochemically based model of photosynthesis. I. Seasonal changes in mature maritime pine (Pinus pinaster Ait.). Plant Cell and Environment, v.25, n.9, p.1155-1165, 2002a. 
MEDLYN, B. E.; DREYER, E.; ELLSWORTH, D.; FORSTREUTER, M.; HARLEY, P. C.; KIRSCHBAUM, M. U. F.; LE ROUX, X.; MONTPIED, P.; STRASSEMEYER, J.; WALCROFT, A.; WANG, K.; LOUSTAU, D. Temperature response of parameters of a biochemically based model of photosynthesis. II. A review of experimental data. Plant Cell and Environment, v.25, n.9, p.1167-1179, 2002b.

MEINZER, F. C.; GOLDSTEIN. G. Scaling up from leaves to whole plants and canopies for photosynthetic gas exchange. in: MULKEY, S. S.; CHAZDON, R. L.; SMITH, A. P. (Ed.). Tropical Forest Plant Ecophysiology, New York: Chapman Hall, 1996. p.89-113.

MEIR, P.; GRACE, J.; MIRANDA, A. C. Leaf respiration in two tropical rainforests: constraints on physiology by phosphorus, nitrogen and temperature. Functional Ecology, v.15, n.3, p.378-387, 2001.

MULKEY, S.S.; KITAJIMA, K.; WRIGHT, S.J. Plant physiological ecology of tropical forest canopies. Trends in Ecology \& Evolution, v.11, n.10, p.408-412, 1996.

NEPSTAD, D. C.; MOUTINHO, P.; DIAS, M. B.; DAVIDSON, E.; CARDINOT, G.; MARKEWITZ, D.; FIGUEIREDO, R.; VIANNA, N.; CHAMBERS, J.; RAY, D.; GUERREIROS, J. B.; LEFEBVRE, P.; STERNBERG, L.; MOREIRA, M.; BARROS, L.; ISHIDA, F. Y.; TOHLVER, I.; BELK, E.; KALIF, K.; SCHWALBE, K. The effects of partial throughfall exclusion on canopy processes, aboveground production, and biogeochemistry of an Amazon forest. Journal of Geophysical Research-Atmospheres, v.107, n.D20, p.118, 2002. 
NIINEMETS, U.; OJA, V.; KULL, O. Shape of leaf photosynthetic electron transport versus temperature response curve is not constant along canopy light gradients in temperate deciduous trees. Plant Cell and Environment, v.22, n.12, p.1497-1513, 1999.

OGREN, E.; OQUIST, G. Photoinhibition of photosynthesis in lemna-gibba as induced by the interaction between light and temperature 2. Photosynthetic electron-transport. Physiologia Plantarum, v.62 n.2, p.187-192, 1984.

PACALA, S. W.; CANHAM, C. D.; SAPONARA, J.; SILANDER, J. A.; KOBE, R. K.; RIBBENS, E. Forest models defined by field measurements: estimation, error analysis and dynamics. Ecological Monographs, v.66, p.1-43, 1996.

PETIT, J. R.; JOUZEL, J.; RAYNAUD, D.; BARKOV, N. I.; BARNOLA, J.M, BASILE, I.; BENDER, M.; CHAPPELLAZ, J.; DAVIS, M.; DELAYGUE, G.; DELMOTTE, M.; KOTLYAKOV, V. M.; LEGRAND, M.; LIPENKOV, V. Y.; LORIUS, C.; PEPIN, L.; RITZ, C.; SALTZMAN, E.; STIEVENARD, M. Climate and atmospheric history of the past 420,000 years from the Vostok ice core, Antarctica. Nature, v.399, n.6735, p.429-436, 1999.

PITMAN, J.I. Ecophysiology of tropical dry evergreen forest, Thailand: Measured and modelled stomatal conductance of Hopea ferrea, a dominant canopy emergent. Journal of Applied Ecology, v.33, n.6, p.1366-1378,1996.

PONS, T. L.; WELSCHEN, R. A. M. Midday depression of net photosynthesis in the tropical rainforest tree Eperua grandiflora: contributions of stomatal and internal conductances, respiration and Rubisco functioning. Tree Physiology, v.23, n.14, p.937-947, 2003. 
RADAM-BRASIL. Programa de Integração Nacional. Levantamento de Recursos Naturais. v.18 (Manaus) - RADAM (projeto) DNPM, Ministério das Minas e Energia. Brasil. 626 p, 1978.

RASCHKE, K. Heat transfer between the plant and the environment. Annual Review Of Plant Physiology And Plant Molecular Biology, v.11, p.111126, 1960.

REICH, P. B.; WALTERS, M. B.; ELLSWORTH, D. S. From tropics to tundra: global convergence in plant functioning. Proceedings of the National Academy of Sciences of the United States of America, v.94, p.1373013734, 1997.

RIJKERS, T.; PONS, T. L.; BONGERS, F. The effect of tree height and light availability on photosynthetic leaf traits of four neo-tropical species differing in shade tolerance. Functional Ecology, v.14, p.77-86, 2000.

RYAN, M. G.; HUBBARD, R. M.; CLARK, D. A.; SANFORD JUNIOR, R. L. Woody-tissue respiration for Simarouba amara and Minquartia guianensis, two tropical wet forest trees with different growth habits. Oecologia, v.100, p.213-220, 1994.

SAXE, H.; CANNELL, M.G.R.; JOHNSEN, B.; RYAN, M.G.; VOURLITIS, G. Tree and forest functioning in response to global warming. New Phytologist, v.149, n.3, p.369-399, 2001.

SCHRADER, S.M.; WISE, R. R.; WACHOLTZ, W. F.; ORT, D. R.; SHARKEY, T. $D$. Thylakoid membrane responses to moderately high leaf temperature in Pima cotton. Plant Cell and Environment, v.27, n.6, p.725-735, 2004. 
SCHONGART, J.; JUNK, W.J.; PIEDADE, M.T.F.; AYRES, J.M.; HUTTERMANN, A.; WORBES, M. Teleconnection between tree growth in the Amazonian floodplains and the El Nino-Southern Oscillation effect. Global Change Biology, v.10, n.5, p.683-692, 2004.

SENTELHAS, P.C.; PEREIRA, A.R.; ANGELOCCI, L.R.; ALFONSI, R.R.; CARAMORI, P.H.; SWARTS S. BHBRASIL - Balanços hídricos climatológicos de 500 localidades brasileiras. http://www.lce.esalq.usp.br/bhbrasil/amazonas/manaus.xls. (2005).

SIEBKE, K.; GHANNOUM, O.; CONROY, J. P.; VON CAEMMERER, S. Elevated $\mathrm{CO}_{2}$ increases the leaf temperature of two glasshouse-grown C-4 grasses. Functional Plant Biology, v.29, n.12, p.1377-1385, 2002.

SOMBROEK, W. Spatial and temporal patterns of Amazon rainfall. Ambio, v.30, p.388-396, 2001.

SWAINE, M.D. Rainfall and soil fertility as factors limiting forest species distributions in Ghana. Journal of Ecology, v.84, n.3, p.419-428, 1996.

TARNOPOLSKY, M.; SEGINER, I. Leaf temperature error from heat conduction along thermocouple wires. Agricultural and Forest Meteorology, v.93, p.185-194,1999.

TJOELKER, M. G.; OLEKSYN, J.; REICH, P.B. Modelling respiration of vegetation: evidence for a general temperature-dependent $Q(10)$. Global Change Biology, n.7, v.2, p.223-230, 2001. 
TRIBUZY, E. S.; TEIXEIRA, L. M; CHAMBERS, J. Q.; REIS, T. S.; TRUMBORE, S.; CAMARGO, P.; SILVA, R. P.; HIGUCHI, N. Physiological Responses of Tree Species Growing under Different Site Conditions in the Central Amazon. In: LBA-ECO SCIENCE TEAM BUSINESS MEETING, 7. , Fortaleza-CE-Brazil, 2003. LBA annual book of congress, Fortaleza: LBA/INPA/NASA-AM, 2003. p.94.

UDDLING, J.; PLEIJEL, H.; KARLSSON, P.E. Measuring and modelling leaf difusive conductance in juvenile silver birch, Betula pendula. Trees, v.18, n.8, p.686-695, 2004.

VARGAS-LUNA, M.; MADUENO, L.; GUTIERREZ-JUAREZ, G.; BERNALALVARADO, J.; SOSA, M.; GONZALEZ-SOLIS, J.L.; SANCHEZ-ROCHA, S.; OlALDE-PORTUGAL, V.; ALVARADO-GIL, J.J.; CAMPOS, P. Photorespiration and temperature dependence of oxygen evolution in tomato plants monitored by open photoacoustic cell technique. Review of Scientific Instruments, v.74, n.1, p.706-708, 2003.

WAN, X.; LANDHÄUSSER, S.M.; ZWIAZEK, J.J.;LIEFFER, V.J. Stomatal conductance and xylem sap properties of aspen (Populus tremuloides) in response to low soil temperature. Physiologia Plantarum, v.122, p.79-85, 2004.

WULLSCHLEGER, S. D. Biochemical limitations to carbon assimilation in $\mathrm{C}_{3}$ plants - $A$ retrospective analysis of the $A / C_{i}$ curves fron 109 species. Journal of Experimental of Botany, v.44, n.262, p.907-920. 1993.

ZOTZ, G.; WINTER, K. Short-term photosynthesis measurements predict leaf carbon balance in tropical rainforest canopy plants. Planta, v.191, p.409412. 1993. 
ZOTZ, G.; WINTER, K. Dial patterns of $\mathrm{CO}_{2}$ exchange in rainforest canopy plants. in: MULKEY, S. S.; CHAZDON, R. L.; SMITH, A. P. (Ed.). Tropical Forest Plant Ecophysiology. New York: Chapman Hall, 1996. cap.8, p.89113. 